I NTERNATIONAL MONETARY FUND

European Department

Demographic Headwinds in

Central and Eastern Europe

An IMF staff team led by Anna llyina, Jaewoo Lee, Iva Petrova, and Alasdair Scott

No. $19 / 12$ 
European Department

\section{Demographic Headwinds in Central and Eastern Europe}

Cristina Batog, Ernesto Crivelli, Anna llyina, Zoltan Jakab, Jaewoo Lee, Anvar Musayev, Iva Petrova, Alasdair Scott, Anna Shabunina, Andreas Tudyka, Xin Cindy Xu, and Ruifeng Zhang

I N TER N A T I O NAL MO NETARY F U N D 
Copyright (92019 International Monetary Fund

\section{Cataloging-in-Publication Data IMF Library}

Names: Batog, Cristina, author. | Crivelli, Ernesto, author. | Ilyina, Anna, author. | Jakab, Zoltán, author. | Lee, Jaewoo, author. | Musayev, Anvar, author. | Petrova, Iva, author. | Scott, Alasdair, author. | Shabunina, Anna, author. | Tudyka, Andreas, author. |Xu, Xin Cindy, author. | Zhang, Ruifeng (Economist), author. | International Monetary Fund. European Department, issuing body. | International Monetary Fund, publisher.

Title: Demographic headwinds in Central and Eastern Europe / Cristina Batog, Ernesto Crivelli, Anna Ilyina, Zoltan Jakab, Jaewoo Lee, Anvar Musayev, Iva Petrova, Alasdair Scott, Anna Shabunina, Andreas Tudyka, Xin Cindy Xu, and Ruifeng Zhang.

Other titles: International Monetary Fund. European Department (Series).

Description: Washington, DC: International Monetary Fund, 2019. | At head of title: European Department. | European Departmental Paper Series. | No. 19. | Includes bibliographical references.

Identifiers: ISBN 9781498319768 (paper)

Subjects: LCSH: Europe, Central—Population. | Europe, Eastern—Population. | Demography—Europe, Central. | Demography—Europe, Eastern. | Europe, Central—Economic conditions. | Europe, EasternEconomic conditions.

Classification: LCC HB3582.7.A3 B38 2019

The Departmental Paper Series presents research by IMF staff on issues of broad regional or cross-country interest. The views expressed in this paper are those of the author(s) and do not necessarily represent the views of the IMF, its Executive Board, or IMF management.

Publication orders may be placed online, by fax, or through the mail: International Monetary Fund, Publication Services P.O. Box 92780, Washington, DC 20090, U.S.A.

Tel. (202) 623-7430 Fax: (202) 623-7201

E-mail: publications@imf.org www.imfbookstore.org www.elibrary.imf.org 


\section{Contents}

Acknowledgments.................................................................................................... vii

Executive Summary ....................................................................................................... 1 ix

1. Introduction ................................................................................................................... 1

2. Demographic Prospects for CESEE Economies ........................................................... 5

Projected Population Dynamics for the CESEE Region.................................................. 5

Economic Implications of CESEE Demographic Changes..............................................11

3. Implications for Labor Supply.................................................................................... 15

4. Implications for Age-Related Public Spending ………………………………………... $\underline{23}$

5. Implications for Productivity.................................................................................. $\underline{33}$

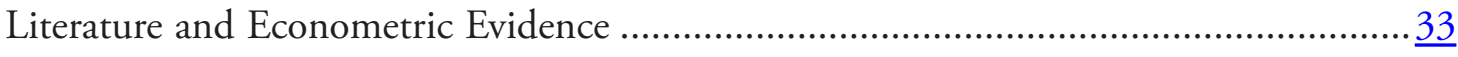

Productivity Implications of Aging Workforces in the CESEE Region ............................. $\underline{38}$

6. Implications for Growth, Convergence, Spillovers, and Fiscal and External Balances..포

Prologue: A First Pass at Implications for Growth and Convergence .............................. $\underline{43}$

Channels of Economic Adjustment to Demographic Pressures ........................................ $\underline{46}$

General Equilibrium Outcomes of Demographic Transition in CESEE Economies ....... $\underline{48}$

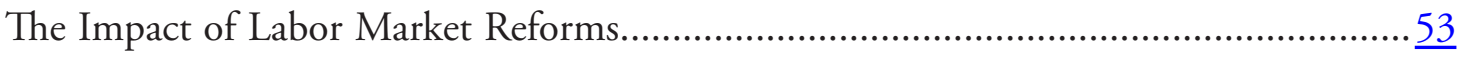

The Impact of Different Fiscal Reactions to Demographic Pressures............................... 54

7. Summary and Implications for Policies ..................................................................... 61

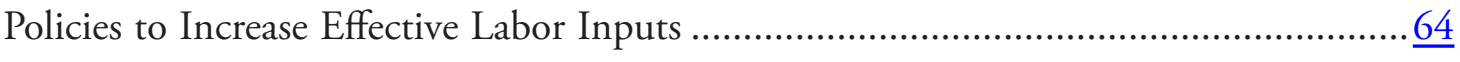

Policies to Support Capital Deepening....................................................................66

Policies to Boost Productivity ................................................................................ 66

Policies to Ensure Sustainability of the Public Finances ……………………………...... 68

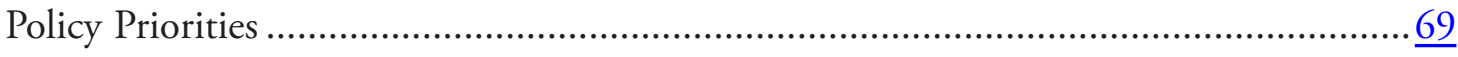

Annex 1. The UN Population Projections …………………............................................... $\underline{73}$

Annex 2. Participation Rates and Labor Force Projections ............................................... 81

Annex 3. Projecting Pension and Health Care Costs ............................................................ 87

Annex 4. Estimating the Effects of Aging on Productivity ................................................ 89

Annex 5. Evaluating Growth Prospects Through a Production Function Approach...... 93

Annex 6. The EEUMOD Macroeconomic Model and Simulations ................................. 95

Annex 7. The IMF's External Balance Assessment Model of Current Account Balances..97

References................................................................................................................................... 101 


\section{Boxes}

Box 1. Fertility Policies .................................................................................. 21

Box 2. Policies to Contain Health Care Spending........................................................ 29

Box 3. Costs of Active Labor Market Policies ............................................................. 31

Box 4. Industrial Structure and Productivity ......................................................... 41

Box 5. Can Automation Offset Demographic Effects on Productivity?.......................... $\underline{42}$

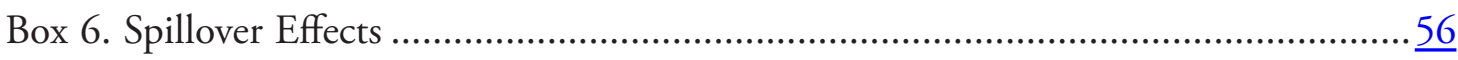

Box 7. Another Perspective on External Balances: The IMF's External Balance

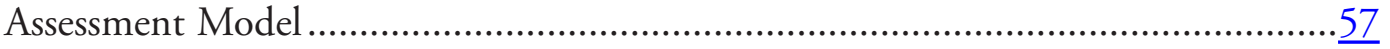

Box 8. Implications for Interest Rates …............................................................ 59

\section{Figures}

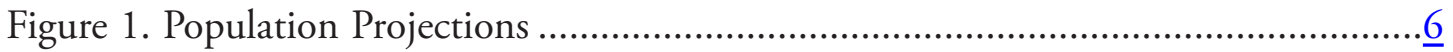

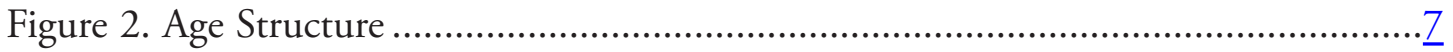

Figure 3. Fertility and Mortality .......................................................................

Figure 4. Death and Life Expectancy ….........................................................

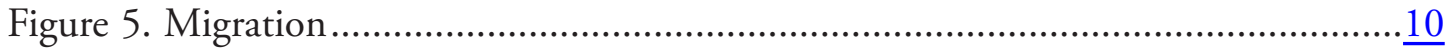

Figure 6. Population Changes ......................................................................... 11

Figure 7. Key Demographic Shifts ............................................................. 12

Figure 8. Labor Force Projections under the Baseline Scenario .................................... 16

Figure 9. Labor Force Participation Rates in CESEE Countries, 2015........................17

Figure 10. Effects of Labor Force Participation Policies..............................................19

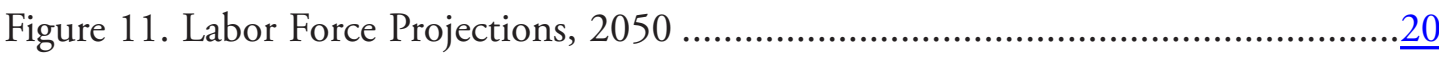

Figure 12. Projected Change in Age-Related Spending: Mid-Fertility Scenario.............24

Figure 13. Age-Related Spending: The ILO's 40 Percent Replacement Rate ..................25

Figure 14. Impact of Reforms on Pension Costs .......................................................

Figure 15. Net Change in Pension Costs, 2015-50 ................................................

Figure 16. Shares of Workers in the Total Workforce by Age .....................................

Figure 17. Impact of Workforce Aging on Total Factor Productivity Growth ................39

Figure 18. Distributions of Older Worker Shares....................................................

Figure 19. Assessing the Impact of Demographic Pressures on Growth and

Convergence-The Production Function Approach .............................................. 44 
Figure 20. CESEE Relative Income Levels under Aging Scenarios............................... 45

Figure 21. Responses to Demographic Shocks ....................................................... 49

Figure 22. Effects of Demographic Changes .................................................... 51

Figure 23. Impacts of Labor Market Reforms ….................................................. 53

\section{Table}

Table 1. Shares of Older Workers.................................................................. 13

Table 2. Old-age Dependency Ratio ......................................................................... 14

Table 3. Selected Macro-Based Studies on the Effect of Aging on Productivity …........... $\underline{35}$

Table 4. Productivity Regression Results ............................................................... 37

Table 5. Effects of Alternative Fiscal Reaction on GDP Growth Rates and Debt........... 55

Table 6. Effects of Demographic Shocks on GDP Growth Ratess................................ 62

Table 7. Impacts of Labor Market Reforms............................................................

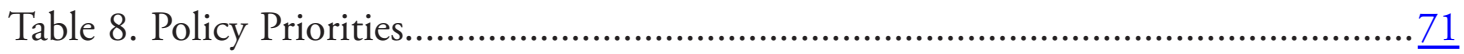


This page intentionally left blank 


\section{Acknowledgments}

The paper was completed under the overall guidance of Jörg Decressin. The authors are grateful for helpful comments and suggestions, without implication, from IMF colleagues and from authorities. We thank David Amaglobeli and Wei Shi of the IMF's Fiscal Affairs Department and Benjamin Hunt from the Research Department for their assistance. Patrick Gerland of the UN Population Division provided valuable guidance. The authors would also like to thank Aniko Madaraszova for editorial assistance and Houda Berrada of the Communications Department for leading the editorial and production process. 
This page intentionally left blank 


\section{Executive Summary}

The populations of Central, Eastern, and Southeastern European (CESEE) countries - with the exception of Turkey — are expected to decrease significantly over the next 30 years, driven by low or negative net birth rates and outward migration. These changes will have significant implications for growth, living standards, and fiscal sustainability. First, the labor force in CESEE countries is projected to shrink over the next three decades. Second, aging populations will also increase demands on health care and pension resources. Some public pension systems currently appear sustainable, but spending would increase substantially if pensions were more in line with preretirement earnings. Third, aging of the labor force itself could cause aggregate productivity to deteriorate; for some CESEE countries, this effect could be significant.

The scale and speed of these demographic changes are striking. Populations of Africa, Asia, and the Americas are expected to increase, not decrease, and the rate at which the populations will fall is expected to be as fast as those of other rapidly aging countries such as Japan.

Assessing these three mechanisms together shows that, without mitigating policies, growth and convergence to Western European living standards would slow considerably. The impacts of reduced labor and productivity are obvious, but the feedback from fiscal pressures back to growth itself is also important. Through a combination of increases in taxation and spending compression, or if accommodated by increased public debt and higher borrowing costs, fiscal pressures could displace public or private investment. For a given country, the effects are worsened by trade linkages to other CESEE and Western European countries that are also experiencing demographic pressures. 
There is no single or easy remedy to address demographic pressures. Policies to increase fertility rates are unlikely to offset the decline in the labor force. Some countries have room to increase participation rates, especially of women and older workers, along with raising retirement ages. For most countries, however, such changes would mitigate-but not fully offset—-the growth effects of shrinking and aging populations, although they could help ease fiscal pressures. Nonetheless, policymakers will face tough choices to contain age-related spending, such as the extent of health care coverage and the level of pensions; meanwhile, they will also need to preserve fiscal space for infrastructure, research and development, and active labor market policies. The appropriate policy package will have to be tailored for each country.

Given limited scope for boosting labor supply in many CESEE countries, more would have to be done to retain and better use the existing workforce. Support for education and adult (re)training and automation may help increase productivity. Further liberalization of immigration regimes, especially for skilled workers, could be considered. Better institutions and policies would make it more attractive for local workers to stay and for foreign workers to seek jobs in the region.

\section{Regional Definitions}

This paper defines regions as follows:

Central, Eastern, and Southeastern Europe (CESEE): Albania, Belarus, Bosnia and Herzegovina, Bulgaria, Croatia, Czech Republic, Estonia, Hungary, Latvia, Lithuania, Republic of North Macedonia, Moldova, Montenegro, Poland, Romania, Russia, Serbia, Slovakia, Slovenia, Turkey, Ukraine. ${ }^{1}$

Baltic states: Estonia, Latvia, Lithuania.

Central European New Member States (CE): Czech Republic, Hungary, Poland, Slovakia, Slovenia.

Eastern Europe (EE): Belarus, Moldova, Russian Federation, Ukraine.

Southeastern European EU Member States (SEE EU): Bulgaria, Croatia, Romania.

Southeastern European Non-EU Member States (SEE non-EU or Western Balkans): Albania, Bosnia and Herzegovina, Republic of North Macedonia, Montenegro, Serbia. ${ }^{1}$

Western Europe (WE): Austria, Belgium, Denmark, Finland, France, Germany, Greece, Iceland, Ireland, Italy, Luxembourg, Malta, Netherlands, Norway, Portugal, San Marino, Spain, Sweden, Switzerland, United Kingdom.

${ }^{1}$ No data are available for Kosovo. 


\section{Chapter}

\section{Introduction}

Central and eastern European countries face severe demographic pressures. Working-age populations are rapidly shrinking, after having peaked a few years ago, and are expected to decrease further. Emigration has exacerbated the problem of contracting labor supply and has accelerated aging, as emigrants have tended to be younger and more educated than those they left behind. Despite being generally younger than Western Europe, the region is projected to age more quickly than Western Europe, putting more pressure on social support. And most central and eastern European countries are still some distance away from the per capita income levels of Western Europe, making them at risk of "growing old before becoming rich."

This study examines the implications of these forces. It contributes to the literature on demographics in three respects. First, it looks at demographic pressures across Central, Eastern, and Southeastern European (CESEE) countries, covering central European states, Baltic states, the Commonwealth of Independent States, western and eastern Balkan states, and Turkey. Second, it aims to draw out the macroeconomic implications of demographic trends, not just for public spending, but also on potential output and income convergence, and attempts to evaluate policy options to address them. Third, it emphasizes general equilibrium effects, such as spillovers from trade, feedback from fiscal constraints and public debt accumulation, and second-round effects of policy initiatives on growth. ${ }^{1}$

\footnotetext{
${ }^{1}$ Existing studies of the economic impact of demographic trends do not have the same scope as this study. The European Commission's Aging Report contains extensive details on implications of demographic changes for pension systems, but it does not consider macroeconomic spillovers and covers only EU states. The Organisation for Economic Co-operation and Development has published many studies on aging and employment, but only for advanced countries (eight of which are CESEE countries). The European Bank for Reconstruction and Development's Transition Report covers CESEE countries, and Chapter 1 of the 2019 edition considers many of the themes considered in this study, although without the macroeconomic projections and policy simulations. Several recent IMF studies have analyzed specific channels through which aging would have effects on the economy, including productivity (Aiyar, Ebeke, and Shao 2016), public finance (Clements and others 2015), and the current account (Dao and others 2018), but they lack a comprehensive analysis that incorporates all channels. A few IMF reports do have comprehensive assessments-such as the 2016 Asia-Pacific Regional Economic Outlook — but have not covered the CESEE region.
} 
To that end, the study is structured as follows: Chapter 2 lays out demographic projections for CESEE countries. Before assessing the implications for convergence and spillovers, the next three chapters examine channels by which demographic trends could have direct effects. Chapters 3 and 4 examine the implications for, respectively, labor supply and public spending on pensions and health care; both chapters illustrate the scale of the problems by including scenarios for increases in labor participation and increases in the retirement age. Chapter 5 assesses potential effects on productivity. With these mechanisms in mind, we then turn, in Chapter 6, to evaluating the effects on growth and income convergence, with particular attention to spillovers across countries and saving and investment flows. Chapter 7 concludes and summarizes policy priorities for individual CESEE countries.

We find considerable heterogeneity across countries: all CESEE countries face challenging demographics, but in different ways. Turkey is a young country with a sizable young population, whereas populations in other CESEE countries are older. And within the latter group, the characteristics of demographic change vary, as seen in how country rankings change in terms of the degree of expected change in total and working-age populations, the share of older workers in working-age population, the speed of aging, and the increase in old-age dependency ratios. This heterogeneity implies that no single "one-size-fits-all" package of policies applies across countries in the region.

However, some issues are common:

- Most countries will face significant declines in their labor force by 2050. Some might be able to temporarily stall or reverse these declines by increasing labor force participation rates and retirement ages, but none by enough to ultimately offset the underlying population dynamics.

- Rising health care and pension expenditures as populations age will challenge the public finances. Under current policies for contributions, payments, and retirement ages, public pensions are fiscally sustainable in most CESEE countries, but costs would increase dramatically if pension payments were to be set closer to preretirement earnings.

- Workforce aging is associated with declines in aggregate labor productivity and total factor productivity growth. For some countries, given the age composition of their populations, this could have very strong effects on growth, unless there are offsetting effects from increased labor supply and/ or investment in labor-saving machines.

- Putting these three factors together, CESEE countries will face headwinds, not only because of their own demographic changes, but because of spillovers from the effects of demographic changes facing neighboring countries. 
What are the appropriate policy responses? Fundamentally, sustaining growth and social support requires some combination of more people working and people working more effectively, neither of which are easy to achieve. There are also difficult choices to be made about the extent and allocation of public resources. Our intention in this study is to provide a framework that could be used to analyze policy options and inform policy decisions. 
This page intentionally left blank 


\section{Chapter}

\section{Demographic Prospects for CESEE Economies}

The total populations of CESEE countries—except for Turkey—are expected to decrease significantly over the next 30 years, driven by low or negative net birth rates and outward migration.

These changes will be accompanied by shrinking and aging workforces and greater numbers of the aged relative to those of working age.

This chapter takes a first look at the demographic prospects of CESEE countries. It assesses what is projected to happen to total and working-age populations, discusses what is driving population dynamics in the CESEE region, and raises some economic implications that are elaborated in later sections.

\section{Projected Population Dynamics for the CESEE Region}

The total population of the CESEE region is expected to decline significantly (Figure 1). Projections by the United Nations present a striking picture: the total population of the CESEE region is expected to decrease, whereas populations in other regions increase. ${ }^{1}$ Total population growth in the Baltic, Central European, Southeastern European (SEE) European Union, and SEE non-EU states is worse than for the CESEE region as a whole—only Turkey, of all CESEE countries, is expected to have positive population growth. The largest rates of decline are projected for Baltic and SEE EU states, whereas the Eastern European (EE) region, owing to the size of its population, contrib-

\footnotetext{
${ }^{1}$ For comparability and consistency, the data in this and following sections are from the UN's World Population Prospects; see http://www.un.org/en/development/desa/population/. The data are presented by country and aggregated for the CESEE region and subregions: CESEE, Baltic states, Central European New Member States (CE), Eastern Europe (EE), Southeastern European (SEE) EU member states, Southeastern European non-EU member states (SEE non-EU or Western Balkans), and Western Europe. Annex 1 compares the UN data with those from other sources and assesses their reliability.
} 


\section{Figure 1. Population Projections}

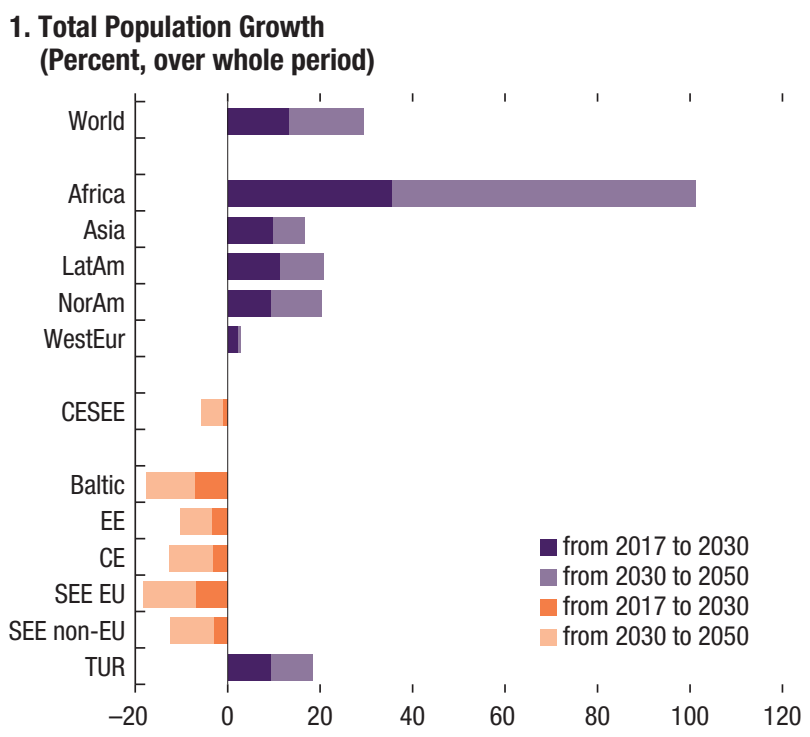

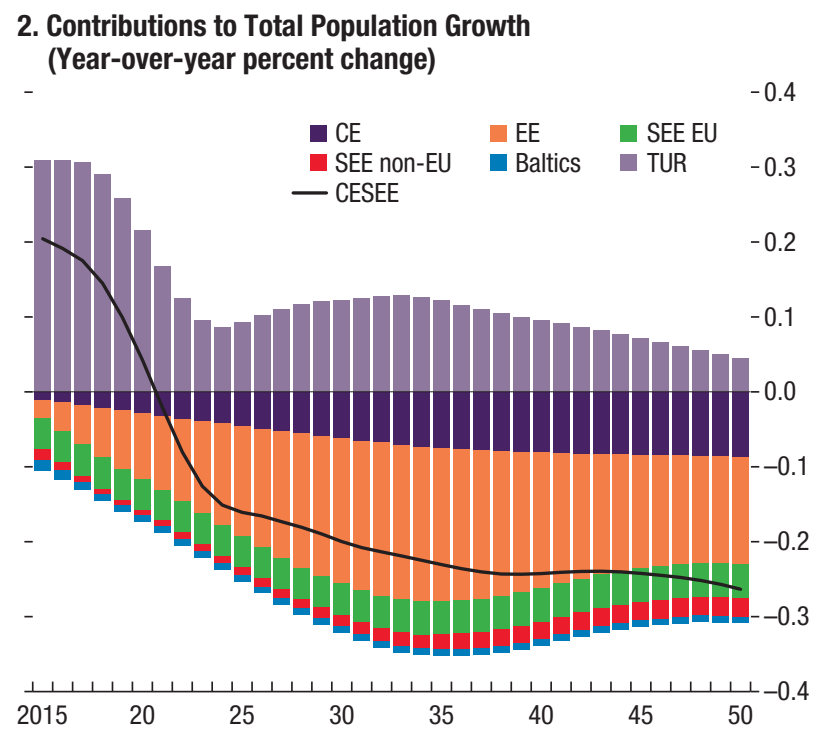

Sources: United Nations; and IMF staff calculations.

Note: $\mathrm{CE}=$ Central Europe; CESEE = Central, Eastern, and Southeastern Europe; EE = Eastern Europe; SEE EU = Southeastern European EU members; SEE non-EU = Southeastern European non-EU members; TUR = Turkey.

utes the most to the decline in the total population of the CESEE region. The population growth rate of the CESEE-excluding-Turkey region is substantially lower than that of Western Europe.

The adverse population dynamics of the CESEE region are driven mainly by high mortality rates and persistent net outward migration. To understand the population projections, we need to understand the starting point- the distribution of the current population by age cohorts - and the assumptions for subsequent births, deaths, and net migration. In comparison to Western Europe, the CESEE region starts with a younger population overall, and birth rates between now and 2050 are expected to be roughly the same. But relatively high mortality rates and net outward migration account for more rapid declines in population than in Western Europe. ${ }^{2}$

- Current population stock. CESEE countries generally have younger populations than those in Western Europe. Whereas the distribution of the population of Western Europe shows a single bulge, the CESEE-excluding-Turkey total population structure has two bulges: one for those in their 50s and early 60s, and another for those in their 30s and late 20s. Turkey has a "triangular" age structure, with larger cohorts of the young (Figure 2).

\footnotetext{
${ }^{2}$ For more details by country, see also the profiles in United Nations (2017b).
} 
Figure 2. Age Structure

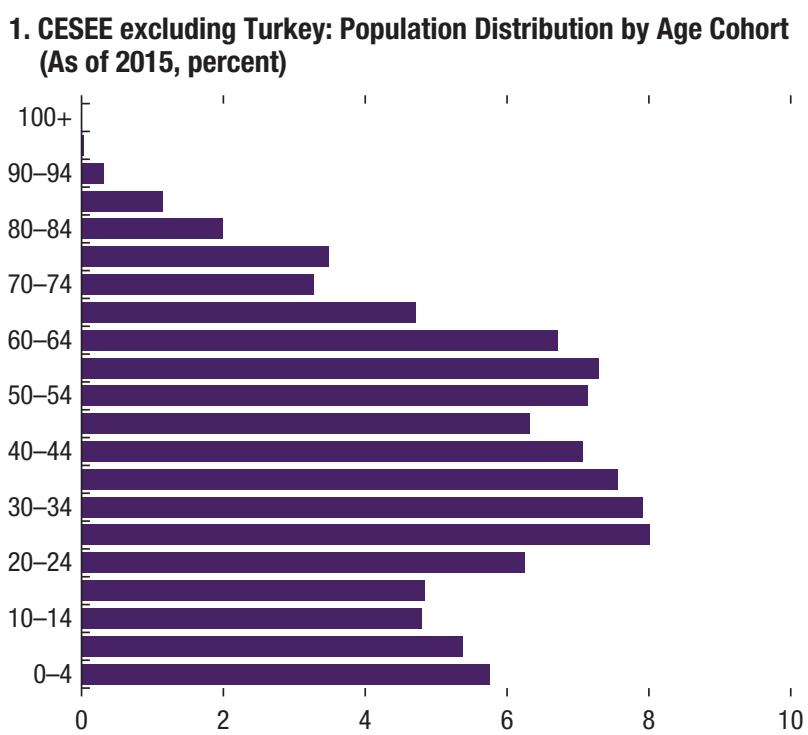

2. Western Europe: Population Distribution by Age Cohort (As of 2015, percent)

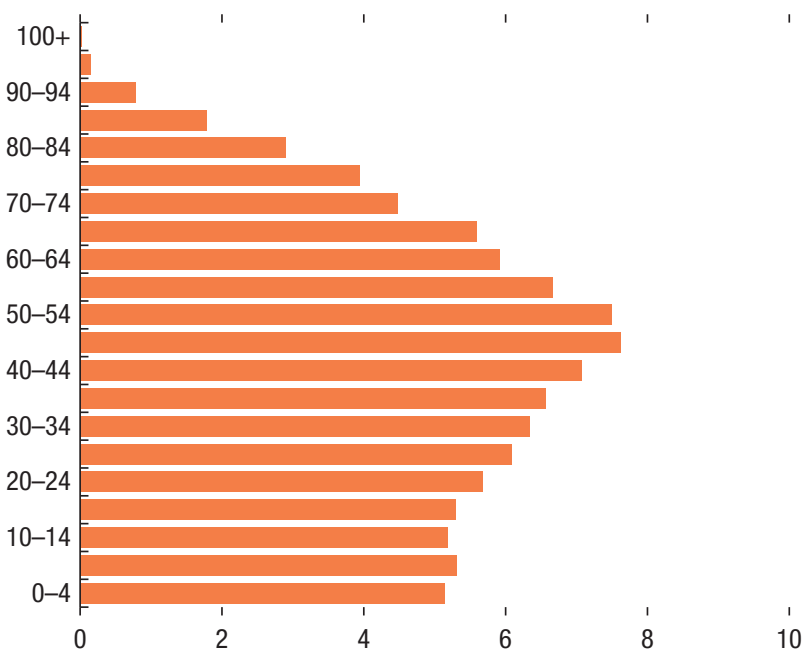

Sources: United Nations; and IMF staff calculations.

- Birth rates. Projected CESEE birth rates - the numbers born per head of population ${ }^{3}$ — are on average lower than in most other regions (Figure 3, panel 1). That said, they are mostly in line with those in Western Europe and projected to plateau only a little bit below current rates; hence, the projected decline in population relative to Western Europe is mostly not driven by a worsening in birth rates. Only two CESEE countries-Albania and Turkey - are projected to have significantly positive "natural" (that is, births minus deaths) population growth rates.

- Mortality rates. Overall mortality rates for a given country-deaths per thousand of population - reflect the probabilities of death in that country for each age cohort and the age structure of the population. Age-standardized death rates are higher in CESEE countries, particularly for EE countries, than is typical in Western European countries (Figure 4, panel 1). The causes of death that are relatively high include cardiovascular diseases, unintentional and intentional injuries, maternal and neonatal conditions, and digestive diseases; more generally, EE lags behind in terms of life expectancy at birth as a consequence of excess mortality due to noncommunicable diseases occurring among adults aged 30 years and older (Figure 4, panel 2). ${ }^{4}$ The UN projections make assumptions for mortality caused by these and other diseases at each age and gender for each birth

${ }^{3}$ This is different than the fertility rate, which is the number of live births per woman. The fertility rate in CESEE-excluding-Turkey varies between 1.2 and 1.8 - well below the replacement rate of 2.1, which is considered necessary to keep the population size constant.

${ }^{4}$ See also United Nations (2012). 
Figure 3. Fertility and Mortality
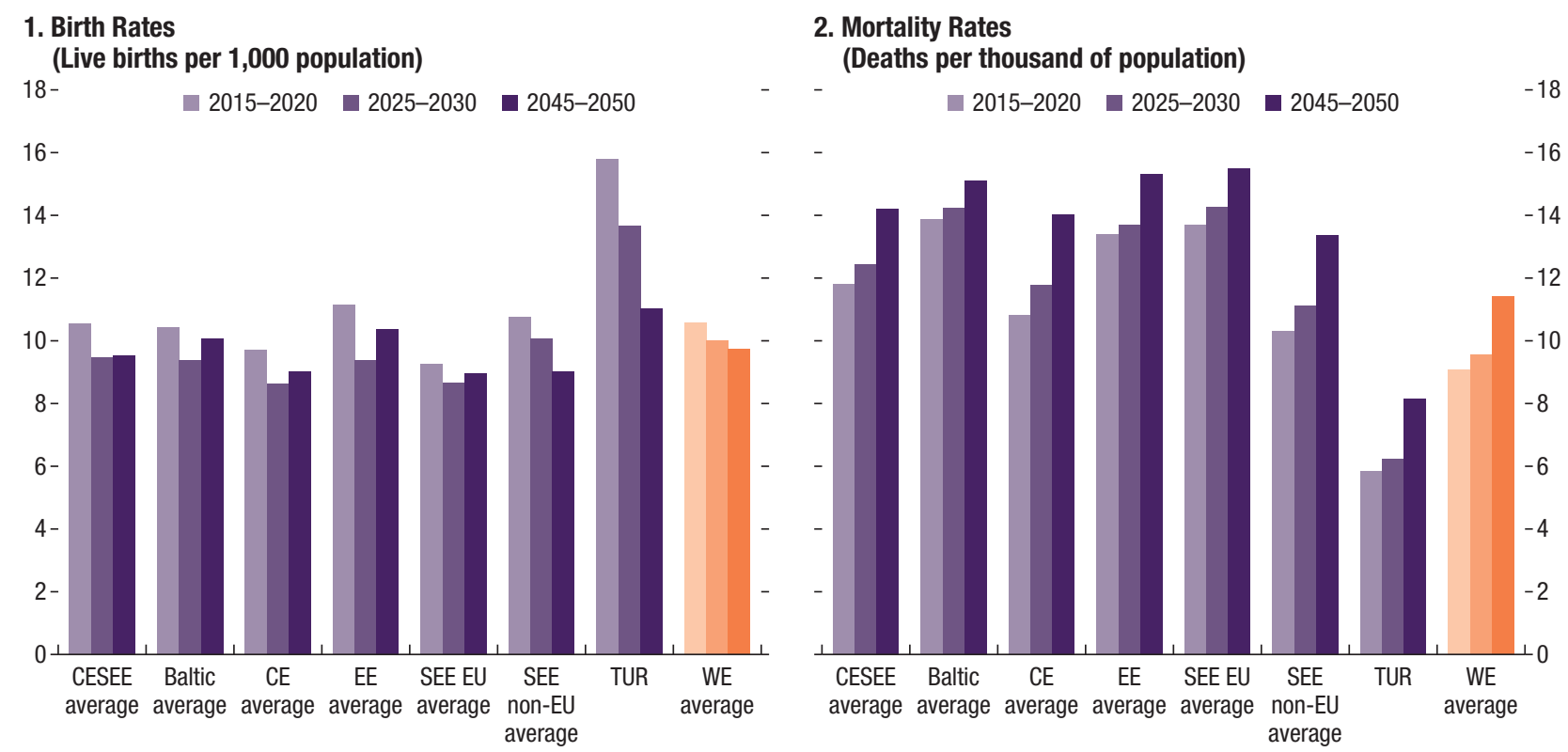

Sources: United Nations; and IMF staff calculations.

Note: $\mathrm{CE}=$ Central Europe; CESEE = Central, Eastern, and Southeastern Europe; EE = Eastern Europe; SEE EU = Southeastern Europe EU members; SEE non-EU = Southeastern Europe non-EU members; TUR = Turkey; WE = Western Europe.

cohort, based on models of prevention and survival improvements. ${ }^{5}$

The high mortality rates imply low expected lifespans-the 10 countries with the lowest expected lifespan of the United Nation's "more developed regions" are all from the CESEE region. ${ }^{6}$ However, probabilities of death at all ages - particularly for older cohorts - are expected to fall for CESEE as a whole, reflecting advances in health care and lower risks from illness and accident (Figure 4, panel 3). Falling mortality rates imply increasing lifespans, gradually catching up to those of Western Europe. For example, the United Nations estimates life expectancy for males at birth in CESEE countries during 2015 to 2020 to average 72.3 years, increasing to 77.9 years by 2050, whereas life expectancy at birth in Western Europe currently averages 79.9 years, increasing to 84.7 years by 2050 (Figure 4, panel 5). A similar, although less strong, pattern applies to life expectancy for females (Figure 4, panel 6). Correspondingly, CESEE countries with lower life expectancies are generally expected to increase life expectancies by more. But the improvements are slow-Russia and Moldova, for example, are not projected to reach the current CESEE average even by 2050.

Nonetheless, mortality rates are projected to remain significantly higher than those of Western Europe, mainly because the probabilities of death

\footnotetext{
${ }^{5}$ See United Nations (2017a).

${ }^{6}$ See United Nations (2015).
} 
Figure 4. Death and Life Expectancy

\section{Age-Standardized Death Rates, All Causes, 2016 (Ratio, relative to Germany)} $2.5-$

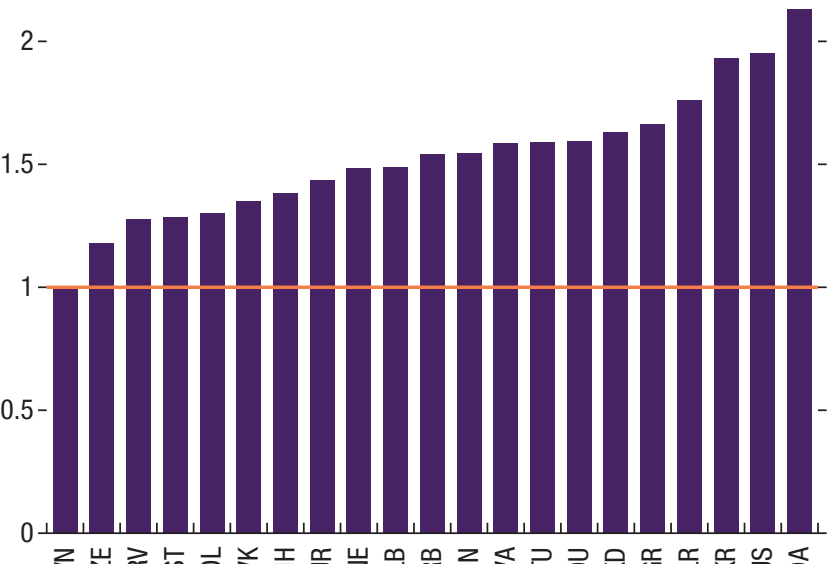

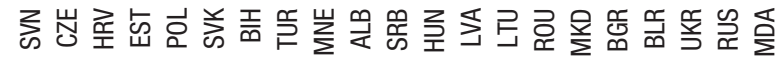

3. Probabilities of Death: CESEE Average

0.40

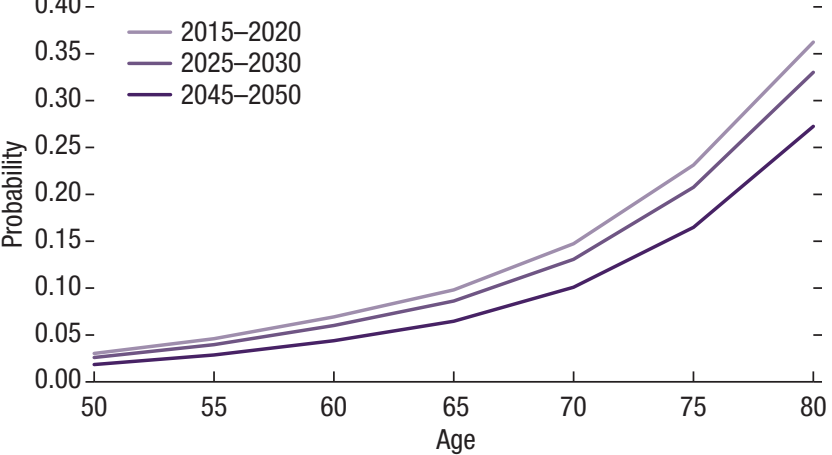

5. Life Expectancy Improvements in Males

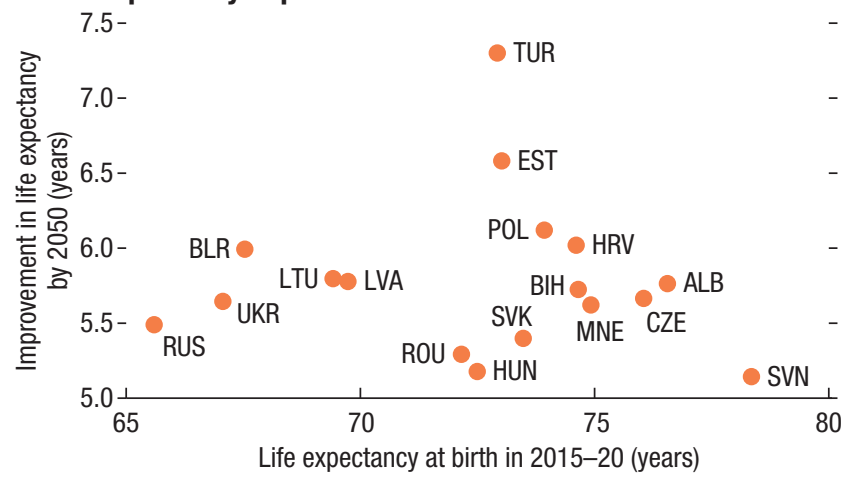

2. Causes of Death, 2016

(Ratio, relative to Germany)

Cardiovascular diseases Unintentional injuries

Maternal conditions

Neonatal conditions

Intentional injuries

Digestive diseases Respiratory Infectious Congenital anomalies Oral conditions Diabetes mellitus

Mental and substance use disorders Infectious and parasitic diseases Malignant neoplasms Sudden infant death syndrome

Genitourinary diseases Skin diseases

Respiratory diseases

Nutritional deficiencies

Neurological conditions Other neoplasm

Musculoskeletal diseases Endocrine, blood, immune disorders

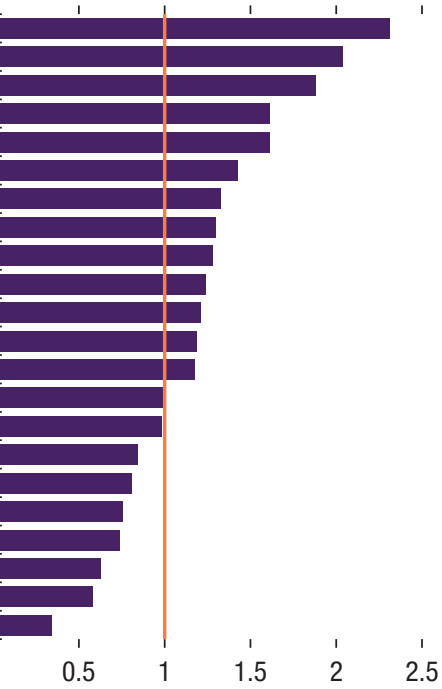

\section{Probabilities of Death: WE Average}

- 2015-2020

- 2025-2030

- 2045-2050

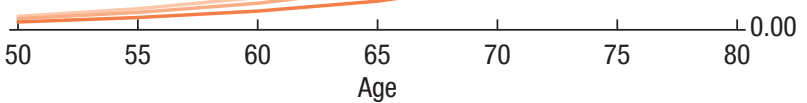

\section{Life Expectancy Improvements in Females}

TUR

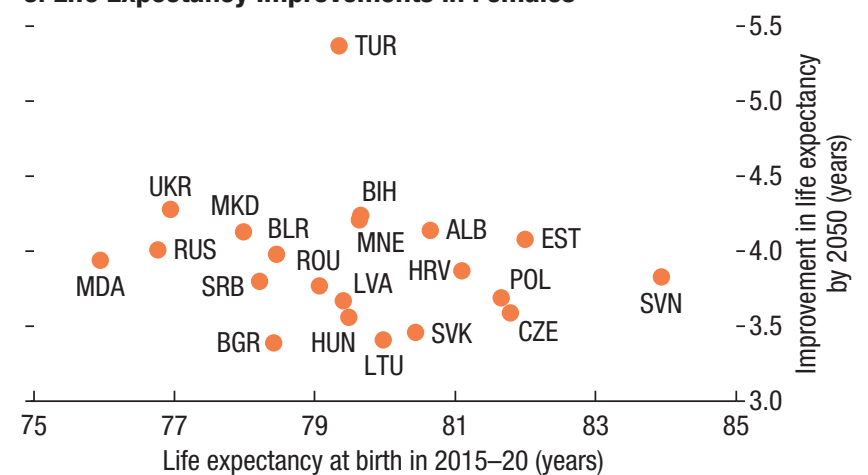

Sources: United Nations; World Health Organization; and IMF staff calculations.

Note: CESEE = Central, Eastern, and Southeastern Europe; WE = Western Europe. Data labels use International Organization for Standardization (ISO) codes. 
Figure 5. Migration

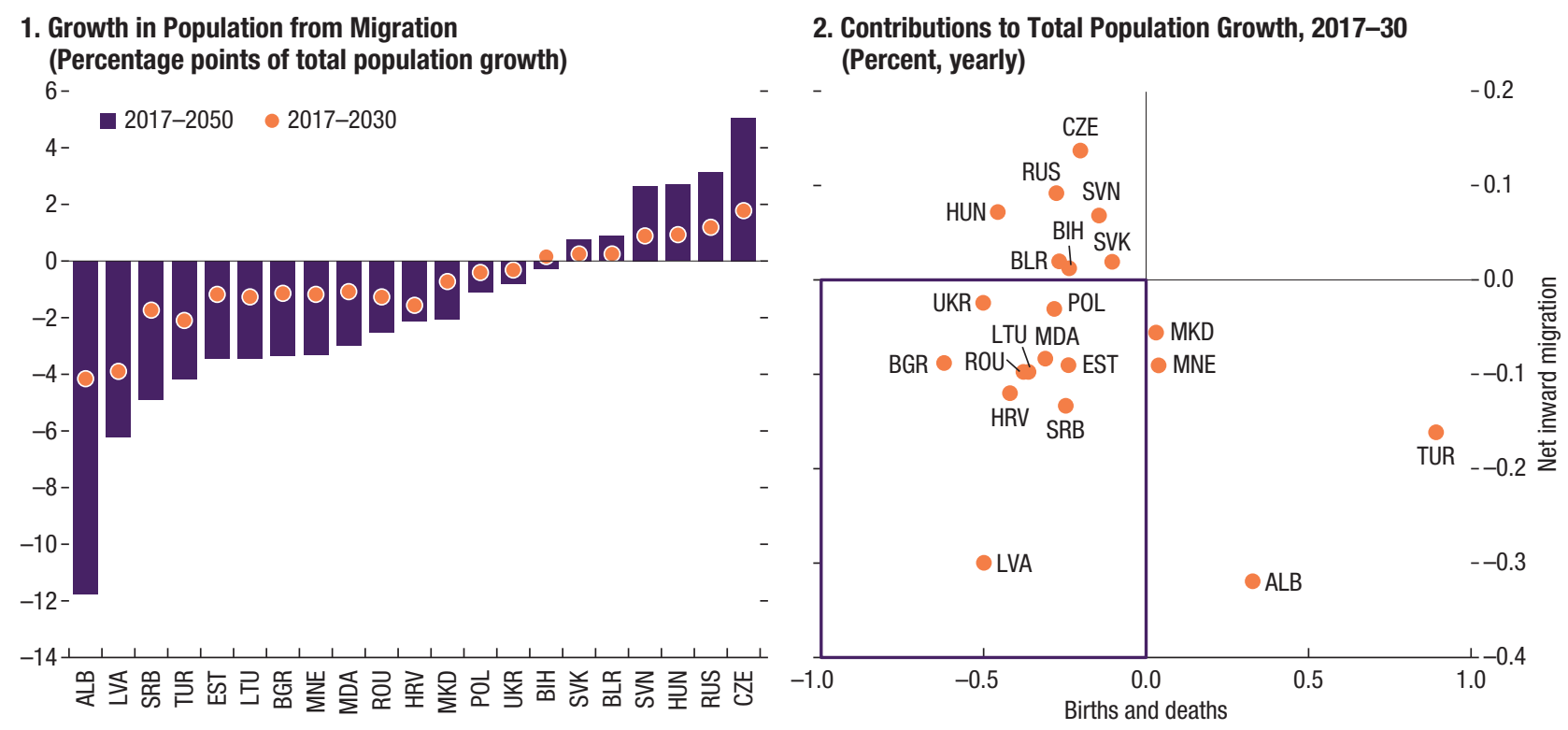

Sources: United Nations; and IMF staff calculations.

Note: Data labels use International Organization for Standardization (ISO) codes.

are projected to be higher in CESEE countries, despite assumed improvements. Hence, even though the CESEE population is younger than that of Western Europe, mortality rates_-deaths per head of population-are higher now and expected to remain at a relative high level. In all countries, mortality rates increase over time, despite lower probabilities of death at each age, because of population aging (Figure 3, panel 2).

- Migration. Most CESEE countries have experienced significant outward migration since the 1990s. As most emigrants have tended to be younger than those they left behind, persistent emigration has exacerbated demographic pressures and has accelerated aging; migration will likely continue to play a significant role for the region. As the United Nations notes, international migration is the component of population change that is most difficult to project. ${ }^{7}$ Not only has international migration shown drastic changes in absolute numbers, but the direction of the flows has changed as well. Abstracting from refugee flows, the starting point for migration projections is to an assumption that recent levels, if stable, would continue until 2050, with adjustments for migration policies in each country. On this basis, about half of CESEE countries are projected to experience both negative natural population growth rates and outward migration over the next 30 years (Figure 5).

\footnotetext{
${ }^{7}$ Note, however, that the United Nation's assumptions for migration have improved the accuracy of total population projections for CESEE countries_-see Annex 3.
} 
These demographic factors imply dramatic declines in populations in most CESEE countries over the next three decades. Nearly half of CESEE countries are projected to experience net total population losses of 5 percent between now and 2030, and 15 percent by 2050 . Latvia and Bulgaria are projected to lose more than a fifth of their populations by 2050 . Only Turkey's population is expected to increase significantly (Figure 6).

\section{Figure 6. Population Changes} (Percent)

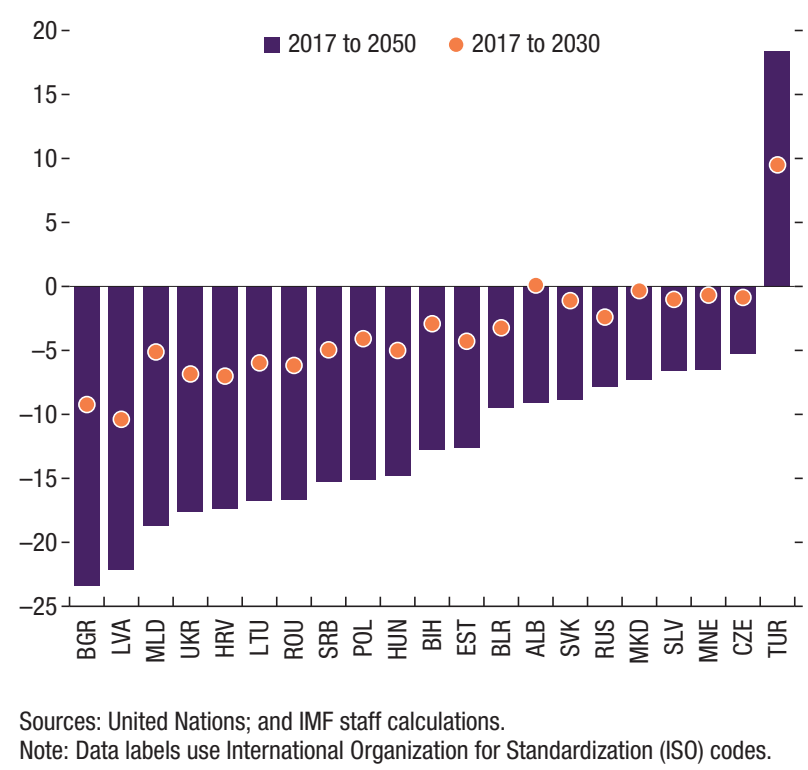

\section{Economic Implications of CESEE Demographic Changes}

Several challenges arise from these unfavorable demographic changes. The decline in CESEE populations are expected to be accompanied by shrinking and aging workforces and greater numbers of the aged to those of working age.

- A shrinking labor force. A falling total population is likely to result in a shrinking working-age population (Figure 7, panel 1). This holds for both CESEE and Western European populations, but the decline in working-age populations is generally more severe in CESEE economies. It is particularly pronounced for the Baltic states, CE, and SEE EU (Figure 7, panel 3).

The "lumpy" age structure of CESEE countries seen here implies that the decline in the working-age population is more rapid in the short term than in Western Europe. The rate of decline is projected to decelerate by 2035, owing to the current bulge of those aged 25 to 34 years in CESEE populations, but accelerates markedly thereafter (Figure 7, panel 2).

- An aging labor force. CESEE countries are projected to age more quickly than the Western European average, and the populations of younger and poorer CESEE countries are generally expected to age more quickly than those in other CESEE countries (Figure 7, panel 4). The aging of the population will consequently result in an aging labor force: although there are large variations among CESEE countries-with some countries starting 
Figure 7. Key Demographic Shifts

1. Total Population

(Five-year growth rates of aggregate populations, percent)

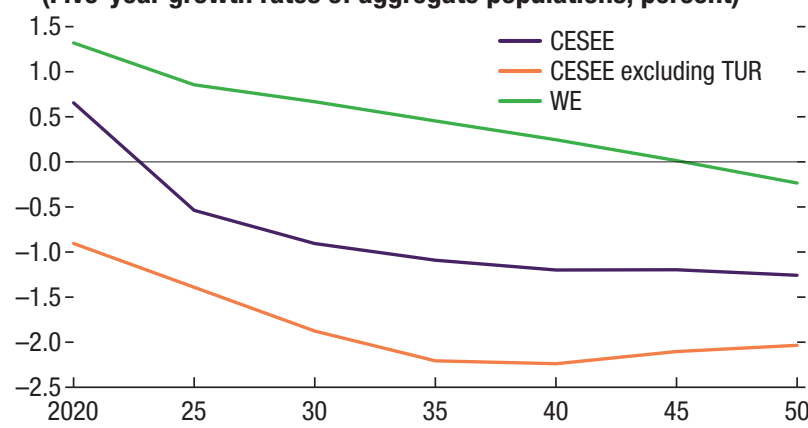

3. Change in Working Age Population (Percent)

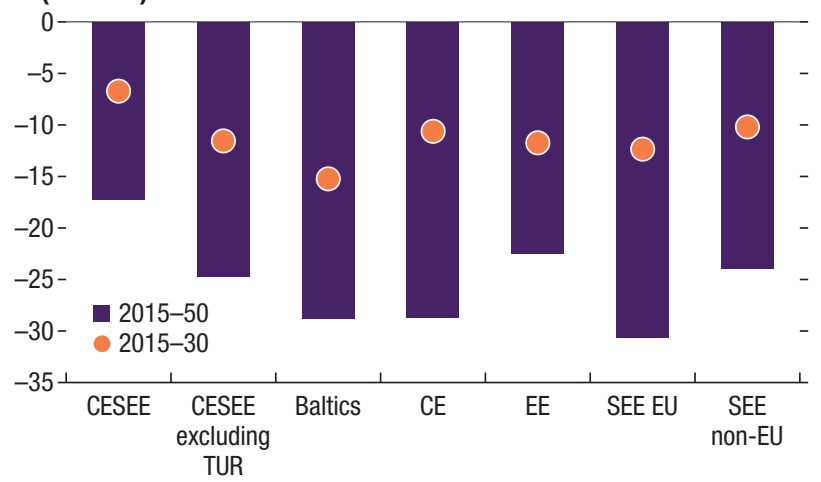

2. Working Age Population (15-64)

(Five-year growth rates of aggregate populations, percent)

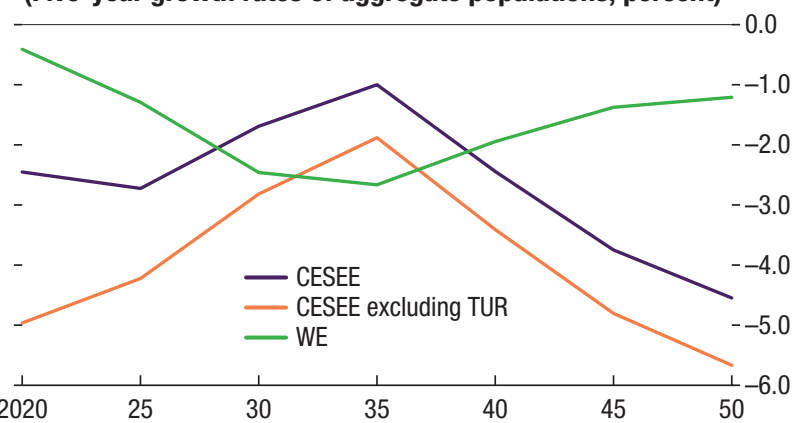

4. Median Age: Starting Point versus Change (Years)

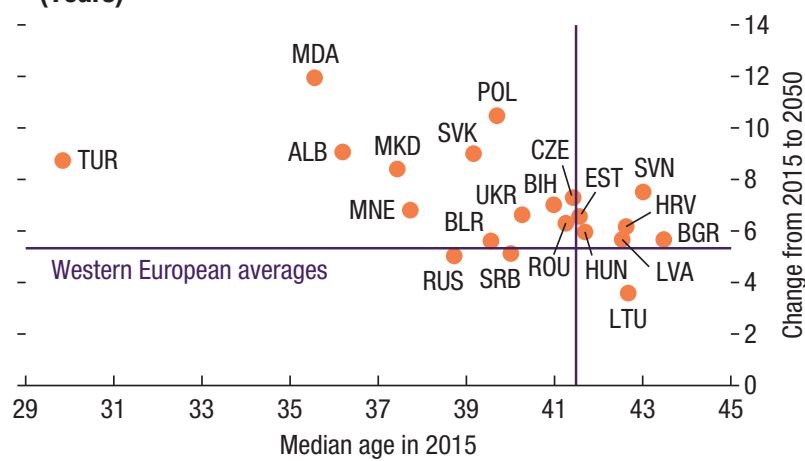

Sources: United Nations; and IMF staff calculations.

Note: $\mathrm{CE}=$ Central Europe; CESEE $=$ Central, Eastern, and Southeastern Europe; EE $=$ Eastern Europe; SEE $=$ Southeastern Europe; TUR = Turkey; WE $=$ Western Europe. Data labels use International Organization for Standardization (ISO) codes.

off with a significantly younger labor force than others- the share of older workers is projected to increase in all CESEE countries (Table 1).

- Increasing old-age dependence. The combination of low birth rates and decreasing mortality rates is projected to raise life expectancy and old-age dependency ratios. The ratio of those over 65 years of age to the working-age population of the CESEE region is currently lower than that of Western Europe. But some countries-Bulgaria, Croatia, and the Baltic states - already have higher dependency ratios, and all CESEE countries, even Turkey, will rapidly reach old-age dependency ratios higher than considered already problematic in comparatively rich Western European countries. In some cases, notably the Czech Republic, Poland, and Slovenia, the old-age dependency ratio is projected to be higher than the Western European average (Table 2).

These developments can be expected to have significant macroeconomic effects. A shrinking and aging labor force could slow potential growth. 
Table 1. Shares of Older Workers

(Percent of total workforce)

\begin{tabular}{|c|c|c|c|c|c|c|c|c|}
\hline Country & 2015 & 2020 & 2025 & 2030 & 2035 & 2040 & 2045 & 2050 \\
\hline MDA & 18.2 & 19.3 & 17.9 & 18.2 & 20.2 & 23.9 & 30.0 & 31.5 \\
\hline SVK & 15.4 & 15.9 & 16.1 & 18.6 & 22.2 & 25.1 & 27.1 & 27.9 \\
\hline EST & 21.5 & 22.7 & 22.9 & 23.9 & 24.6 & 25.9 & 28.2 & 27.1 \\
\hline LVA & 19.9 & 21.8 & 22.3 & 22.8 & 22.8 & 23.7 & 25.7 & 25.2 \\
\hline ROU & 17.2 & 16.3 & 18.9 & 22.6 & 24.1 & 23.8 & 25.2 & 24.0 \\
\hline LTU & 19.4 & 21.6 & 21.9 & 22.0 & 21.0 & 20.6 & 21.9 & 23.8 \\
\hline BGR & 19.2 & 19.1 & 19.6 & 21.6 & 23.6 & 23.8 & 24.8 & 23.4 \\
\hline ALB & 16.6 & 18.5 & 18.2 & 18.2 & 18.4 & 19.8 & 20.9 & 23.0 \\
\hline CZE & 17.1 & 17.0 & 17.8 & 21.1 & 24.5 & 23.9 & 23.3 & 22.3 \\
\hline HRV & 15.2 & 15.7 & 15.4 & 16.8 & 18.4 & 19.6 & 20.0 & 21.7 \\
\hline SRB & 16.0 & 16.1 & 16.9 & 18.6 & 19.7 & 20.2 & 21.2 & 21.6 \\
\hline UKR & 11.8 & 17.2 & 16.7 & 17.4 & 19.0 & 21.3 & 23.1 & 21.4 \\
\hline POL & 15.6 & 14.7 & 14.1 & 15.3 & 17.8 & 20.6 & 21.5 & 21.2 \\
\hline MKD & 14.5 & 15.0 & 15.7 & 16.3 & 17.5 & 19.3 & 20.5 & 20.9 \\
\hline HUN & 15.6 & 14.5 & 15.9 & 18.5 & 21.1 & 20.2 & 19.6 & 20.5 \\
\hline RUS & 15.6 & 16.6 & 15.4 & 16.1 & 17.1 & 18.8 & 20.7 & 19.0 \\
\hline $\mathrm{BIH}$ & 13.1 & 14.1 & 13.9 & 14.4 & 15.1 & 15.9 & 16.8 & 17.5 \\
\hline TUR & 9.4 & 10.4 & 11.5 & 12.8 & 14.1 & 15.4 & 16.3 & 17.0 \\
\hline SVN & 12.8 & 14.3 & 15.8 & 16.6 & 18.0 & 18.5 & 18.0 & 16.3 \\
\hline BLR & 12.5 & 13.4 & 12.6 & 12.5 & 13.1 & 14.7 & 16.2 & 14.9 \\
\hline Avg CESEE & 15.8 & 16.7 & 17.0 & 18.2 & 19.6 & 20.8 & 22.0 & 22.0 \\
\hline Avg WE & 16.9 & 19.1 & 20.8 & 21.3 & 21.7 & 22.1 & 22.3 & 22.5 \\
\hline
\end{tabular}

Sources: ILOSTAT; United Nations; and IMF staff calculations.

Note: Older workers are defined as workers aged 55 years or older. CESEE $=$ Central, Eastern, and Southeastern Europe; WE $=$ Western Europe. Data labels use International Organization for Standardization (ISO) codes.

Greater dependency is likely to put pressure on the cost of public services, whereas the aging population could affect labor productivity. These themes are developed in the chapters that follow. 
Table 2. Old-Age Dependency Ratio $(65+/(20-64))$

\begin{tabular}{|c|c|c|c|c|c|c|c|c|}
\hline Country & 2015 & 2020 & 2025 & 2030 & 2035 & 2040 & 2045 & 2050 \\
\hline SVN & 28.8 & 35.0 & 41.1 & 46.7 & 51.8 & 55.9 & 61.8 & 66.8 \\
\hline POL & 24.3 & 30.0 & 36.4 & 39.3 & 41.2 & 44.8 & 51.4 & 60.8 \\
\hline CZE & 28.8 & 34.0 & 37.1 & 39.1 & 41.1 & 46.7 & 54.5 & 58.9 \\
\hline HRV & 31.2 & 35.3 & 39.8 & 43.7 & 45.8 & 49.2 & 53.0 & 57.4 \\
\hline EST & 31.0 & 35.0 & 39.2 & 42.3 & 44.5 & 48.1 & 51.5 & 56.3 \\
\hline BGR & 32.6 & 36.2 & 39.2 & 41.0 & 42.8 & 46.5 & 51.4 & 54.9 \\
\hline SVK & 21.5 & 26.5 & 31.4 & 35.2 & 37.5 & 41.4 & 47.7 & 53.9 \\
\hline $\mathrm{BIH}$ & 24.9 & 28.5 & 33.3 & 39.1 & 42.6 & 46.3 & 49.6 & 53.2 \\
\hline ROU & 27.4 & 31.7 & 35.3 & 35.2 & 40.3 & 45.1 & 50.7 & 52.7 \\
\hline HUN & 27.9 & 33.3 & 36.6 & 37.0 & 39.0 & 43.7 & 50.0 & 52.4 \\
\hline LVA & 31.5 & 34.7 & 39.0 & 42.4 & 44.3 & 47.0 & 48.9 & 52.3 \\
\hline ALB & 20.6 & 23.4 & 29.0 & 35.6 & 40.1 & 43.6 & 46.6 & 51.0 \\
\hline LTU & 30.7 & 32.4 & 36.7 & 42.2 & 45.3 & 47.6 & 47.7 & 47.9 \\
\hline UKR & 24.7 & 27.9 & 31.6 & 34.6 & 35.5 & 37.6 & 41.1 & 46.8 \\
\hline MNE & 22.8 & 27.0 & 31.0 & 34.9 & 36.8 & 39.3 & 42.3 & 46.6 \\
\hline MKD & 19.5 & 22.9 & 26.5 & 30.2 & 33.8 & 36.8 & 40.6 & 45.8 \\
\hline SRB & 26.8 & 31.8 & 34.3 & 35.9 & 37.3 & 39.6 & 42.6 & 45.3 \\
\hline BLR & 22.2 & 25.1 & 30.2 & 34.5 & 36.1 & 37.6 & 39.6 & 43.8 \\
\hline RUS & 20.7 & 25.1 & 30.1 & 34.1 & 33.4 & 34.2 & 36.0 & 40.0 \\
\hline MDA & 14.5 & 18.9 & 23.0 & 27.2 & 27.9 & 29.4 & 32.9 & 39.9 \\
\hline TUR & 13.4 & 14.9 & 17.3 & 20.2 & 23.3 & 27.2 & 31.6 & 36.2 \\
\hline Avg CESEE & 25.0 & 29.0 & 33.2 & 36.7 & 39.1 & 42.3 & 46.3 & 50.6 \\
\hline Avg WE & 30.6 & 33.6 & 37.5 & 42.1 & 46.7 & 50.3 & 53.0 & 55.2 \\
\hline
\end{tabular}

Sources: ILOSTAT; United Nations; and IMF staff calculations.

Note: CESEE $=$ Central, Eastern, and Southeastern Europe; WE $=$ Western Europe. Data labels use International Organization for Standardization (ISO) codes. 


\section{Chapter}

\section{Implications for Labor Supply}

The labor force in CESEE countries is projected to decrease substantially over the next three decades.

Policies to increase fertility rates are unlikely to offset the decline in the labor force.

Increasing participation rates—especially of women and older workers—along with raising retirement ages would ameliorate but not fully offset the decline in the labor force.

This chapter examines the implications of declining working-age population for labor supply in CESEE countries, an important first step toward understanding the implications of demographic changes for future growth and convergence. To complement the projections for labor supply, we take a first look at policies to offset the expected decline labor force, before considering these and other policy interventions together in later sections.

The projected population decline in CESEE countries would reduce the supply of labor. As seen in Chapter 2, CESEE countries are expected to have particularly large decreases in working-age populations that would, all else equal, have significant long-term implications for economic growth.

- Concerns about adverse effects of demographics on future growth have already prompted policy actions: Some countries have sought to stem outward migration, and many have overhauled their pension systems. Notably, a number of CESEE countries have already legislated increases in their statutory retirement ages.

- However, under current labor market policies, the labor force in CESEE countries is nonetheless projected to decline drastically by 2050 (Figure 8). Calculations show the labor force in the CESEE region (excluding Turkey) 
Figure 8. Labor Force Projections Under the Baseline Scenario (Percent change from 2015)

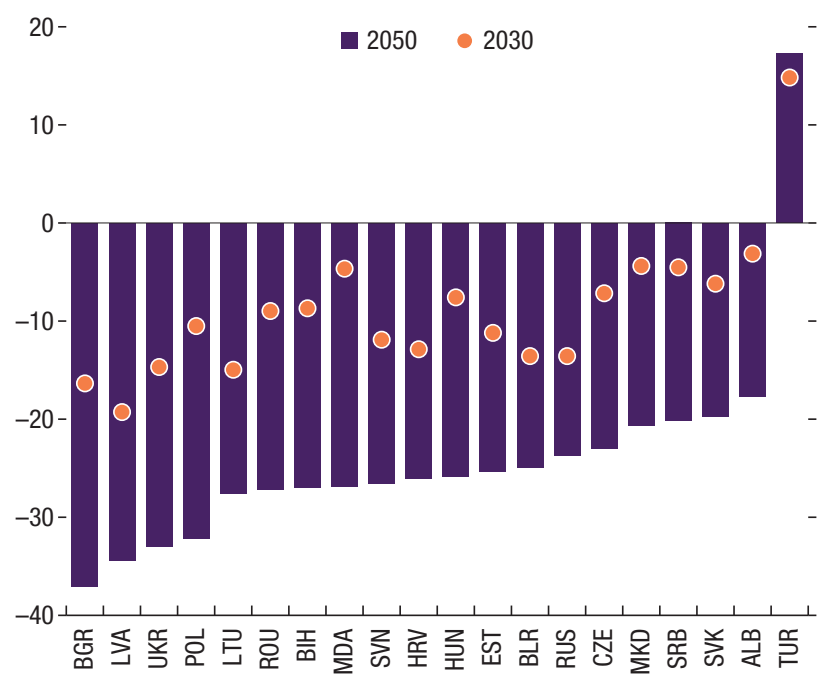

Sources: United Nations; and IMF staff calculations.

Note: Data labels use International Organization for Standardization (ISO) codes. shrinking by 10 percent by 2030 and by 26 percent by 2050 , even after accounting for legislated increases in retirement ages that are expected to increase average participation rates for men 55 to 64 years old from 58 to 61 percent, and for women of the same age from 42 to 46 percent (see Annex 2). Bulgaria, Latvia, Poland, and Ukraine are projected to experience the worst labor force declinesmore than 30 percent-by 2050 .

But even in some of the more benign cases (for example, Slovakia and Serbia), the labor force would decline by 20 percent by 2050 .

A declining labor force could in principle be remedied by higher fertility, higher net inward migration, or, temporarily, higher labor force participation:

- Fertility policies. Many CESEE countries have experimented with policies to increase fertility rates, including childbirth grants, cash child benefits, tax deductions, housing allowance, and social assistance. Family and child benefits are most generous (in terms of share of GDP) in Central European countries. ${ }^{1}$ However, there is little evidence that direct financial incentives to boost fertility are effective. Furthermore, even if fertility rates could be raised successfully, a tangible impact on labor supply would only materialize 20 years hence (Box 1).

- Inward migration policies have been used in some cases to address seasonal labor shortages. For example, the Czech Republic, Poland, and Slovakia have recently simplified procedures for short-term foreign workers from selected non-EU countries (notably Ukraine). However, most CESEE countries do not have long-term strategies for inward migration. Some countries (for example, Poland) have also adopted measures to promote return migration, including programs to maintain ties and facilitate communication of job opportunities with diaspora abroad, but return migration so far has been limited (see Chapter 7, "Policies to Increase Effective Labor Inputs").

- Labor force participation. There is a significant scope to increase labor force participation in CESEE countries. The average labor force participation

${ }^{1}$ Per Table A.1 of Bradshaw and Hirose (2016) and 2016 data from Eurostat. 
Figure 9. Labor Force Participation Rates in CESEE Countries, 2015
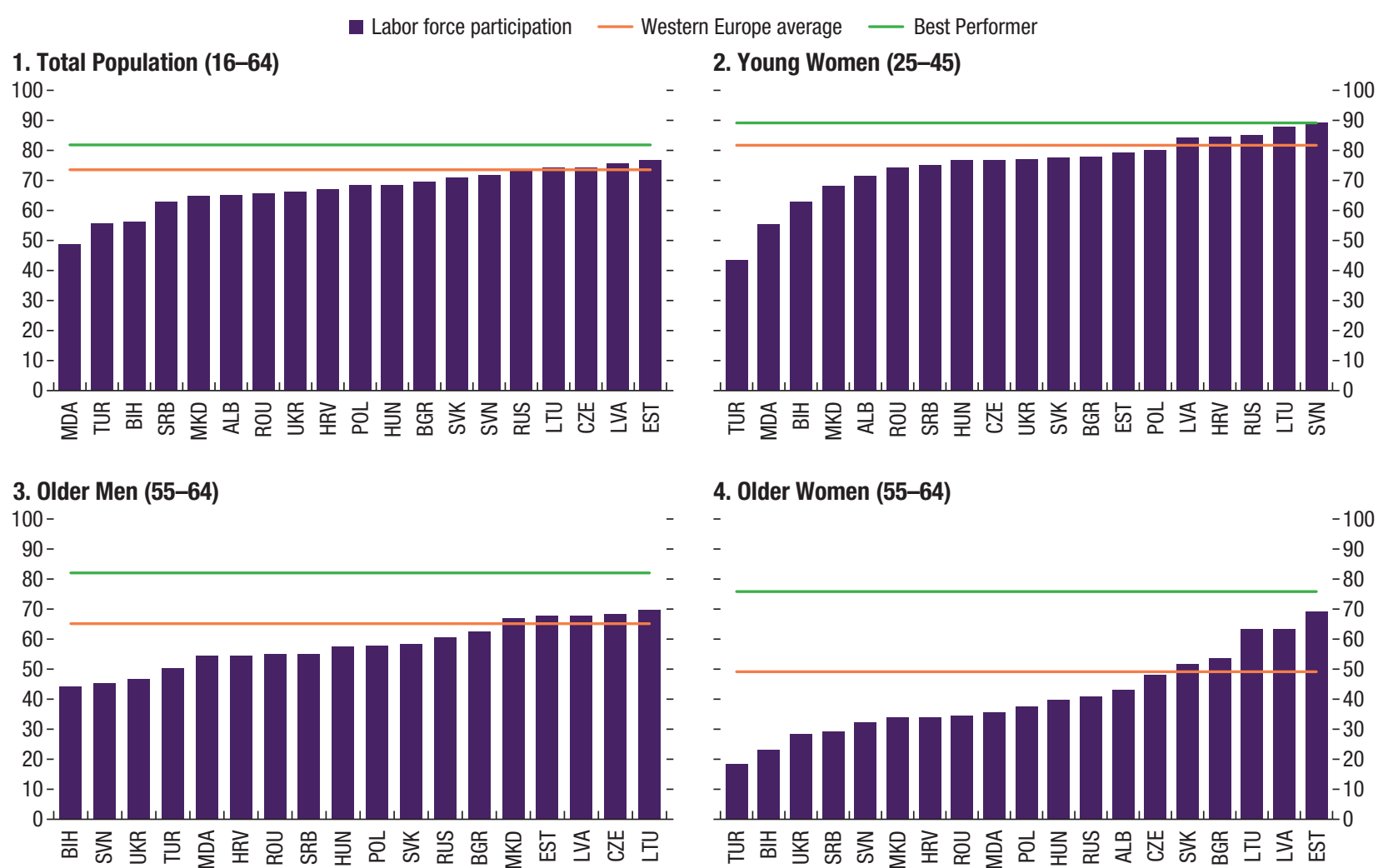

4. Older Women (55-64)

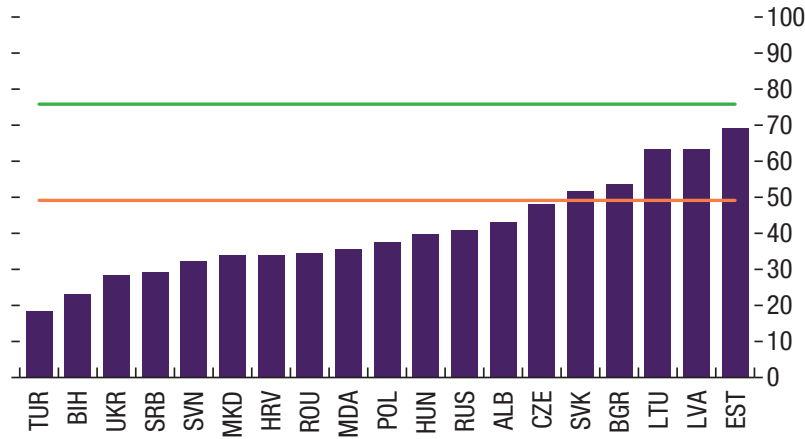

Sources: International Labour Organization; and IMF staff calculations.

Note: Data labels use International Organization for Standardization (ISO) codes.

rate in the region is 68 percent, below the Western European average of 74 percent, and all CESEE countries have significant potential for improvement compared with countries with the highest labor force participation rates in Europe (such as Sweden, with a rate of 82 percent). There is particular room to improve the participation of older workers and women. Participation of older workers ( 55 years or older) is significantly lower in CESEE countries than in Western Europe, in part due to still lower retirement ages. The average participation rate for women aged 55 to 64 years in the CESEE region is only 42 percent, compared with 49 percent in Western Europe and 76 percent in Sweden. For men, participation rates are higher, but the corresponding gaps are similar, with an average participation rate of 58 percent in CESEE countries and 65 percent in Western Europe (and 82 percent in Sweden). In many CESEE countries, participation of women of childbearing age (those aged 25 to 45 years) is below the Western European average, with the largest gaps in Turkey and the Balkan countries (Figure 9). 
The rest of this chapter focuses on increasing labor force participation, given limited evidence that policies to support higher fertility could be effective, and currently limited scope for substantially higher inward migration. To gauge the potential benefits from raising labor force participation, we evaluate two scenarios to illustrate the potential impact of increased female labor force participation, participation of older workers, and retirement ages (see Annex 2):

- A relatively "moderate" reform scenario assumes moderately paced increases in female labor force participation rates to the highest Western European rates and retirement age increases in line with life expectancy, but not higher than 67.

- An ambitious reform scenario assumes rapid increases in female labor force participation rates to the highest Western European rates and raising the retirement age above 70 by 2050 .

We emphasize that these are illustrative scenarios. For some countries, reaching even the participation rates in the moderate scenario could be quite demanding - the scenario is not meant as a policy proposal, but to illustrate what could be gained across CESEE countries by reaching a common benchmark.

Policies to increase labor force participation would help to reduce the decline in the labor force, with increases to statutory retirement ages typically providing the biggest boost to the labor force. Figure 10 shows results from the ambitious reform scenario, to see the likely limits of what could be achieved. The first three panels show the effects of changes to female labor participation, older worker participation, and retirement ages over time; in each, the dotted lines compare median paths for CESEE countries under the baseline labor force projections and respective policy scenarios. Measures to increase the participation of women in the labor force could increase the available labor force compared to the baseline labor force projection, especially before 2030 (Figure 10, panel 1). Boosting participation of older workers without lifting retirement ages would have a larger impact, increasing over time as the share of older cohorts in the total population continues to grow (Figure 10, panel 2). In the long term, the most significant impact would come from raising statutory retirement ages, which could reduce the median decline in the labor force by nearly 10 percentage points by 2050 (Figure 10, panel 3).

Across CESEE countries, the potential gains from the policies vary. Potential gains from different reforms will depend on the labor force structure, current retirement age, and participation rates. For example, Slovenia and Lithuania, which already have high female labor force participation rates, would benefit the most from increasing the retirement age, whereas Bosnia and Herzegov- 
Figure 10. Effects of Labor Force Participation Policies

(Percent change from 2015)

Boosting FLFP can have sizable effect in short term ...

1. Change in Labor Force under Higher Female Labor Force Participation

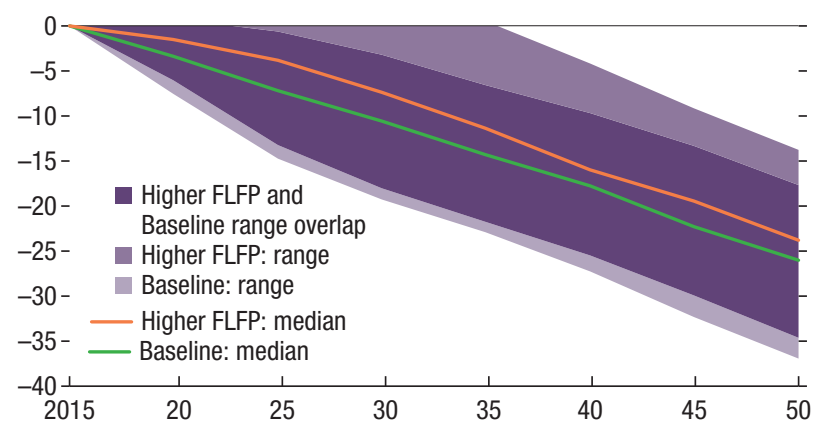

Raising the retirement age will have the largest effect in the long run ...

\section{Change in Labor Force under Higher Retirement Age}

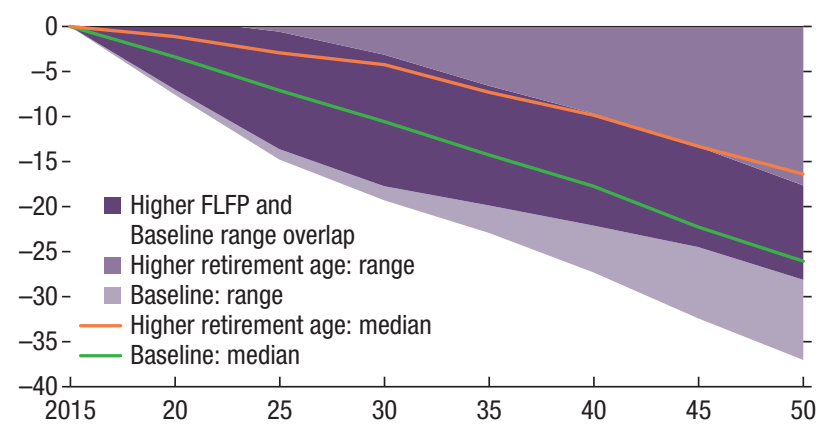

... whereas higher older worker participation could increase labor supply in medium to long term.

2. Change in Labor Force under Higher Older Workers' Participation

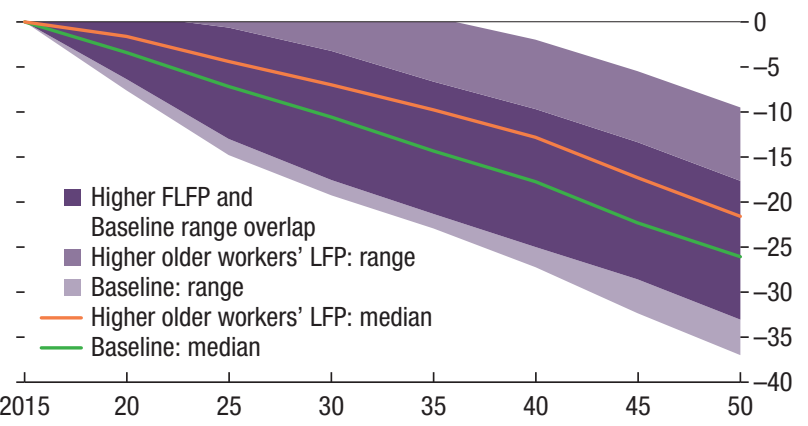

... and can help offset the projected labor force decline in several countries.

4. Labor Force in $\mathbf{2 0 5 0}$ and Ambitious Policy Measures

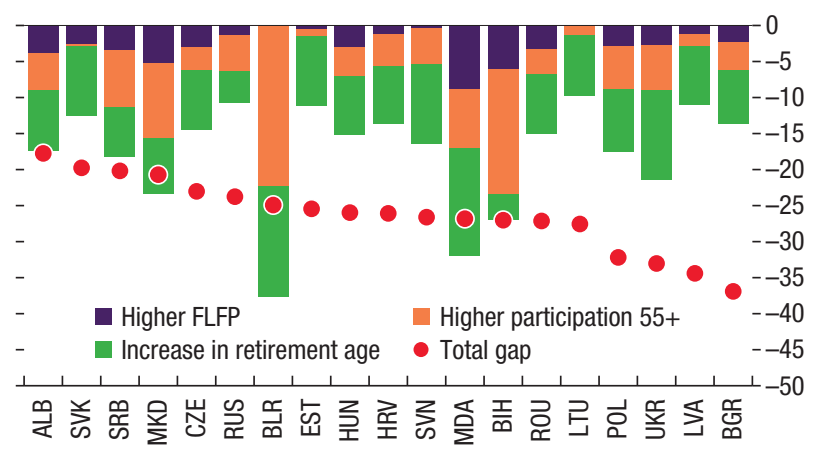

Source: IMF staff calculations.

Note: FLFP = female labor force participation; LFP = labor force participation. Data labels use International Organization for Standardization (ISO) codes.

ina and Moldova could significantly boost labor supply by increasing female labor force participation. By contrast, Belarus would benefit significantly from increasing the participation of older workers, even without changing the retirement age (Figure 10, panel 4).

Reform packages could substantially_but not fully_offset the effects of demographic trends on labor supply. Reforms could usefully reduce the declines in labor supply in most countries, in a typical case by half in the moderate reform scenario. However, in only a few cases would the reforms fully offset the decline in labor supply, and in some countriessuch as the Baltic states - the measures would not significantly reduce the decline (Figure 11). 
Figure 11. Labor Force Projections, 2050

(Percent change, $2015=100$ )

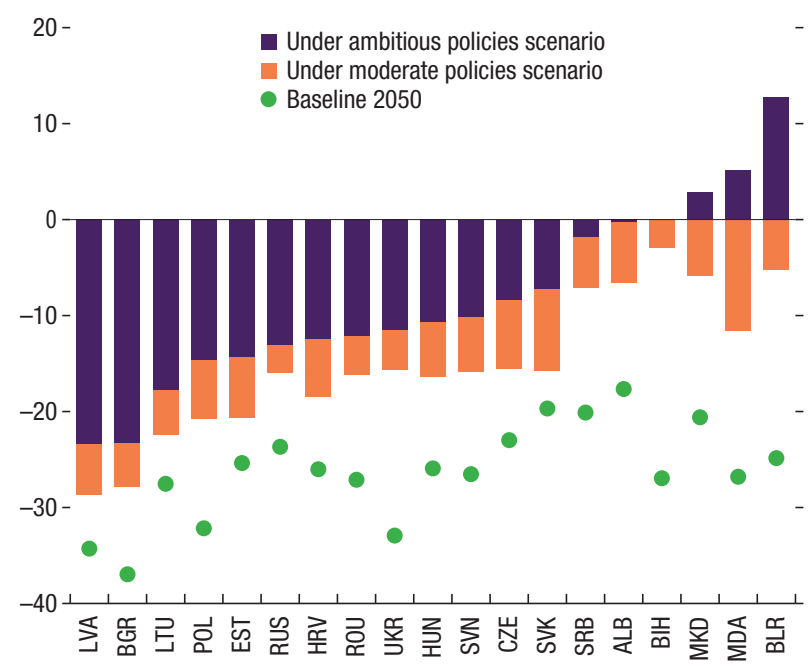

Sources: United Nations; and IMF staff calculations.

Note: Data labels use International Organization for Standardization (ISO) codes.
- A moderate reform effort would help mitigate the labor force declines but would not be sufficient to reverse them. Under this scenario, the average labor force decline would be limited to 3 percent by 2030 , but it would nonetheless be 16 percent by 2050. Reforms in Albania, Belarus, Bosnia and Herzegovina, Republic of North Macedonia, Moldova, and Serbia would bring the net decline in 2050 to below 10 percent. But many countries-Bulgaria, Estonia, Latvia, Lithuania, and Poland-would face labor force declines of more than 20 percent despite increases in labor force participation.

- In most countries, even ambitious reforms would ultimately be overwhelmed by population changes. Under the ambitious reform scenario, labor force declines in many countries would stall or even be reversed, but only temporarily. In several countries, including Belarus, Moldova, and the Western Balkan countries, ambitious reforms could potentially halt the decline in the labor force in the long term. In most other countries, however, population trends are projected to dominate, and in some, the shortfall would still be large, including in Bulgaria and Latvia, where the labor force is projected to decline by more than 23 percent, even with ambitious reform measures. 


\section{Box 1. Fertility Policies}

Fertility rates in the CESEE region are among the lowest in the world, and, with the exception of Turkey, often well below replacement rates. This raises the question of whether declines in the labor force could be addressed by policies to support higher fertility, as have been promoted in some countries. Such policies have included direct payments on birth of a baby, child allowances, and reduced tax rates for larger families.

The empirical evidence is not encouraging. The fall in fertility rates has been associated with an increase in the median age of women having their first child, driven in part by increasing costs of raising children. To the extent that some studies have found suggestive evidence that financial incentives have affected behavior, the effect has mainly been to bring births forward, with little increase in fertility rates. Otherwise, "the success of policies to influence fertility in low-fertility countries has not been impressive" (United Nations 2013; see also Kalwij 2010). Policies that reduce the opportunity costs of having children appear more effective (Hoorens and others 2011), although here too the evidence is mixed; policies that would make it easier for women with children to reenter the workforce would also be consistent with facilitating increased female labor participation.

\section{Box Figure 1.1. Impact of Higher Fertility}

1. Labor Force Change, 2015-50 (Percent of 2015 level)

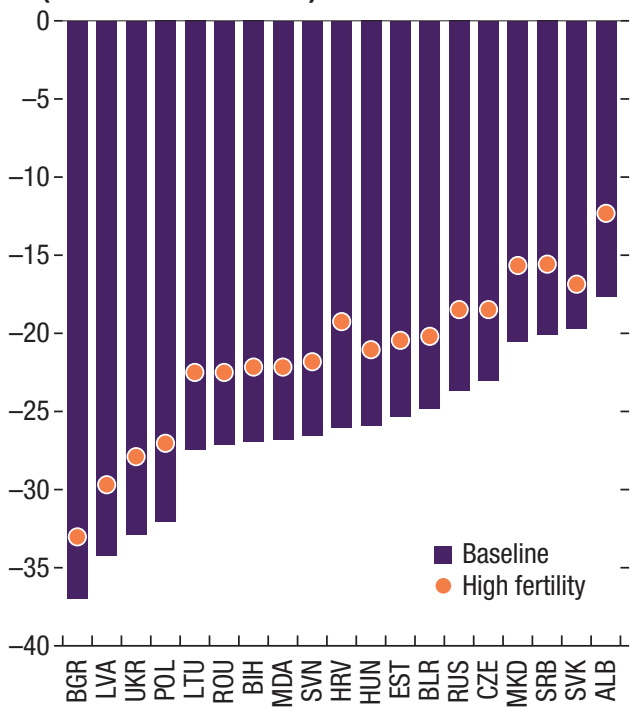

2. Labor Force CESEE excluding Turkey (Millions)
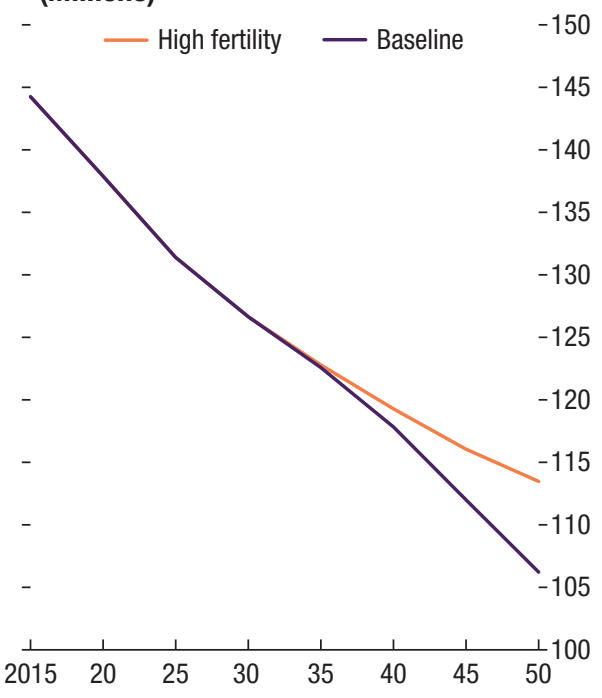

Sources: United Nations; and IMF staff calculations.

Note: Data labels use International Organization for Standardization (ISO) codes. 


\section{Box 1. Fertility Policies (continued)}

It is of course possible that some combination of sufficiently strong incentives could produce higher fertility rates. Simulations show that even if fertility were to immediately increase to rates assumed in the UN high fertility scenario of the 2017 vintage population projections, much higher than those seen over the past 50 years (see Annex 2), the effects would be limited (Box Figure 1.1). First, the working-age population would still not increase for at least 15 years; recall from Chapter 2 that the decline in the working-age population in the CESEE region is particularly severe over this period. Second, over longer periods the increased population is still not sufficient to offset the reduction in the labor force; indeed, in all countries, the effects by 2050 are limited. 


\section{Chapter}

\section{Implications for Age-Related Public Spending}

Aging populations will substantially increase demands on health care resources.

Public pension systems currently appear sustainable, but spending would increase substantially if pensions were more in line with preretirement earnings.

Ambitious reforms to increase labor force participation rates and retirement ages would help to offset projected increases in public pension spending.

Fiscal space also needs to be preserved for measures to increase labor participation.

This chapter examines the implications of demographic trends for spending on public health care and pensions, before the full assessment of implications for public finances in Chapter 5. We also look at the direct effects of increasing labor supply described in Chapter 3 to offset the expected increases in pension and health care costs, before the simulations that combine all effects in Chapter 6.

Population aging poses a formidable fiscal challenge for CESEE countries. Worsening demographics, notably rapid aging, increase the costs of public programs, such as pensions and health care. Today, CESEE countries spend 9 percent of GDP on public pensions and 5 percent of GDP on public health care each year, significantly less than their euro area peers, which spend 12 and 7 percent of GDP, respectively (Figure 12). ${ }^{1}$

- On current fiscal policies, costs related to pensions and health care in CESEE are expected to increase by nearly 4 percentage points of GDP, on average, between 2015 and 2050 (see Annex 3). Almost half of the increase is explained by rapidly rising health care spending: the fiscal cost of pub-

\footnotetext{
${ }^{1}$ See European Commission (2018), Table 1, page 12.
} 
Figure 12. Projected Change in Age-Related Spending: Mid-Fertility Scenario (Percent of GDP, change from 2015 to 2050)

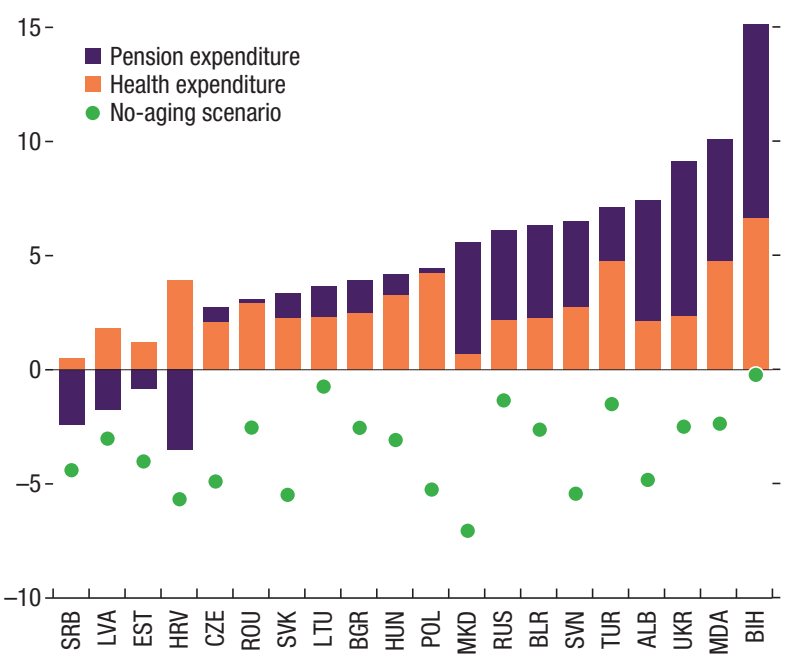

Source: IMF staff calculations.

Note: Data labels use International Organization for Standardization (ISO) codes. lic health care systems is projected to increase by $23 / 4$ percentage points of GDP, putting most of the pressure on public budgets over the next decade. By contrast, the projected fiscal cost of public pension systems on current policies appears to remain relatively contained, rising by just over 1 percentage point of GDP.

- The implications for each CESEE country vary significantly. Pension costs are projected to remain unchanged or fall in several of the countries in the sample, whereas they are projected to increase between about 4 to 7 percentage points of GDP in several Western Balkan and Eastern European countries. Besides expected demographic trends, differences in projected age-related costs are mostly explained by differences in country-specific pension systems (retirement age, entitlement, etc.) and coverage of public health care systems.

Unlike in Western Europe, pension systems in many CESEE countries are based on defined contributions. The systems appear fiscally sustainable, but have relatively low replacement rates (that is, pension payments as a percentage of preretirement earnings). Although recently adopted pension system reforms in the region have aimed to increase retirement ages (or link retirement ages to life expectancy), they have incorporated sharp reductions in projected replacement rates. On average, a pensioner in 2050 will receive about one-third of their preretirement earnings. Except for Ukraine, the replacement rate is projected to drop in CESEE countries, especially in Republic of North Macedonia, Moldova, and Poland (by 28, 30, and 25 percentage points, respectively).

Governments might come under pressure to increase replacement rates. This could substantially increase pension costs (Figure 13). To illustrate, bringing replacement rates to 40 percent - the level recommended by the International Labour Organization-would increase estimated fiscal costs of pensions by 4 percentage points of GDP, on average. Total pension and health care costs in the CESEE region would therefore increase by nearly 7 percentage points of GDP, on average, between 2015 and 2050. In countries currently with relatively low replacement rates (that is, Croatia, Latvia, and Lithuania), 
the increase in annual aging costs in percentage of GDP between now and 2050 could be significant; in other countries with higher replacement rates and/ or more benign demographic outlooks (that is, Moldova, the Slovak Republic, and Turkey), the costs would be correspondingly small. On average, age-related spending is projected to reach 20 percent of GDP by 2050 , with some countries in the region (such as Bosnia and Herzegovina, Croatia, Poland, Slovenia, and Ukraine) spending as much as 25 percent of GDP or more in pensions and health care.

Reforms would help offset projected age-related fiscal costs.

- Pension costs. We consider the impact of the moderate and ambitious labor market reform packages - an increase in labor force participation of women and older workers, and an increase in the retirement age-first described in Chapter 3 (see Annex 2). In both cases, we also consider the additional fiscal cost of increasing replacement rates to the International Labour Organization's recommended 40 percent. Moderate reforms would help to offset some of the projected increase in pension
Figure 13. Age-Related Spending: The ILO's 40 Percent Replacement Rate
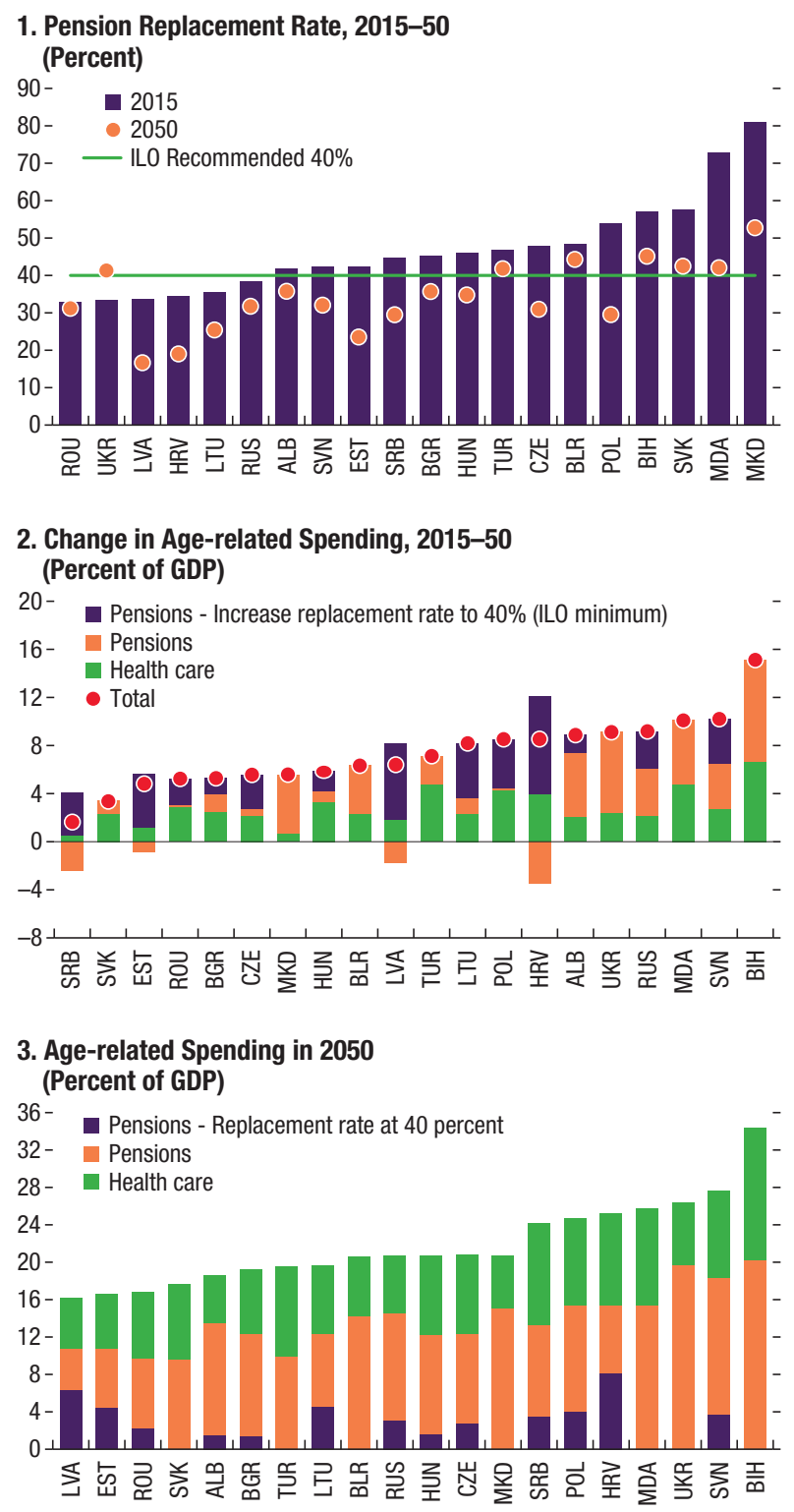

Source: IMF staff calculations.

Note: ILO = International Labour Organization. Data labels use International Organization for Standardization (ISO) codes. 


\section{Figure 14. Impact of Reforms on Pension Costs}
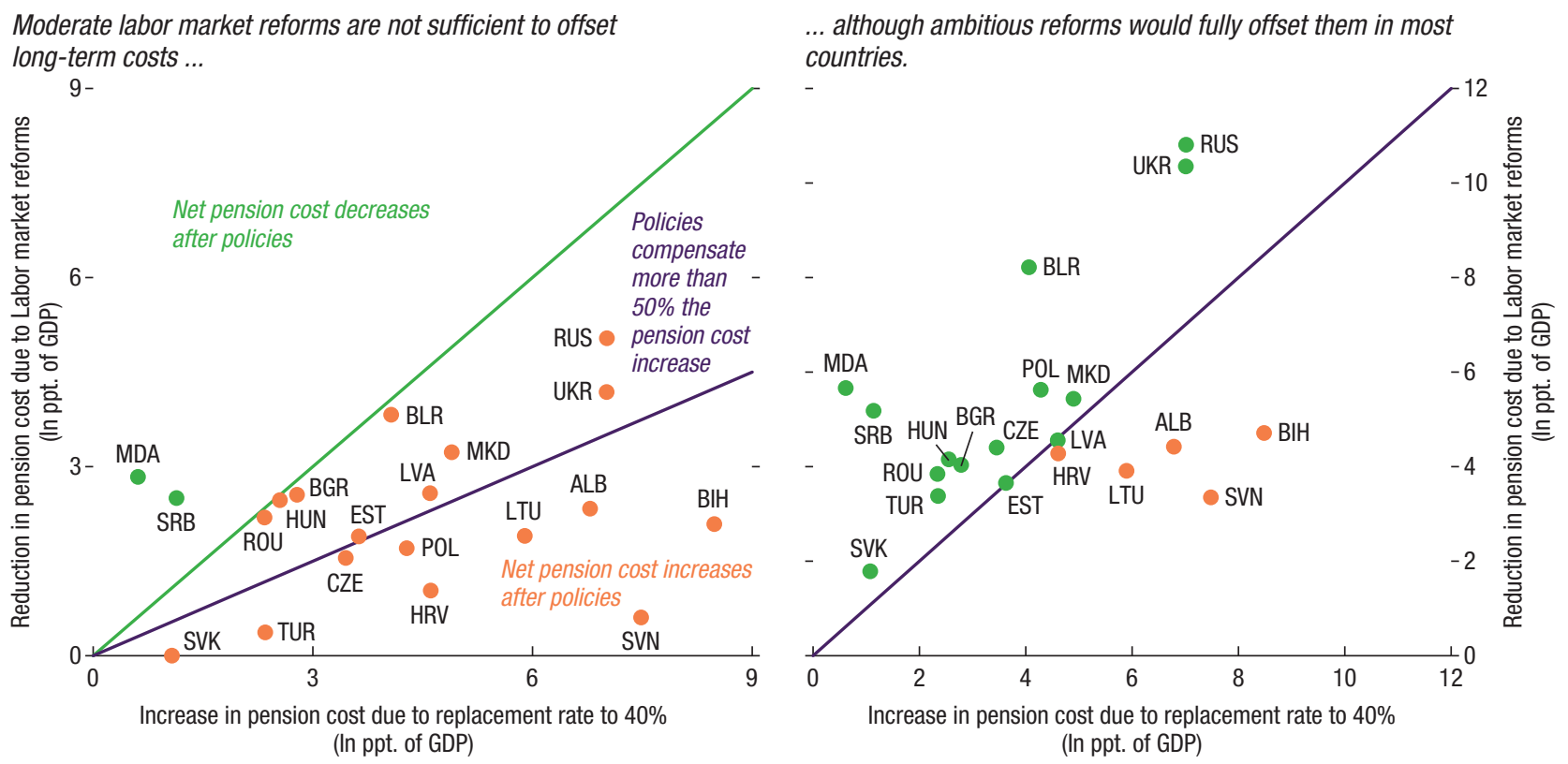

Source: IMF staff calculations.

Note: ppt. $=$ percentage point. Data labels use International Organization for Standardization (ISO) codes.

costs over the period from 2015 to 2050 , by about 2 percentage points of GDP on average. Although pension costs would still increase in most countries, the reforms would help to offset at least half of the projected increase in pension outlays implied by increasing replacement rates. Ambitious reforms would fully offset projected increases in pension costs in most countries, generating average savings of nearly 5 percentage points of GDP (Figure 14). The savings would imply a reduction in the estimated cost of socially sustainable pension systems in the majority of CESEE countries.

The variation in the impact of reforms on pension costs among CESEE countries is accounted for by (1) the projected increase in the share of population reaching retirement age, (2) the policy objectives (that is, the gap between the current labor force participation rate prevailing in each country and the highest Western European rates, as defined in Chapter 3); and (3) the speeds at which retirement ages need to be increased. There is substantial scope to increase labor force participation in some countries (for example, Hungary, Moldova, and Serbia). In some countries, aligning retirement ages with life expectancy implies large increases from current retirement ages (especially among women); in other countries, retirement ages are close to proposed policy objectives, but the countries face much larger shares of the population reaching retirement age during the next decades (For example, Bosnia and Herzegovina, and Slovenia). 
- Health care costs. Health care reform could contain the growth of public health spending, for example by ensuring that new technologies reduce, rather than raise, health care costs, without adversely affecting health outcomes. $^{2}$

The delivery of health care could be improved through better management of hospitals and improved incentives in the remuneration of health providers. Governments can also support primary and preventive care-which helps improve health and reduce the need for more costly treatments at a later stage-and improve provider payment systems to control costs. In addition, the use of health information technology (for example, to collect, store, and share patient data) has the potential to reduce costs while protecting outcomes (see Box 2).

Labor market reforms would have direct fiscal costs that would need to be taken into account. ${ }^{3}$ Reducing the tax wedge, for example, could lower labor costs for firms and boost job creation, but would lead to revenue losses. Active labor market policies such as training, job creation programs, effective placement services, or extended child daycare services to incentivize female labor force participation have direct budgetary effects (Box 3). Ambitious labor market reforms would reduce the cost of public pensions, but could potentially generate additional demand for health care services, with evidence suggesting that sick leave and disability payments tend to increase with a higher share of older workers. The costs of reforms therefore offset some of the fiscal savings from reforms (Figure 15). Ambitious labor market reforms would still reduce the projected fiscal cost of pensions in most CESEE coun-

\footnotetext{
${ }^{2}$ See Clements, Coady, and Gupta 2012.

${ }^{3}$ See IMF 2014.
} 
tries. In some countries, such as Albania, the Baltic states, Croatia, and the Czech Republic, the fiscal cost of pensions is projected to increase after considering the cost of policies, but nonetheless remain well below the projected increase in the absence of reforms. In other countries, such as Romania or to some extent the Slovak Republic, the cost of implementing labor market reforms would need to be assessed carefully, as the projected fiscal savings are more limited.

The challenges of meeting increasing demands on public pensions and health care spending are clearly not trivial. Reforms can help to contain costs, but some-such as labor participation reforms - come with fiscal costs themselves, and they often imply significant social choices (such as the extent of health care the state should provide). Moreover, the fiscal costs considered here understate the implications for public finances-in a full assessment, we would take into account the effects of demographic changes on growth, and hence revenues and debt sustainability. These issues are taken up in Chapter 4. 


\section{Box 2. Policies to Contain Health Care Spending}

Public health costs have increased rapidly in advanced economies in the past two decades, from relatively high levels compared with CESEE economies. Spending rose by about $1 \frac{1 / 2}{2}$ percentage points of GDP since the early 2000s in Organisation for Economic Co-operation and Development (OECD) countries (about 11/4 percent in Western Europe). CESEE countries, in contrast, have so far managed to keep government health spending on average roughly constant in percent of GDP. However, as seen in this chapter, cost pressures are likely to increase substantially.

Several reforms have been adopted that could keep heath costs under control. These reforms can be grouped into three main categories (Clements and others 2012):

\section{Macro-level Controls}

- Budget caps, either on the entire health care budget (England) or on selected sectors like hospitals, ambulatory care (most EU countries), or physician costs (Canada). Austria has managed to contain the growth of public health care spending well below the OECD average by imposing financial targets to gradually bring health care spending in line with annual average GDP growth (OECD 2017).

- Supply constraints: Governments may impose "input" controls such as determining the types of prescription drugs to be subsidized with public funds and rationing expensive medical equipment. "Output" controls include listing certain medical interventions from the list of insured treatments. Restrictions on supply have been used in Canada (hospital closures and mergers) and Germany, France, Italy, and the Netherlands (delisting ineffective treatments, and/or establishing positive drug lists). In the past decade, the number of acute-care hospital beds has been reduced in all EU countries (Schwierz 2016). In the early 2000s, governments sought to use cost-effectiveness evaluations to determine what treatments should be financed from public funds. Many countries (Australia, Canada, Finland, France, the Netherlands, Sweden, the United Kingdom) have established government bodies to conduct cost-effectiveness appraisals of new pharmaceuticals and provide evidence-based clinical guidelines.

- Price controls, such as setting the salaries of health care professionals and/or the prices of drugs and medical treatments. This approach has been implemented mainly in countries in which the public sector contracts the private sector to provide services, such as in Canada (targeted physician fee reductions), France and England (cuts to radiologist rates and lab test rates), and Germany and the Netherlands (reference pricing for pharmaceuticals). To be effective, prices have to be agreed through negotiation at the national or regional level instead of being determined unilaterally by the government or suppliers. Several countries have observed the price of pharmaceutical care dropping significantly after the adoption of external reference pricing (ERP): ERP implementation or review resulted in a reduction in the prices of prescription medicines by 4 to 20 percent in Bulgaria, Greece, Moldova, the Netherlands, and 


\section{Box 2. Policies to Contain Health Care Spending (continued)}

the Slovak Republic. An increased reliance in generic drugs has supported the ERP (Kanavos and others 2017).

\section{Micro-level Reforms}

- Public management and coordination seeks to create cost savings by streamlining the administration and interaction of different levels of the health care system. Reviewing fiscal decentralization has been effective at reducing health care costs, either by allowing greater involvement of subnational governments in key health care decisions while maintaining central oversight (Canada, Sweden), or by consolidating regional health authorities and introducing new management practices (the United Kingdom in the late 1970s to 1980s). An enhanced control of public procurement, especially with the introduction of modern information technology systems, was fostered in a few countries (Bulgaria, the Czech Republic, Estonia, and the United Kingdom) (Schwierz 2016).

- Contracting: How providers are reimbursed is one of the most important factors affecting the micro-level efficiency of health spending. In most EU countries, payment methods have shifted from traditional fee-for-service methods to case-based payments, such as diagnosis-related groups. Diagnosis-related group-based payment systems are designed to incentivize efficient use of resources within hospitals, where payments are made based on the number and type of cases treated. Several countries have adopted explicit contracts with health care providers that target cost control, efficiency, and quality of care.

- Market mechanisms, such as allowing greater competition between insurers and/ or relying on a greater degree of private provision, can be particularly effective in containing health care costs (Estonia, Germany, the Netherlands, and Switzerland). Key elements to consider when introducing, changing, or increasing competition are ensuring market transparency, with availability of information on quality and prices, careful monitoring of access and equity effects, promoting health literacy, and enforcing competition rules to prevent abuse of dominant positions (European Commission 2015).

\section{Demand-side Reforms}

- These reforms intend to increase the share of health care costs borne by patients, often with the objective of avoiding excessive consumption of specific health services. Two common ways this cost-sharing is achieved is by having patients share part of the cost of their treatment and by changing the way private health insurance is taxed. 


\section{Box 3. Costs of Active Labor Market Policies}

Active labor market policies are programs to assist the unemployed or those not active in the labor market to find employment (as compared with "passive" labor market policies such as unemployment benefits). They are many and varied, including training programs, job placement assistance, employer subsidies, and public works. $^{1}$

Implementation of active labor market policies in CESEE may require additional fiscal space. Based on past episodes of active labor market policies in EU countries, the required policies to boost female labor force participation through 2050 would imply a fiscal cost projected at about 0.7 percent of GDP for the moderate reform package and close to 1 percent of GDP for the ambitious reform package. There is some variation among CESEE countries: the fiscal cost of ambitious labor market reforms is close to $1 \frac{1}{2}$ percent of GDP in Croatia, the Czech Republic, Poland, and Ukraine, but close to $1 / 2$ percent of GDP in the Slovak Republic and Romania. This variation is explained by differences in the sensitivity of female labor force participation rates to government spending in active labor market policies (based on individual country experience over the last decade) and differences in the gap between the female labor force participation rate prevailing in each country and the highest Western European rate (Box Figure 3.1).

The upfront cost of adopting the needed reforms is especially challenging for some countries with limited fiscal space. The estimated gap between the debt-stabilizing primary balance and the observed primary balance is positive in Belarus, Moldova, Romania, Russia, and Turkey, suggesting that fiscal consolidation may be required to stabilize public debt.

${ }^{1}$ For a summary and assessment, see Bown and Freund 2019.

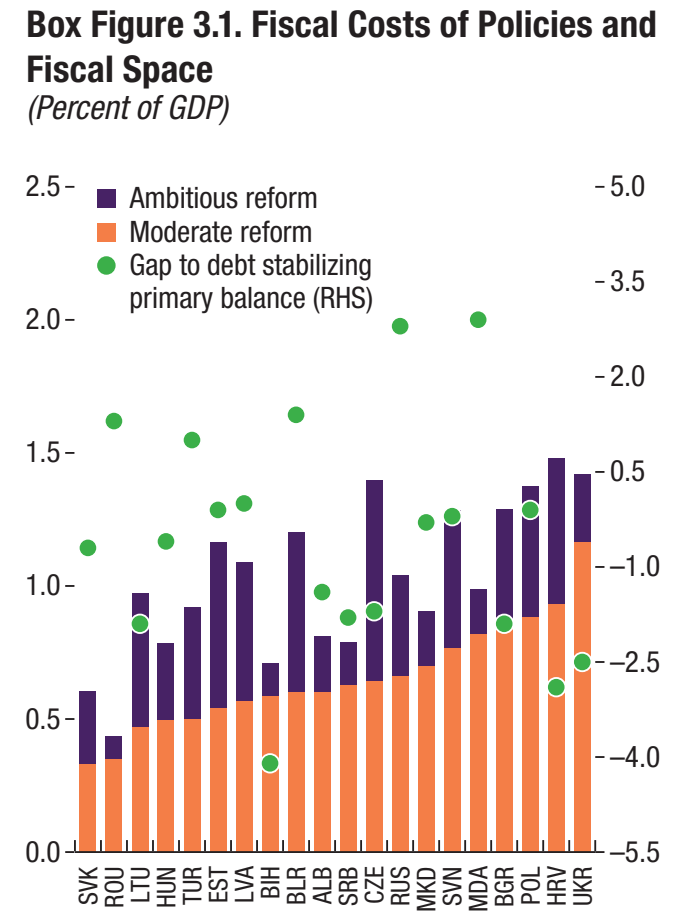

Source: IMF staff calculations

Note: Data labels use International Organization for Standardization (ISO) codes. 
This page intentionally left blank 


\section{Chapter}

\section{Implications for Productivity}

Aging of the labor force per se could cause aggregate productivity to deteriorate. For some CESEE countries, this effect could be significant.

With shrinking and aging populations, the workforce in CESEE countries will also shrink and age. Between 2015 and 2030, the share of older workers (ages 55+) in the CESEE workforce will increase by 2.5 percentage points; by 2050 , it will expand by another 3 percentage points. The question then arises as to what extent these demographic changes might adversely affect productivity and growth. This chapter looks at the potential implications of these changes on productivity, to complement the examination in Chapter 3 of the direct effects on labor supply.

\section{Literature and Econometric Evidence}

Theory suggests many ways by which demographic changes can affect productivity. They can affect labor productivity by changing physical capital intensities as labor supply changes (Cutler and others 1990). Total factor productivity (TFP) itself can also be expected to respond to demographic changes:

- Positive effects: Older workers may have more work experience, with potentially positive effects on productivity (Disney 1996). Incentives to innovate should increase as skilled labor becomes scarce, increasing the payoffs to automation (Acemoglu and Restrepo 2017; Habakkuk 1962; Romer 1990).

- Negative effects: An age-related deterioration in physical and mental capabilities and depreciation of knowledge could adversely impact aggregate TFP if the share of older workers in the workforce were to increase. Older workers might find it more challenging to adapt to job requirements that are 
changing over time (OECD 1998). For example, the increased use of information technologies might place older workers at a disadvantage (Dixon 2003). Empirically, average skill scores tend to decline over the working life, including in CESEE economies (European Bank for Reconstruction and Development 2019). Innovation might become less profitable as population growth slows, such as by reducing market size, and aging societies may lose some of their "dynamism" slowing the rate of technological progress (Simon 1981; Wattenberg 1987). The entry of new firms and entrepreneurship can slow with the aging of population and workforce (Hopenhayn, Neira, and Singhania 2018; Liang, Wang, and Lazear 2018). If a large share of the workforce is employed in manual work sectors, its aging would cause a rapid deterioration in productivity associated with the deterioration in physical abilities (Veen 2008; Box 4).

- Magnification effects: Several hypotheses have been proposed to explain the apparent externalities that drive the often sizable estimates of the effects of aging workforce on aggregate productivity (Feyrer 2008). For example, evidence suggests that idea generation and innovation activity peaks when workers are in their 40s (see Galenson and Weinberg 2000, 2005; Jones 2005). Hence, the age structure of the workforce could affect the probability that far-reaching inventions - that expand the technological frontier and increase productivity of all workers - are attempted and accomplished. Idea adoption, which facilitates movement toward the technology frontier, can peak at a certain age due to a tradeoff between up-to-date education-sourced human capital and experience-based human capital. Consequently, aging workforce-more so when accompanied by a lower share of workers in their prime age-can generate externalities at the macro level beyond what can be observed of individual workers.

Empirical studies show a negative link between workforce aging and productivity. Labor productivity typically increases until workers are in their 40 s and declines toward the end of working lives (Feyrer 2007).

- Macro-based studies look at the direct impact of workforce age distribution on aggregate productivity measured by labor productivity or TFP. They find that an increase in the share of workers in their 40s is associated with an increase in aggregate productivity, whereas an increase in the share of older workers (above ages 50 to 55) coincides with a reduction in aggregate productivity (Table 3).

- Micro-based studies draw inference on productivity from wage data under the assumption that earnings are proportional to productivity. ${ }^{1}$ By focusing

\footnotetext{
${ }^{1}$ If markets are perfectly competitive, a worker's hourly wage should equal the value of the marginal product of an hour worked. This relationship may not be valid if, for example, workers and employers engage in long-term contracts, earnings increases are linked to seniority and company affiliation, or compensation schemes are backloaded to encourage workers to stay with the company.
} 
Table 3. Selected Macro-based Studies on the Effect of Aging on Productivity

\begin{tabular}{|c|c|c|c|}
\hline Authors & Approach/channels & Sample and method & Result \\
\hline Feyrer (2007) & $\begin{array}{l}\text { Impact of changes in workforce age } \\
\text { structure on labor productivity and } \\
\text { production function components. }\end{array}$ & $\begin{array}{l}\text { Panel regressions for } 87 \text { non-oil countries, } \\
1960-1990 .\end{array}$ & $\begin{array}{l}\text { Finds strong support for a hump-shaped relationship between labor force age } \\
\text { distribution and labor productivity with the cohort aged } 40-49 \text { showing the highest } \\
\text { productivity, mainly driven by lower TFP. A } 5 \text { percentage point shift from the cohort } \\
\text { aged } 40-49 \text { to the cohort aged } 50-59 \text { is associated with over a } 10 \% \text { decrease } \\
\text { in TFP, or equivalently about } 1 \text { percentage point TFP growth per year if this shift } \\
\text { occurred over a ten-year period. }\end{array}$ \\
\hline Feyrer (2008) & $\begin{array}{l}\text { Impact of changes in workforce age } \\
\text { structure on TFP and drivers. }\end{array}$ & $\begin{array}{l}\text { Panel regressions for } 87 \text { non-oil countries, } \\
\text { 1960-1990; NBER patent database; US state } \\
\text { and metropolitan data, 1960-2000. }\end{array}$ & $\begin{array}{l}\text { Finds strong support for a hump-shaped relationship between labor force } \\
\text { age distribution and TFP at the country level, but not at the US state and MSA } \\
\text { level, suggesting that externalities are stronger at higher levels of aggregation. } \\
\text { The creativity profile of inventors may be quite stable with a peak somewhere } \\
\text { in the mid-40s. }\end{array}$ \\
\hline Werding (2008) & $\begin{array}{l}\text { Follows Feyrer (2007) but also looks at } \\
\text { TFP growth. }\end{array}$ & $\begin{array}{l}\text { Panel regressions, up to } 106 \text { countries, } \\
1960-2000 .\end{array}$ & $\begin{array}{l}\text { Confirms Feyrer's (2007) findings. Expected changes in the age composition of the } \\
\text { workforce may temporarily reduce trend TFP growth and trend productivity growth } \\
\text { by more than } 1 \text { percentage point a year. }\end{array}$ \\
\hline Aiyar et al (2016) & $\begin{array}{l}\text { Impact of workforce aging on labor } \\
\text { productivity, main transmission channels, } \\
\text { and possible policy responses. }\end{array}$ & $\begin{array}{l}\text { Panel regressions, EU28 countries, } \\
\text { 1950-2014. }\end{array}$ & $\begin{array}{l}\text { A } 1 \text { percentage point increase in the share of workers aged } 55-64 \text { leads to a } \\
\text { decline in the growth of output per worker of } 0.25-0.7 \text { percentage points, mainly } \\
\text { through a decline in TFP growth. }\end{array}$ \\
\hline IMF (2017) & $\begin{array}{l}\text { Impact of workforce aging on } \\
\text { productivity growth and channels. }\end{array}$ & $\begin{array}{l}\text { Panel regressions, } 12 \text { Asian and } 20 \text { EU } \\
\text { countries, 1950-2014. }\end{array}$ & $\begin{array}{l}\text { A } 1 \text { percentage point increase in the share of workers aged } 55-64 \text { is associated } \\
\text { with a reduction in TFP growth of } 0.74 \text { percentage points. }\end{array}$ \\
\hline $\begin{array}{l}\text { Lindh and } \\
\text { Malmberg (1999) }\end{array}$ & $\begin{array}{l}\text { Impact of demographic age structure on } \\
\text { economic growth. }\end{array}$ & $\begin{array}{l}\text { Panel regressions, OECD countries, } \\
1950-1990 .\end{array}$ & $\begin{array}{l}\text { An increase in the share of people aged } 65 \text { and over has a negative effect on } \\
\text { labor productivity growth, while younger age groups (15-29 and } 30-49) \text { have } \\
\text { insignificant effects. }\end{array}$ \\
\hline $\begin{array}{l}\text { Liu and Westelius } \\
\text { (2016) }\end{array}$ & $\begin{array}{l}\text { Impact of demographics on productivity } \\
\text { and inflation. }\end{array}$ & Panel regressions, 1990-2007. & $\begin{array}{l}\text { Broadly confirm the magnitude of Feyrer's (2007) results for Japan: a } 1 \text { percentage } \\
\text { point shift from the cohort aged } 40-49 \text { to the cohort aged } 50-59 \text { decreases TFP } \\
\text { by } 1.3 \text { percent. }\end{array}$ \\
\hline $\begin{array}{l}\text { National Research } \\
\text { Council (2012) }\end{array}$ & $\begin{array}{l}\text { Long-term impact of aging population on } \\
\text { economic growth. }\end{array}$ & $\begin{array}{l}\text { Panel regressions, quadratic and cubic } \\
\text { effects, OECD countries. }\end{array}$ & $\begin{array}{l}\text { The change in the age distribution, measured by the mean age of the labor force, } \\
\text { reduces aggregate TFP by about } 0.1 \text { percent per year. }\end{array}$ \\
\hline $\begin{array}{l}\text { Aksoy and others } \\
\text { (2015) }\end{array}$ & $\begin{array}{l}\text { Impact of changes in demographic } \\
\text { structure on medium run trends of key } \\
\text { macroeconomic variables. }\end{array}$ & Panel VAR, 21 OECD countries. & $\begin{array}{l}\text { Innovation activity/patent application is positively affected by young and } \\
\text { middle-aged cohorts and negatively affected by dependents and retirees. }\end{array}$ \\
\hline $\begin{array}{l}\text { Cutler and others } \\
\text { (1990) }\end{array}$ & $\begin{array}{l}\text { The relation between aggregate labor } \\
\text { force growth and labor productivity } \\
\text { growth. }\end{array}$ & Panel regression, 29 countries, 1960-1985. & $\begin{array}{l}\text { A } 1 \text { percentage point decrease in annual labor force growth raises labor productivity } \\
\text { growth by about } 0.6 \text { percentage points with a similar effect on TFP growth for } \\
\text { a smaller sample of OECD countries; the effect is dampened when controlling for } \\
\text { average labor force age. }\end{array}$ \\
\hline $\begin{array}{l}\text { Acemoglu and } \\
\text { Restrepo (2017) }\end{array}$ & $\begin{array}{l}\text { The relationship between population } \\
\text { aging and GDP per capita.B22 }\end{array}$ & $\begin{array}{l}\text { Cross sectional TSLS regressions for } 169 \\
\text { countries, 1990-2007. }\end{array}$ & $\begin{array}{l}\text { Positive association between aging (measured by either the ratio of the population } \\
\text { above } 50 \text { to the population } 20-49 \text {, or by the average age of the population above 20) } \\
\text { and the growth of GDP per capita. }\end{array}$ \\
\hline
\end{tabular}


on private returns, micro-based studies do not capture externalities observable at the aggregate level (for example, from experience, education, and innovation) and deliver mixed results about the effect of aging on productivity. For example, Börsch-Supan and Weiss (2016) find that individual worker productivity continues to increase until age 65 as experience keeps older workers' productivity from falling. However, Acemoglu and others (2014) find that companies with young chief executive officers have greater innovation quality, due to greater openness to disruption and more creative innovation. Göbel and Zwick (2012) and Maestas, Mullen, and Powell (2016) confirm the results of macro-based studies that productivity declines as the share of older workers increases.

Our empirical estimates support previous macro-based studies. The specification described in Annex 4 is applied to a data panel of up to 167 countries spanning the period from 1990 to 2015 . The annex discusses estimation details, including controls used for country-specific effects, instruments used to address endogeneity, and various robustness checks that have been undertaken. The results (Table 4) show that:

- In the first specification (columns 1-4), a one-percentage-point increase in the share of older workers (ages 55+) in the total workforce is associated with a decrease in growth of output per worker of $0.7-0.8$ percentage points (column 1). Most of this effect stems from lower TFP growth, which decreases by about 0.6 percentage points for every percentage point increase in the older-worker share (column 2). The results do not provide evidence that human capital is an important channel of transmitting the impact of workforce aging on productivity (column 3). However, workforce aging is associated with a statistically significant (albeit smaller) increase in the capital-output ratio, suggesting that there may be some capital intensification to compensate for an older and less productive workforce (column 4).

- An alternative specification (columns 5-8) provides some evidence-as in other empirical literature - that productivity is highest around age 50. In particular, the negative impact of a higher older-worker share on total factor productivity may be mitigated if the share of workers in the 45-54 age cohort also increases (column 6). ${ }^{2}$

\footnotetext{
${ }^{2}$ Since the coefficient of the 45-54 age cohort is significant in the TFP regression, but not in the labor productivity regression, we did not select this specification for projections. Only time dummies that were significant were included in the final specification. (The significant dummies include crisis episodes.) In a specification with full set of year dummies, the negative impact of an increase in the share of older workers on labor productivity growth increases by near 0.3 percentage points, of which 0.2 percentage points channeled through a decline in TFP growth. We also experimented with non-overlapping five-year averaged observations in pooled and fixed effects panel specifications, which yielded significantly larger negative coefficients at lower significance levels as the number of observations drops rapidly in this case.
} 
Table 4. Productivity Regression Results

(Instrumented with 10-year lagged population cohorts)

\begin{tabular}{|c|c|c|c|c|c|c|c|c|}
\hline \multicolumn{9}{|c|}{$\Delta \log Y L_{i t}=\alpha_{i}+\gamma_{t}+\sum_{s} \beta_{s} w_{s i t}+\delta y a d r_{i t}+\varphi o a d r_{i t}+\varepsilon_{i t}$} \\
\hline Variables & $\begin{array}{c}\text { (1) } \\
\text { Labor } \\
\text { Productivity }\end{array}$ & $\begin{array}{l}\text { (2) } \\
\text { TFP }\end{array}$ & $\begin{array}{l}\text { (3) } \\
\text { Human } \\
\text { Capital }\end{array}$ & $\begin{array}{c}\text { (4) } \\
\text { Capital-0utput } \\
\text { Ratio }^{1}\end{array}$ & $\begin{array}{c}\text { (5) } \\
\text { Labor } \\
\text { Productivity }\end{array}$ & $\begin{array}{l}\text { (6) } \\
\text { TFP }\end{array}$ & $\begin{array}{c}\text { (7) } \\
\text { Human } \\
\text { Capital }\end{array}$ & $\begin{array}{c}\text { (8) } \\
\text { Capital-Output } \\
\text { Ratio }^{1}\end{array}$ \\
\hline Share of Workers in $45-54$ Age Cohort & & & & & $\begin{array}{c}0.205 \\
(1.565)\end{array}$ & $\begin{array}{l}0.238^{* \star} \\
(2.003)\end{array}$ & $\begin{array}{l}-0.0216 \\
(-1.051)\end{array}$ & $\begin{array}{l}-0.113^{\star \star} \\
(-2.254)\end{array}$ \\
\hline Share of Workers older than 55 years & $\begin{array}{l}-0.731^{\star \star \star} \\
(-4.006)\end{array}$ & $\begin{array}{l}-0.608^{\star \star \star} \\
(-3.563)\end{array}$ & $\begin{array}{l}-0.0142 \\
(-0.461)\end{array}$ & $\begin{array}{l}0.291^{* * *} \\
(3.931)\end{array}$ & $\begin{array}{l}-0.810^{\star \star \star} \\
(-4.254)\end{array}$ & $\begin{array}{l}-0.687^{\star \star \star} \\
(-4.115)\end{array}$ & $\begin{array}{l}-0.00477 \\
(-0.170)\end{array}$ & $\begin{array}{l}0.335^{\star \star *} \\
(4.457)\end{array}$ \\
\hline Old-age Dependency Ratio & $\begin{array}{c}0.224 \\
(0.670)\end{array}$ & $\begin{array}{l}0.149 \\
(0.441)\end{array}$ & $\begin{array}{l}-0.0162 \\
(-0.390)\end{array}$ & $\begin{array}{l}-0.209 \\
(-1.605)\end{array}$ & $\begin{array}{c}0.309 \\
(0.923)\end{array}$ & $\begin{array}{l}0.239 \\
(0.740)\end{array}$ & $\begin{array}{l}-0.0260 \\
(-0.664)\end{array}$ & $\begin{array}{l}-0.258^{\star *} \\
(-2.020)\end{array}$ \\
\hline Young-age Dependency Ratio & $\begin{array}{l}0.0337 \\
(0.924)\end{array}$ & $\begin{array}{l}-0.00976 \\
(-0.227)\end{array}$ & $\begin{array}{l}-0.00437 \\
(-0.425)\end{array}$ & $\begin{array}{l}-0.0364^{\star \star *} \\
(-2.847)\end{array}$ & $\begin{array}{l}0.0680^{*} \\
(1.709)\end{array}$ & $\begin{array}{c}0.0334 \\
(0.756)\end{array}$ & $\begin{array}{l}-0.00791 \\
(-0.672)\end{array}$ & $\begin{array}{l}-0.0551^{\star \star \star} \\
(-4.175)\end{array}$ \\
\hline Observations & 4,150 & 2,883 & 3,585 & 4,152 & 4,150 & 2,883 & 3,585 & 4,152 \\
\hline Number of Countries & 167 & 116 & 144 & 167 & 167 & 116 & 144 & 167 \\
\hline Country Fixed Effects & Yes & Yes & Yes & Yes & Yes & Yes & Yes & Yes \\
\hline Time Dummies² & Yes* & Yes* & Yes* & Yes* & Yes* & Yes $^{*}$ & Yes* & Yes $^{*}$ \\
\hline Anderson Correlations LR Test $p$-value & 0 & 0 & 0 & 0 & 0 & 0 & 0 & 0 \\
\hline
\end{tabular}

\section{Source: IMF staff calculations.}

Note: Robust $z$-statistics in parentheses. ${ }^{\star * \star} p<0.01 ;{ }^{* \star} p<0.05$; ${ }^{*} p<0.1$. TFP $=$ total factor productivity.

${ }^{1}$ Adjusted by $\alpha /(1-\alpha)$.

${ }^{2}$ Time dummies for years 1990-95; 1998/99; 2008/09. 
Figure 16. Shares of Workers in the Total Workforce, by Age (Averages, percent)

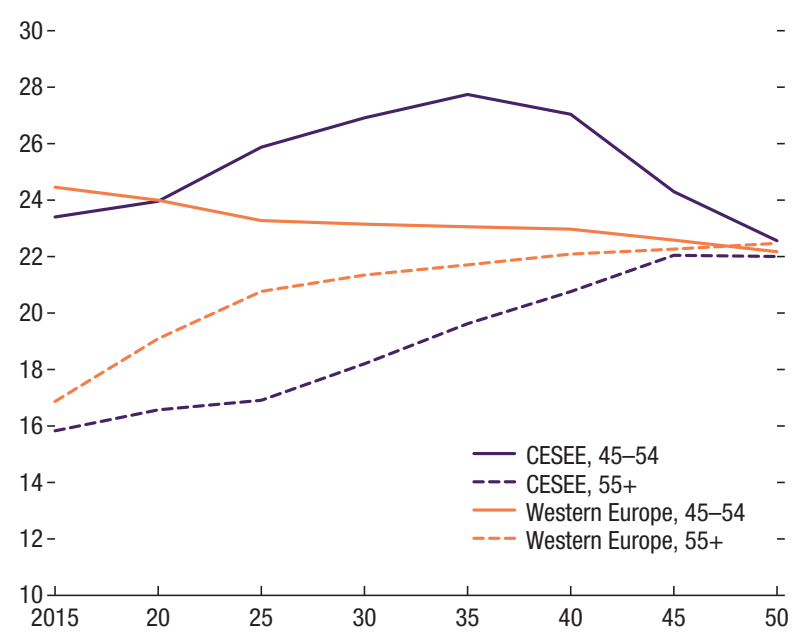

Sources: UN WPP; ILOSTAT; IMF staff calculations. Note: CESEE = Central, Eastern, and Southeastern Europe.
The projected changes to the composition of the workforce suggest that productivity growth in CESEE countries is likely to decline. The population projections of the UN World Population Prospects medium fertility scenario are multiplied by the labor force participation rates from the baseline labor force scenario defined in Chapter 3 to derive, for each country, the size of the labor force for each five-year age cohort (Figure 16):

- In 2015, the share of older workers (those aged 55+ years) in the total workforce was $153 / 4$ percent on average in CESEE economies. This share is projected to increase to about 22 percent by 2050 . The share of the most productive workforce

cohort (those aged 45 to 55) is projected to increase in CESEE countries until the mid-2040s.

- The share of older workers (ages 55+) in the Western European workforce is currently a little bit higher - about 161/2 percent-and most of the further increase in the share is projected to occur before 2030. By contrast, in CESEE it is expected to take place after 2035, and, as noted previously, the share of prime-age workers increases until the 2040s. The relative shifts in the workforce age structures hence imply a slower productivity decline in the CESEE region relative to Western Europe for several decades.

\section{Productivity Implications of Aging Workforces in the CESEE Region}

The simulation results confirm that workforce aging could lower productivity growth in CESEE and Western Europe, but with important differences between the regions. The TFP impact is calculated by multiplying the projected differences in the share of workers ages $55+$ in the total workforce for each 5-year period from 2015 to 2050 by 0.6 , the estimated effect of these changes on TFP growth from the empirical exercise. ${ }^{3}$ This calculation implies that workforce aging could lead to a 0.09 percentage point decrease in annual TFP growth for CESEE countries on average over the period 2015-20, and about a 0.08 percentage point reduction over $2040-50$. The same calculation

\footnotetext{
${ }^{3}$ Country-specific results are then averaged to arrive at region-specific results.
} 
Figure 17. Impact of Workforce Aging on Total Factor Productivity Growth

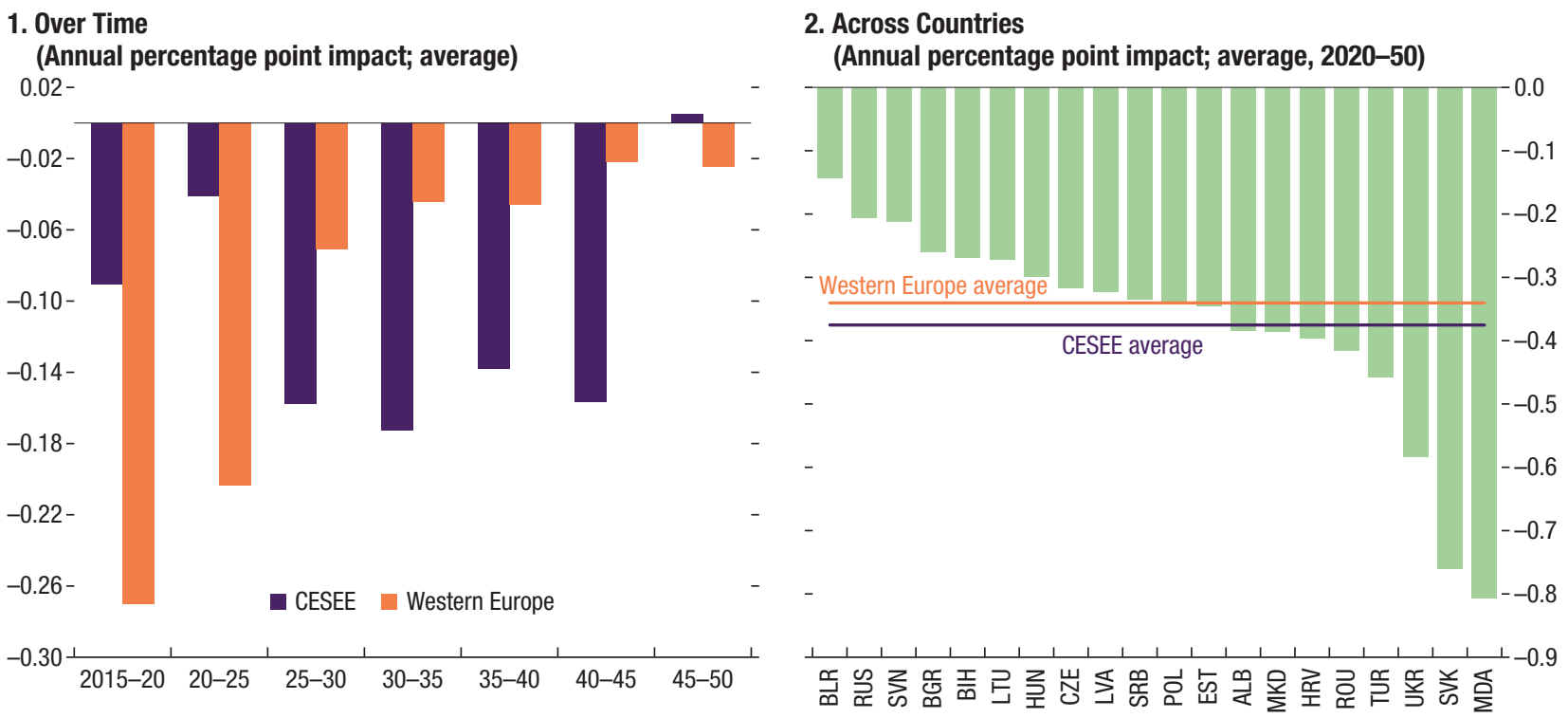

Sources: International Labour Organization; PWT 9.0; UN World Population Prospects; and IMF staff calculations.

Note: CESEE = Central, Eastern, and Southeastern Europe. Data labels use International Organization for Standardization (ISO) codes.

indicates a 0.27 percentage point reduction for Western Europe in 2015-20 and about a 0.02 percentage point reduction at the last decade of the projection horizon. Consequently, whereas the impact on TFP growth is strongest in Western Europe early in the projection horizon and then decreases almost monotonously until 2050, for CESEE it is more muted at the beginning, hovers around 0.15 percentage points between 2025 and 2045, and then turns slightly positive in 2045-50 (Figure 17, panel 1).

There is considerable heterogeneity in the workforce aging and productivity slowdown across countries in both regions. In CESEE, Belarus is expected to experience a relatively small increase in the share of older workers, and hence the average impact from 2020 to 2050 on TFP growth is estimated to be negligible. In the other extreme, Moldova's share of older workers will remain almost constant until 2040 but will pick up very rapidly from 2040 to 2050 , contributing to an average decline of productivity growth of 0.23 percentage points. On average over the period 2020-50, the average annual decrease of TFP growth is 0.38 in CESEE and 0.34 in Western Europe (Figure 17, panel 2).

The estimated effects should be considered seriously, while also treated with due caution. The effects are the same as found in other studies and appear 
Figure 18. Distributions of Older Worker Shares (Percent of total workforce)

8

8- IL0 sample 1990-2015

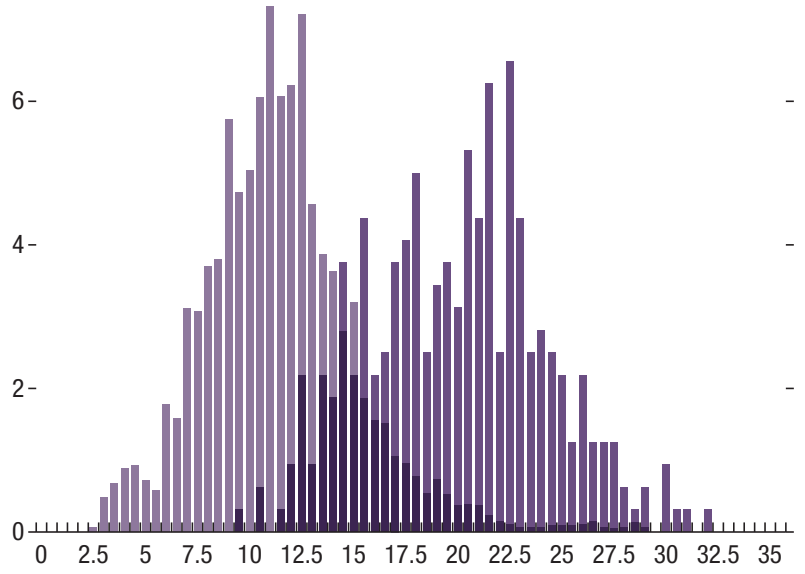

Sources: International Labour Organization (ILO); PWT 9.0; UN World Population Prospects; and IMF staff calculations. statistically robust. However, two issues should be kept in mind when considering the results:

- Inference: The statistical uncertainty about the coefficient $(-0.608)$ measuring the impact of aging on aggregate TFP growth is large, with the 95 percent confidence interval ranging from -0.942 to -0.274 (based on a standard error of 0.171 ). Perhaps more important to bear in mind is the problem of inferring implications for the future from historical experiences of demographic changes that are very different than projected changes (Figure 18). Older worker shares across countries in the historical sample used in the empirical exercise range from about $2 \frac{1}{2}$ percent to 29 percent. For

the same countries, the projected shares of older workers range from about 10 percent to 31 percent. Although the distributions overlap, the historical distribution might not adequately capture the dynamics relevant for future workforce aging and TFP growth.

- Changes in the relationship over time: The behavioral relationship between workforce aging and productivity growth may change over time. Increases in life expectancy and healthy life years due to rapidly improving health care may push out the threshold age of what is considered "older workers" today. For example, there is evidence that the average age of inventors has been rising (Bussolo, Koettl, and Sinnott 2015). Similarly, technological change may progressively increase the productivity of older workers. This effect may prove to be particularly strong if the scarcity of productive labor triggers enough technology adoption so as to completely neutralize or even more than offset the negative effect on productivity and aggregate output (see Box 5).

Nonetheless, the repercussions for productivity are an important potential mechanism. Together, the direct effects of demographic change on labor supply and the potential effects discussed here on productivity raise the question of the effects on investment, and hence the combined effects on growth. These and other issues are taken up in the next chapter. 


\section{Box 4. Industrial Structure and Productivity}

Differences in industrial structure and the composition of occupations can be expected to alter the impacts of workforce aging across countries. For example, the productivity of manual workers might decline faster with age but might actually increase for those in service or professional occupations. ${ }^{1}$ CESEE countries have a higher share of employed personsespecially male-in professions associated with declining productivity of older workers than the EU-15 average. ${ }^{2}$ On this basis, the industrial structure would tend to reinforce the effects of aging on aggregate productivity (Box Figure 4.1).

\section{Box Figure 4.1. Share of Workforce Whose Productivity Rises or Falls with Aging (Percent of total employment, 2016)}

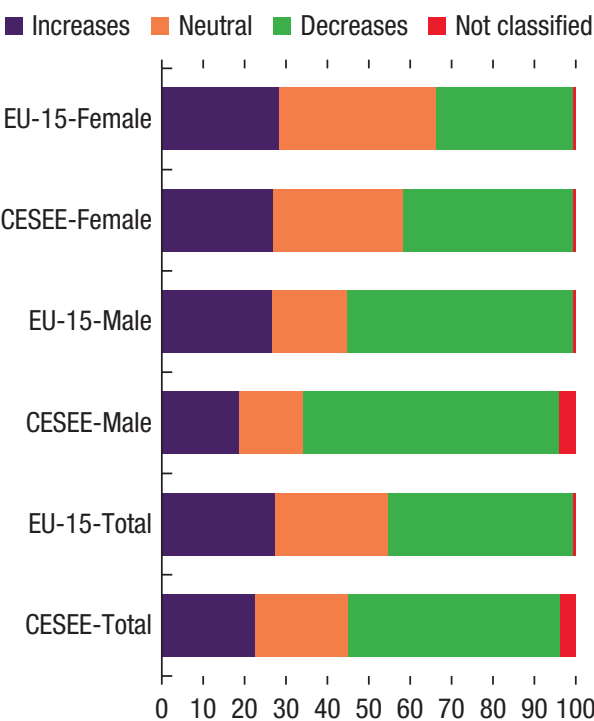

Sources: International Labour Organization; Veen 2008; and IMF staff calculations.

Note: Category productivity "increases" with age comprises managers and professionals; category "neutral" comprises clerical support workers and services and sales workers; category "decreases" comprises technicians, skilled agricultural workers, forestry and fishery workers, craft and related trades workers, plant and machine operators and assemblers, elementary occupations, and armed forces occupations. Category "CESSE" is missing data for Albania, Kosovo, Russia, Ukraine. CESEE = Central, Eastern, and Southeastern Europe; EU = European Union.

\footnotetext{
${ }^{1}$ See Veen 2008.

${ }^{2} \mathrm{~A}$ caveat is in order. These channels were investigated in several alternative regression specifications, which did not yield sufficiently informative results, as labor force data by gender and occupation are generally very scarce, reducing significantly the sample size. Endogeneity and instrumentation issues complicate these types of analyses further.
} 


\section{Box 5. Can Automation Offset Demographic Effects on Productivity?}

One question that arises is whether automation can offset the effect of falling working-age population on output. Responses range from the utopic-that humans will live in a new leisure age as machines go to work-or the apocalyptic-humans will be displaced by ever-more intelligent robots. This box presents a case that the answer is most likely in between, depending on relative productivity costs of labor and machines.

Consider the impact of an aging workforce. First, there is a composition effect: an increase in the share of older and less productive workers per se reduces aggregate labor productivity. Second, as prime-age workers become more scarce, their wages will increase-this creates an incentive for corporates to install machines to boost the output of the scarce prime-age workers.

Machines can automate tasks, but—as yet-workers are still needed to operate the robots, and automation can generate new roles for workers. The net effects of aging on aggregate productivity will therefore depend on the balance of the composition effect and the incentives to automate. When machines become sufficiently relatively productive and cheap, then they could be installed in such numbers as to offset the productivity effect. ${ }^{1}$ Hence, it is possible that the initial effect of aging would be a decrease in aggregate productivity, then an increase as machines become cheaper and more capable. $^{2}$

Regardless of the net effects on productivity, automation will likely mean disruption of jobs. On the upside, machines can produce "re-instatement effects" as new jobs are created (for example, to operate the machines). However, the transition is likely to be accompanied by increased mismatching in the labor market. Empirical evidence on the effects of automation is mixed: Acemoglu and Restrepo (2018b) argue that increases in automation in the United States have been accompanied by decreases in employment and real wages, whereas Schneider, Hong, and Le (2018), applying the same method to Japanese data, find the opposite.

${ }^{1}$ See Acemoglu and Restrepo 2018a.

${ }^{2}$ See also Acemoglu and Restrepo 2017. In their empirical work, they find a positive relationship between the change in $(\log )$ GDP per capita and overall population aging (measured by the ratio of those above 50 to those between the ages of 20 and 49). The results are the opposite to those shown in this chapter and the other cited papers. Note that those specifications estimate the relationship between growth and workforce (not population) aging. 


\section{ChAPTER}

\section{Implications for Growth, Convergence, Spillovers, and Fiscal and External Balances}

Falling labor supply, weaker productivity, and adverse feedback from fiscal stresses would slow growth and the pace of convergence.

The effects on output and revenues add to fiscal pressures from increases in age-related spending.

Current account balances would likely increase as national savings increase and investment declines.

Labor market reforms can mitigate the effects on output, but in most cases not fully offset them. But the reforms are very important for fiscal sustainability.

The previous chapters have focused individually on three mechanisms by which demographic trends would have effects on growth: labor supply, public spending on pensions and health care, and, potentially, productivity. This chapter considers those effects together to assess the implications for growth and convergence, spillovers, and macroeconomic balances. Doing so properly necessitates not just adding up direct effects but evaluating how the entire economy would adjust to demographic pressures. In particular, we need to understand how relative prices will move-how wages will adjust as available labor changes, how exchange rates will move as national savings balances adjust, and how risk premiums could change. All of these crucially affect incentives for investment and employment.

\section{Prologue: A First Pass at Implications for Growth and Convergence}

Before looking at the full adjustment of economies, it is useful to establish a benchmark for prospects for growth and convergence. We do this by 
Figure 19. Assessing the Impact of Demographic Pressures on Growth and Convergence-The Production Function Approach
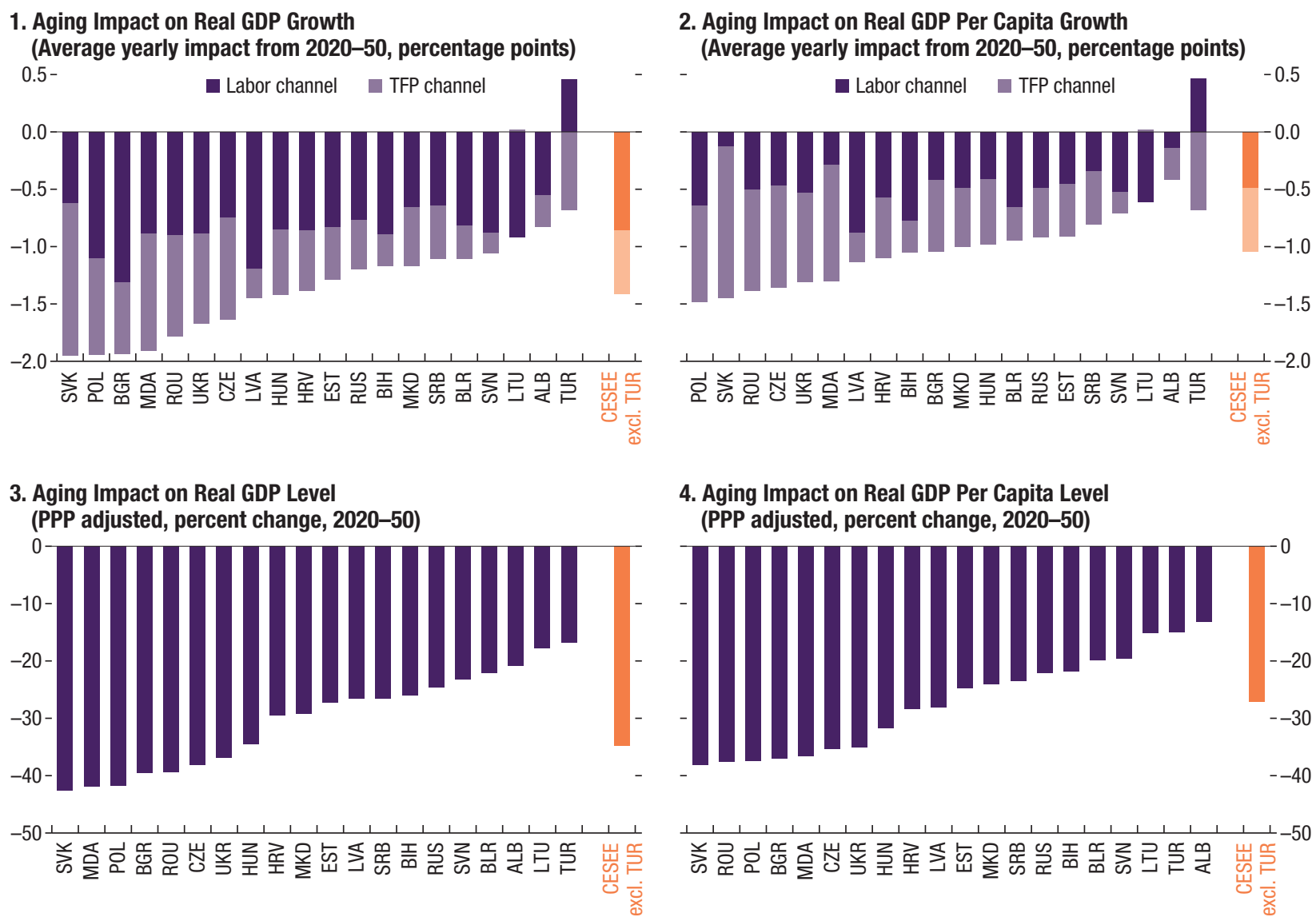
4. Aging Impact on Real GDP Per Capita Level
(PPP adjusted, percent change, 2020-50)

Source: UN WPP; WEO; and IMF staff calculations.

Note: CESEE = Central, Eastern, and Southeastern Europe; excl = excluding; PPP = purchasing power parity; TFP = total factor productivity; TUR = Turkey. Data labels use International Organization for Standardization (ISO) codes.

feeding projected labor supply and productivity changes into a standard Cobb-Douglas production function (see Annex 5).

Falling labor force and TFP would significantly reduce growth in the CESEE region, all else equal (Figure 19). Compared with a "no-demographics" scenario in which the size of the labor force and TFP growth were to remain the same, the labor force and TFP scenarios described in Chapters 3 and 5 imply dramatic reductions in GDP growth. ${ }^{1}$ For CESEE countries (excluding Turkey), on average (purchasing power parity GDP weighted), real GDP growth rates would be lower by about 1.4 percentage points each year over the whole

\footnotetext{
${ }^{1}$ The aging impact on real GDP growth is calculated using a simplified production function framework: $g Y=$ $g A+(1-\alpha) g K+\alpha g L$, assuming a balanced growth path $g Y=g K=g A / \alpha+g L$, where $g Y$ is real GDP growth, $g A$ is TFP growth, $g K$ is capital growth, $g L$ is labor growth, and $\alpha$ is the labor income share (see Annex 5).
} 
horizon. This implies that the level of output in 2050 would typically be about 35 percent lower than it would be in the no-demographics scenario. The fall in labor supply typically explains about 60 percent of the total decline. The effects of the labor channel are notably strong in Bulgaria, Latvia, and Poland (Figure 19, panel 1). The effect of workforce aging on TFP growth is significant, implying that GDP per capita also falls substantially, particularly in those economies with rapidly increasing shares of older workers, such as Moldova and Slovakia (the lighter bars in Figure 19, panel 2). GDP per capita will also be affected by the decline in workforce relative to the total population, which is notable in Bosnia and Herzegovina and Latvia (the darker bars in Figure 19, panel 2). Across countries, there is considerable variation in the total effects on growth, with Poland and Slovakia much more negatively affected than those with relatively benign demographic outlooks, such as Albania and Turkey. ${ }^{2}$

Income convergence would continue but at a slower pace. To estimate convergence speeds, paths for GDP per capita in levels are projected for CESEE and Western European countries, both without and including projected demographic change (Figure 20). ${ }^{3}$

\footnotetext{
${ }^{2}$ Note that even Turkey, with its growing population, would still be worse off, because of the effect of aging on productivity.

3To calculate the "no-demographics" path, GDP per capita growth rates are assumed to remain the same as their initial values during 2020 to 2050 . Three sets of initial values were explored, including (1) the medium-term-2023 - potential growth rates in IMF staff forecasts published in the October 2018 World Economic Outlook; (2) the historical average growth rates of individual countries during 2000 to 2018; and (3) the historical average growth rates of Western European country groups (two income groups) at a similar income
} 
- Convergence continues for most CESEE countries: the simple average real GDP per capita as a share of the Western European average is projected to increase from 52 percent in 2020 to 60 percent in 2050, if we assume that countries grow at their potential growth rates (IMF staff estimates for 2023) adjusted by aging impact. Based on these assumptions, in some cases-Belarus, Croatia, Poland, and very notably, the Czech Republic and Russia-convergence reverses. In most cases, the pace of convergence is slower than that implied by their own historical path during 2000 to 2018 . For some higher-income countries - the Baltic states, the Czech Republic, Slovakia, and Slovenia - convergence would be significantly slower if their future growth rates were to follow a similar path to that of Western European countries with roughly similar initial per capita income levels.

- The speed of convergence slows compared to the no-demographics scenario. For all countries, GDP per capita is lower by 2050 than it would have been assuming no demographic effects. Assuming initial growth at the estimated 2023 potential rates, GDP per capita relative to the Western European (simple) average increases by 8 percentage points on (simple) average across CESEE countries, but it would have increased by 22 percentage points with no demographic effects. Regardless of their initial growth rates, all countries would fall short of the projected Western European average when demographic effects are taken into account.

Of course, these estimates are only indicative. Uncertainties surrounding long-term growth projections are large. Moreover, the simulations here crucially do not explicitly model the endogenous response of investment, the adjustment of relative prices (such as real wages, exchange rates, and interest rates), and spillover effects from other countries also experiencing demographic changes.

\section{Channels of Economic Adjustment to Demographic Pressures}

To assess the adjustment of CESEE economies to demographic trends, taking into account interlinkages and feedback loops, we use a multicountry macroeconomic model, the Europe-oriented version (EEUMOD) of the IMF's Flexible System of Global Models (see Annex 6). EEUMOD models the production of CESEE countries; the spending decisions of households, firms, and governments within those economies; and their trade and financial interactions with each other and the rest of the world. ${ }^{4}$ The model therefore

level. The path with demographic change uses these initial values and applies the aging impact on real GDP growth per capita presented previously.

${ }^{4}$ Note that goods and capital are assumed to be completely mobile, but labor is not mobile- there is no endogenous migration response in these simulations. The simulations also abstract from remittances flows into 
provides a framework for assessing not just effects on CESEE countries, but the effects on the region, taking into account spillover effects through trade.

The demographic effects are modeled through the three channels highlighted in earlier chapters. All shocks (except for those to the population) are treated as transitory and fade away gradually after the end of the simulation horizon, 2050.

- First, lower aggregate population and employment-for each country, as in the baseline labor force projections outlined in Chapter 3 and earlier in this chapter-lead to decreased output and thus lower financial and human wealth relative to a no-demographics scenario. Households respond by lowering consumption and increasing their savings. Firms respond to lower labor supply by reducing investment; the capital stock is permanently lower. The fall in working-age population makes labor more scarce and expensive compared to capital investment, leading to an increase in the capital-labor ratio. This is consistent with the finding that workforce aging is associated with an increase in the capital-output ratio (Table 4 in Chapter 5). With the overall economy shrinking, demand for imports declines; net exports and the current account both improve, reflecting the increase in desired savings by households (that dominates the increase in fiscal deficits).

- Lower productivity, per the calculations in Chapter 5 and earlier in this chapter, reinforces these effects while also decreasing per capita consumption (as real wages fall further with the reduction in productivity). Lower productivity also leads to an additional decline in investment.

- The third channel considers the fiscal consequences of the demographic shocks, per the age-related fiscal costs as laid out in Chapter 4. Both health care and pension expenditures increase (as a percentage of GDP) with aging. The higher public spending supports private consumption, partially compensating for the fall in real wages and wealth. On the other side, increasing public debt raises the sovereign risk premium and crowd out private investment. ${ }^{5}$ Overall, the dissaving from increased public expenditures is more than offset by higher household saving and lower investment, and hence the current account balance improves.

For the purpose of the simulations, the increase in age-related fiscal costs is assumed to be accommodated by increased deficits (and therefore debt stock).

CESEE countries - these are significant for Moldova, Romania, and Ukraine, but not so much for other economies (in terms of own GDP).

${ }^{5}$ The EEUMOD simulations assume that the sovereign risk premium increases by three basis points for each percentage point of GDP increase in the level of public debt, which is a relatively small impact. A more pessimistic assumption of the impact of public debt on the risk premium would result in larger impact on investment and output growth. 
In practice, a number of policy options exist to address these costs (for example, increase in taxes and social security contributions, or reduction in other spending). The assumption that fiscal pressures are accommodated wholly by debt is not crucial. The important point is that there would be some kind of fiscal feedback-for example, if a balanced-budget rule were imposed, the result would be some combination of higher (most likely distortionary) taxes and lower government spending (such as on infrastructure), which would also likely slow growth. This issue is taken up again in the last part of this chapter.

The simulations incorporate the spillovers among CESEE economies and from the rest of Europe-the (demographic) shocks are applied only to CESEE and Western European countries/blocs. The results therefore capture most trade linkages for CESEE countries, but do not fully capture all the effects that would arise if global demographic trends were modeled. ${ }^{6}$

\section{General Equilibrium Outcomes of Demographic Transition in CESEE Economies}

Figure 21 displays the effect of demographic shocks on a representative country, the average of CESEE countries excluding Turkey. In response to demographic shocks, GDP growth declines, lowering real GDP in 2050 considerably below the level under a scenario of no demographic change. If the impact of higher fiscal costs is not considered, the demographic shock alone reduces the level of output by about 27 percent by $2050-22$ percentage points due to the labor supply effect, and 5 percentage points due to the TFP effect. This is much less than estimated in the first section of this chapter (35 percent), as the increase in the relative wage leads to a higher capital-labor ratio, mitigating the effect of declining and aging workforce. The fiscal effect adds 4 percentage points, with a total decline in the output level of 31 percent by 2050 - similar to the total impact in the prologue of this chapter. As for other variables, consumption, investment, exports, and imports decline steadily with the gradual reduction in labor supply and aging of the workforce. Fiscal deficit increases with the rising cost of aging, which is assumed to be wholly deficit financed. Net exports and current account balances increase; the real exchange rate initially depreciates to encourage the switching in net trade balances, and then appreciates over the long term as real exports decline with output. ${ }^{7}$

\footnotetext{
${ }^{6}$ In particular, the evolution of the current account and the real interest rate capture the differences between Western European and CESEE demographic trends only; to the extent that saving and investment is directed within the region, this seems a reasonable approximation.

${ }^{7}$ All countries in the EEUMOD simulations are assumed to have floating exchange rates, except Bulgaria and Croatia, with fixed exchange rate regimes. The paths for the real exchange rates of Bulgaria and Croatia are qualitatively similar to those of other countries, implying that price levels absorb the required adjustment in terms of trade in these simulations.
} 
Figure 21. Responses to Demographic Shocks

\section{Real GDP and Real GDP per Capita} (Percent difference)

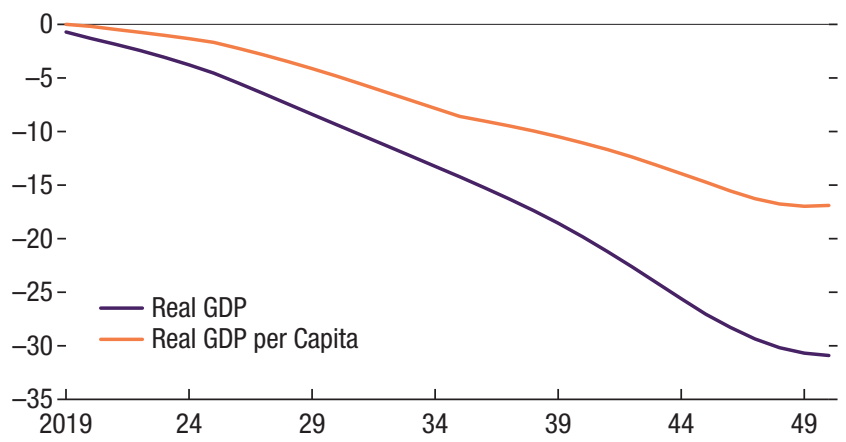

3. Real Consumption and Real Investment (Percent difference)

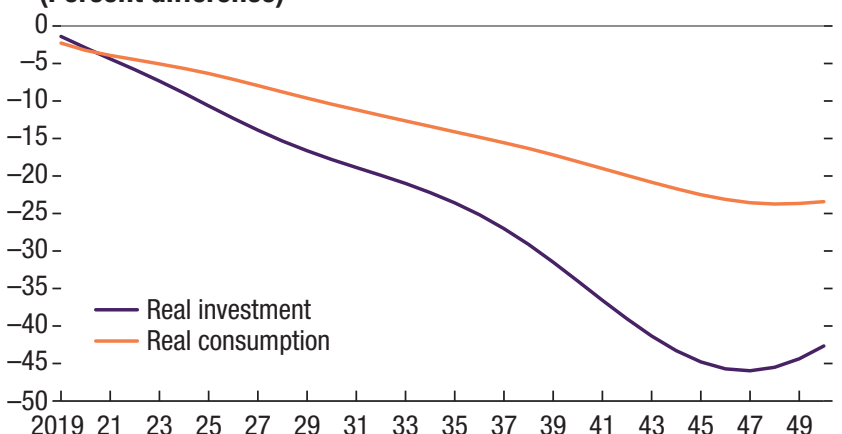

5. Real Exports and Imports; Current Account (Percent difference)

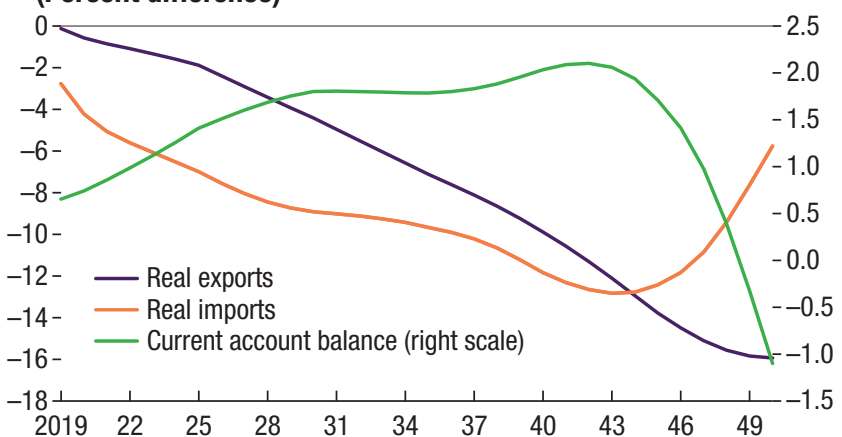

2. Impact Channels of Demographics on GDP in CESEE excluding Turkey

(Percentage points; 2050)

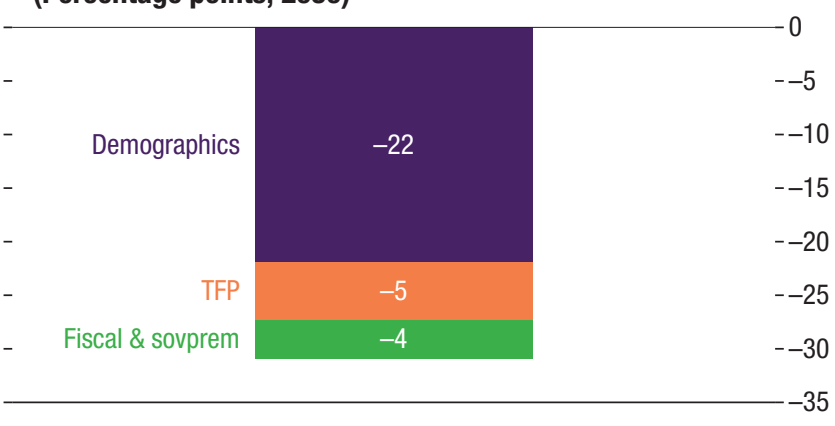

\section{Fiscal Deficit}

(Percentage-point-of-GDP difference)

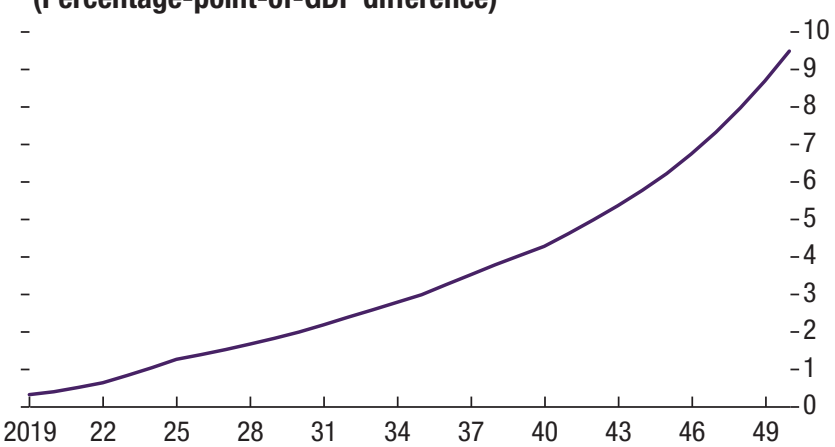

6. Real Effective Exchange Rate (Percent difference; + = appreciation)

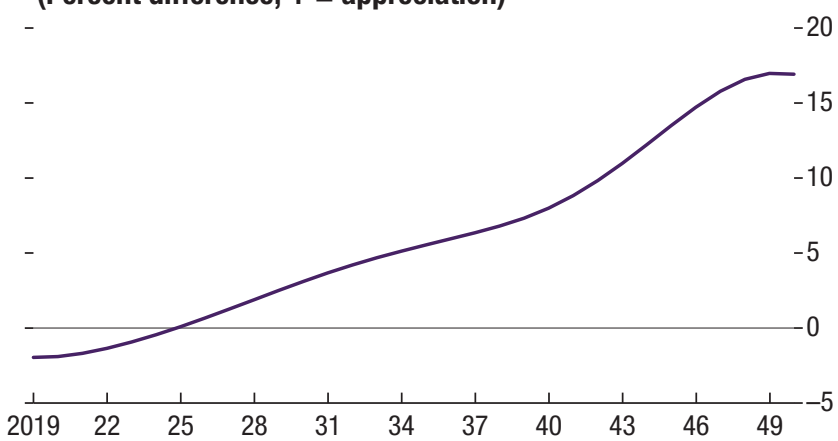

Sources: International Labour Organization; Penn World Tables 9.0; United Nations; and IMF staff calculations. Note: CESEE $=$ Central, Eastern, and Southeastern Europe; TFP = total factor productivity. 
Demographic shifts would lower growth rates in all CESEE countries (excluding Turkey). Compared to the "no-demographics" path, the average annual real GDP growth over the 2020-50 period would be lower by about 1.2 percentage points, cumulating to a total decline in the output level of 31 percent by 2050 (Figure 22, panel 1). The negative impact on the GDP growth rate is smaller than in the prologue of this chapter due to the capital deepening in EEUMOD simulations, whereas the first section of this chapter assumed a balanced growth path (more in the later paragraph on investment). In per capita terms, average yearly growth in the CESEE region over the period from 2020 to 2050 would be lower by about 0.6 percentage points, cumulating to a total decline in the output level of 17 percent (Figure 22, panel 2). Bulgaria and the Ukraine would experience the greatest impact on GDP, but the reasons differ-in the case of Bulgaria, the driver is mainly the very poor outlook for labor supply (see Figure 8); in the case of Ukraine, both labor supply and TFP are very important, given the rapid increase in the share of older workers in its population (see Table 1). Southeastern Europe and Serbia would be the least affected, as their outlooks for labor supply, TFP, and fiscal balances are not as bad as those for the rest of the CESEE region.

Convergence continues in most countries, albeit more slowly. The gap to Western European income levels would narrow by 2050 for the majority of CESEE countries. Except in Croatia, Russia, and other Eastern European countries, per capita income levels would be closer to Western European levels by 2050, with euro area Central Europe having surpassed average Western European income levels (Figure 22, panel 3). ${ }^{8}$

These effects on growth and convergence incorporate mutually reinforcing spillover effects. In addition to the effects of own demographic changes through labor supply, productivity, and fiscal stresses, CESEE countries in these simulations experience spillovers from the effects of demographics in neighboring countries on foreign demand (Box 6).

Private investment plays a key role in the slowdown of growth and convergence. The model used for these simulations assumes that capital and labor are complements - investment will decline with employment. However, the decrease in investment is less than implied by the production function exercise in the prologue of this chapter-here, the ratio of capital to labor increases, as labor becomes scarce and the appreciation of the real exchange rate makes capital cheaper. (The same phenomenon would, all else equal, encourage automation - see Box 5.) Nonetheless, the contribution to growth is significant: over the $2020-50$ period, labor and productivity directly contribute about 0.4 and 0.3 percentage points to the 1.2 percent average yearly

\footnotetext{
${ }^{8}$ Income levels are aggregated using projected purchasing power parity GDP weights.
} 
Figure 22. Effects of Demographic Changes

1. GDP Growth

(Average yearly impact from 2020-50, percentage points)

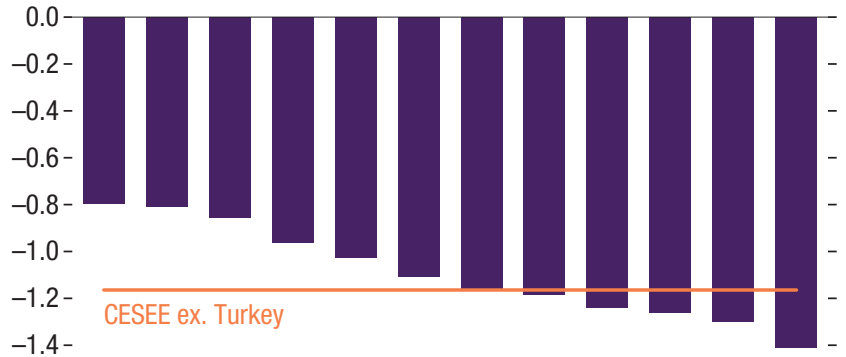

$-1.4-$

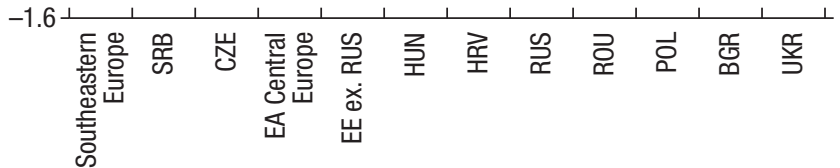

\section{Income Convergence}

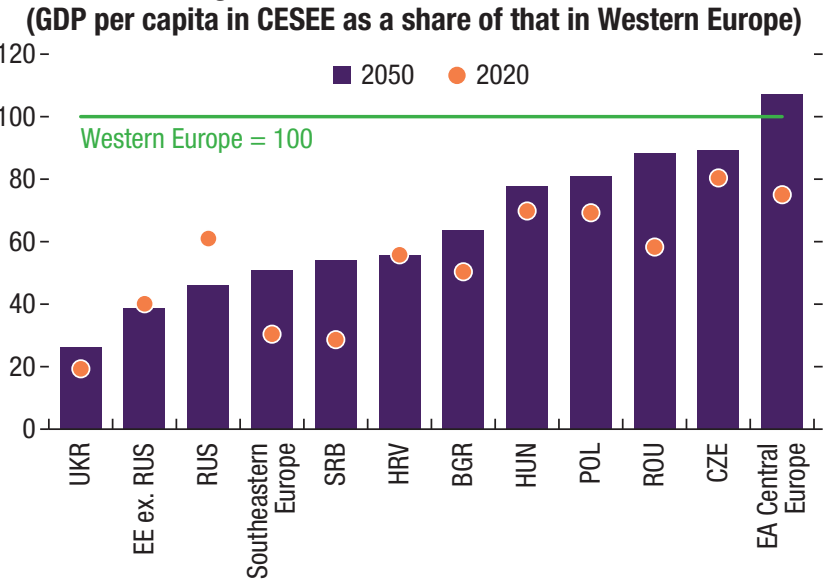

\section{Deficit-to-GDP Ratio}

(Change between 2020-50, percentage points)

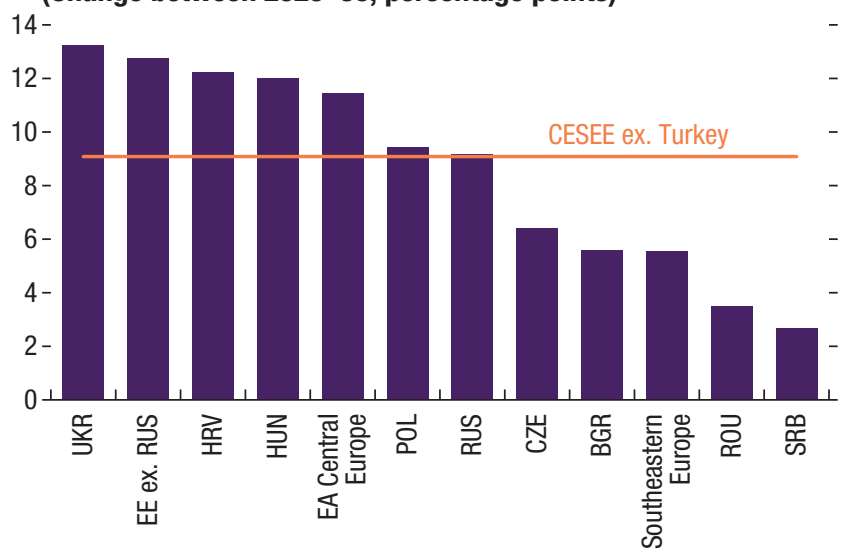

2. GDP per Capita Growth

(Average yearly impact from 2020-50, percentage points)
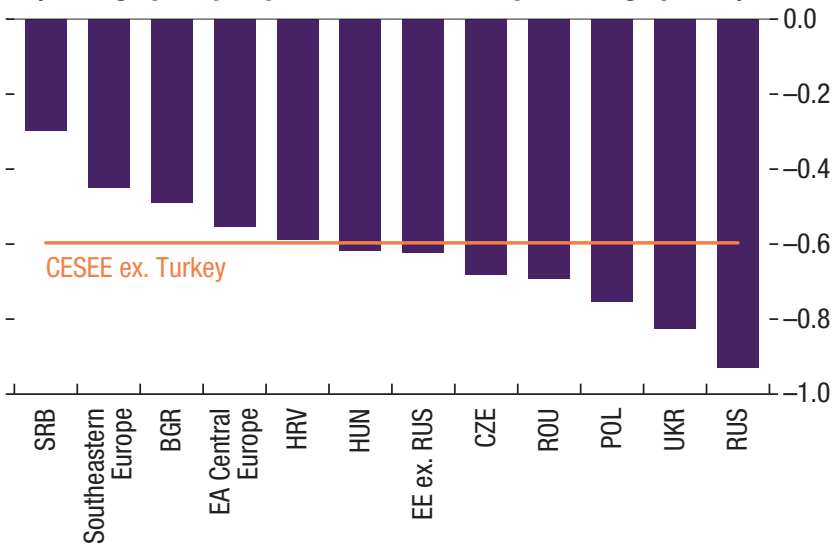

4. Investment Growth

(Average yearly impact from 2020-50, percentage points)
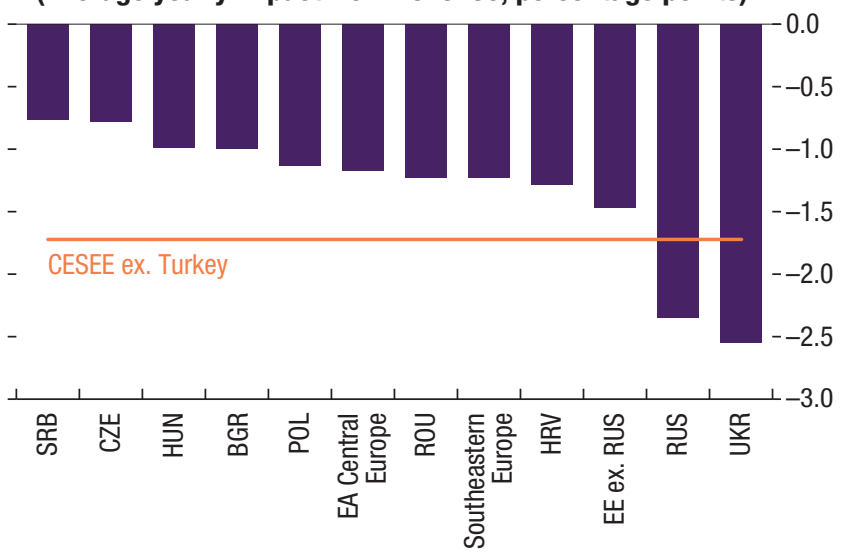

6. CA-to-GDP Ratio

(Average yearly impact from 2020-50, percentage points)

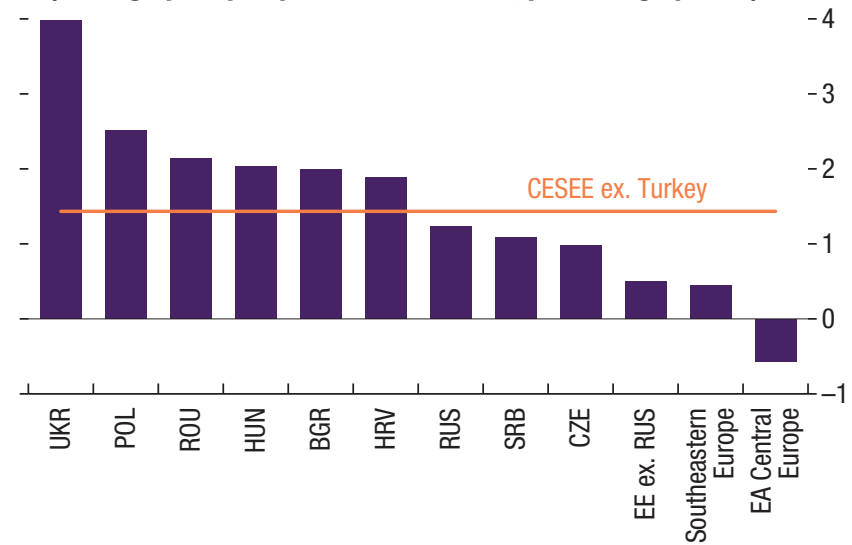

Sources: International Labour Organization; Penn World Tables 9.0; United Nations; Yihan and Westelius (2017); and IMF staff calculations.

Note: CESEE = Central, Eastern, and Southeastern Europe; ex. = excluding. Data labels use International Organization for Standardization (ISO) codes. 
decline in the CESEE region (excluding Turkey), whereas the investment response accounts for 0.5 percentage points. ${ }^{9}$ When all model dynamics are included, private investment in CESEE will be lower by 26 percent by 2050 compared to the no-demographics scenario (Figure 22, panel 4). The projections vary considerably across countries, largely in line with the projections for GDP, but with notable variations depending on debt accumulation.

The public finances would deteriorate notably (in the simulations with this fiscal reaction; see later section in this chapter for sensitivity analysis). In the absence of offsetting policies, the average fiscal deficit in CESEE (excluding Turkey) would increase by about 9 percentage points of GDP (Figure 22, panel 5). The impact of the increase in age-related spending (on health care and pensions) as estimated in Chapter 4 is magnified by the negative impact on output and rising interest payments overtime (also explained by the higher sovereign premium). As a result, public debt would increase by about 75 percentage points of GDP by 2050 compared to the no-demographics scenario.

Current account balances would reflect the balance between lower public savings, likely higher household savings, and weaker investment. In these simulations, CESEE current account balances would, on average, be higher by 1.5 percentage points of GDP from 2020 to 2050, compared to the no-demographics scenario (Figure 22, panel 6). Those countries with relatively rapid population declines (for example, Ukraine) would experience the largest increase; Southeastern Europe, with a relatively small decline in population, would have a substantially smaller increase. Central European euro-area countries would actually see external balances decrease somewhat, compared with the no-demographic scenario. Overall, the current account flows generated by adjustment to demographic factors would likely not be large enough to materially affect world saving-investment balances.

As a cross-check to the results from the simulation model, we use an empirical model of current account balances with a richer demographic structure (the IMF's External Balance Assessment Model). Those simulations confirm that the region as a whole would likely see an increase in net savings over the next 20 years, before declining thereafter as it enters the late stages of demographic change. The scale of the increase is somewhat less - the differences are likely explained by the full general equilibrium effects captured in the EEUMOD simulations, and a larger saving response that reflect the behavior of forward-looking agents in EEUMOD.

${ }^{9}$ Demographic forces (labor supply and the decline in productivity) are responsible for about two-thirds of the fall in private investment; the remaining one-third can mostly be attributed to the increase in the sovereign risk premium leading to an associated increase in the user cost of capital. 


\section{The Impact of Labor Market Reforms}

We evaluate the labor market reforms first considered in Chapter 3. ${ }^{10}$ They work through the same channels as previously: first, the direct effect of changes in the size of the labor force on growth and fiscal balances; second, the impact of workforce aging on TFP growth; and finally the fiscal feedback effects, arising from changes to health care and pension costs and sovereign risk (Figure 23).

Labor market reforms would improve growth and convergence compared with the baseline scenario (that is, with demographic shocks), but the effects vary widely across countries and are generally modest. ${ }^{11}$ For the CESEE (excluding Turkey) region overall, the moderate and ambitious labor market reforms would improve

\footnotetext{
${ }^{10}$ Note that we do not model here the fiscal costs of the labor market reforms.

${ }^{11}$ The effects on growth from increasing participation and retirement ages are in theory ambiguous - the net effect could be negative if the effects on productivity are sufficiently strong. In practice, that situation does not appear in any countries in the EEUMOD simulations of labor market reforms.
}

Figure 23. Impacts of Labor Market Reforms

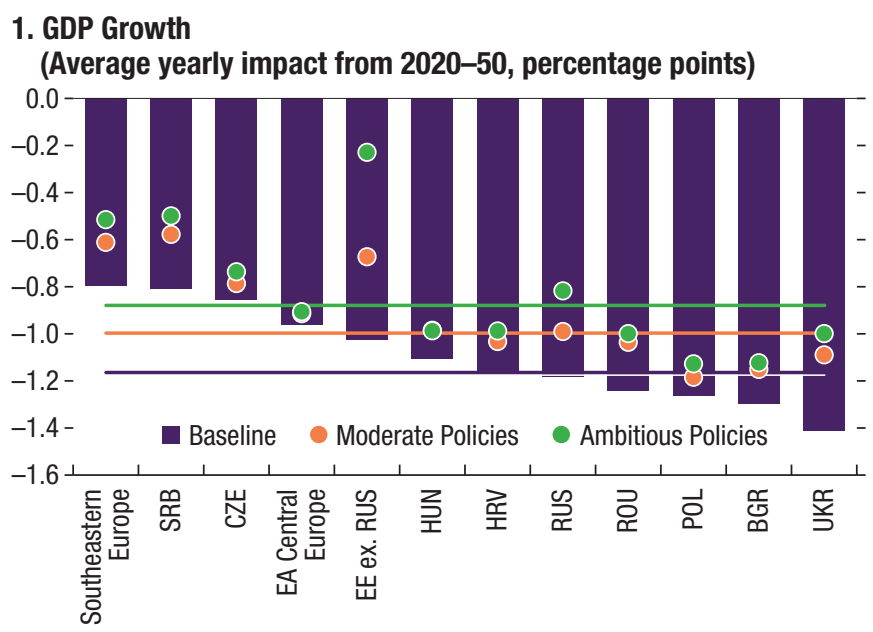

2. GDP Per Capita Growth

(Average yearly impact from 2020-50, percentage points)

0.4 Baseline Moderate Policies Ambitious Policies

$0.2-$

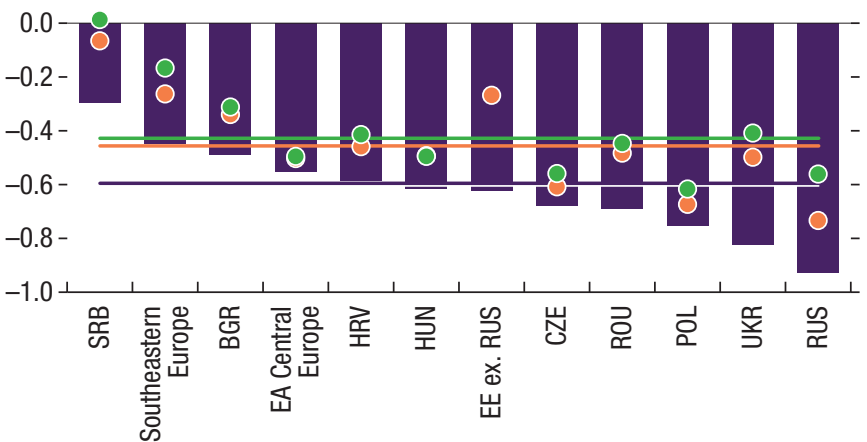

\section{Deficit-to-GDP Ratio}

(Percent of GDP, change between 2020-50)

15- Baseline Moderate Policies Ambitious Policies
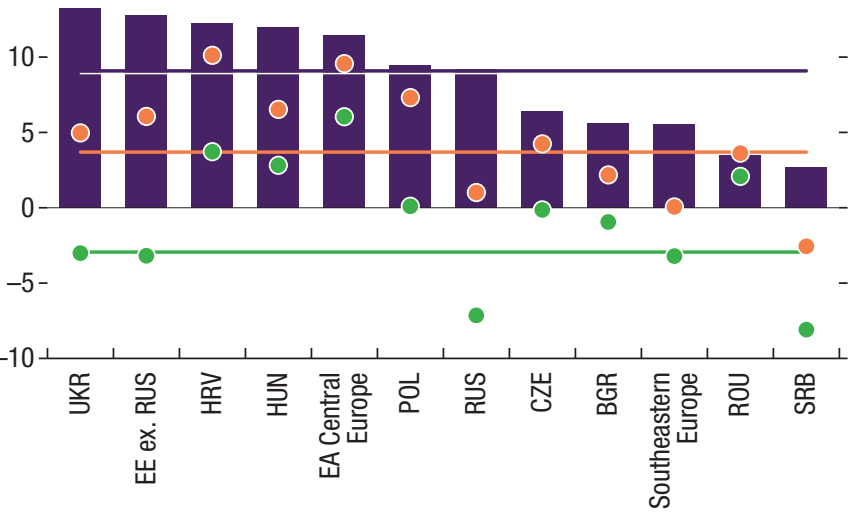

Source: IMF staff calculations.

Note: ex. = excluding. Data labels use International Organization for Standardization (ISO) codes. 
GDP growth by about 0.2 and 0.4 percentage points, respectively, over the period from 2020 to 2050 . The effect is more muted for Central European countries, but particularly strong for Belarus and Moldova. In per capita terms, the effect of ambitious reforms is strong enough over the next decade for those states to be better off than even in a no-demographic scenario, although the effect on total GDP is less pronounced as the scale of population decline tends to dominate over a longer period.

Likewise, these policies improve convergence to Western European incomes. The moderate policy package could lower the per capita income gap between CESEE (excluding Turkey) and Western Europe further by about 3 percentage points of GDP, whereas ambitious polices could narrow the gap further by about 4 percentage points. Eastern European states would benefit most from the ambitious reform scenario, adding about 11 percentage points of GDP per capita to narrowing the income gap by 2050 . This is mostly the result of larger labor reserves and stronger increases in employment in these countries than in other CESEE countries. For Central European states, which have already advanced significantly in terms of income convergence, the impact of the ambitious policy scenario is more modest, at about $1 \frac{1}{2}$ percentage points of GDP per capita by 2050 for countries such as the Baltic states, Slovakia, and Slovenia, and 4 percentage points for the Czech Republic, Hungary, and Poland.

The reforms would improve public finances in most countries:

- The moderate reform scenario helps offset about 50 percent of the projected increase in aging-related government spending and debt for the period 2020 to 2050 . With this reform package, the average government deficit is projected to increase by about 4 percentage points of GDP by 2050 (as compared with 9 percentage points in the baseline), whereas public debt rises by 33 percentage points of GDP compared to a no-demographics scenario (and compared with 75 percent in the baseline).

- The ambitious reform scenario would more than offset the baseline results. This reform package reduces the average projected government deficit by about 3 percentage points of GDP (as compared with an increase of 9 percentage points in the baseline), resulting in public debt lower by about 28 percentage points by 2050 compared to the no-demographics baseline.

\section{The Impact of Different Fiscal Reactions to Demographic Pressures}

The results could change depending on the assumptions about fiscal reactions. Recall that the previous simulations assume that the increase in age-related fiscal costs is accommodated by increased deficits. Here we pres- 
ent the results from an alternative assumption about fiscal reaction. In this higher taxes scenario, distortionary labor and consumption taxes are used to offset increased fiscal costs - specifically, the tax revenue collected from both of these taxes together equals half of the deficit of the previous, accommodating deficits scenario in each year. ${ }^{12}$ Higher taxes could help to contain debt, and lower debt would per se have a positive impact on growth to the extent that it would lower the sovereign premium and cost of capital. However, the higher taxes would also lower demand and reduce employment incentives. The initial level of indebtedness therefore plays an important role in the relative strength of these two channels and consequently the overall net effect on growth.

For CESEE as whole, the net impact on GDP growth is small, but significant for debt (Table 5). To recap from the previous results: annual GDP growth is lower by about 1.2 percentage points on average from 2020 to 2050 under the "accommodating deficits" fiscal reaction relative to the no-demographics scenario. Here, with higher taxes, it is lower by about 1.0 percentage point. Per capita GDP growth is lower by about 0.5 percentage points in the higher taxes scenario. This implies that, by 2050, the level of per capita GDP is 14.7 percentage points lower under the higher taxes fiscal reaction relative to the no-demographics scenario-slightly smaller than the 17 percent fall under the accommodating deficits reaction. The debt-to-GDP ratio under higher taxes is 12 percentage points higher than the no-demographics scenario by 2050 - this is significantly lower than 76 percentage point increase under the accommodating deficits reaction. Overall, under the higher taxes reaction, the positive impact of lower debt outweighs the negative impact of distortionary taxes in this case.

Table 5. Effects of Alternative Fiscal Reactions on GDP Growth Rates and Debt

(Average yearly impact over 2020-50, percentage points)

\begin{tabular}{lcc}
\hline & Accomodating deficits & Higher taxes \\
\hline Real GDP & -1.2 & -1 \\
Real GDP per capita & -0.6 & -0.5 \\
Debt/GDP in 2050 & 76 & 11.9 \\
\hline
\end{tabular}

${ }^{12}$ This essentially means that the overall deficit is closed in this scenario, as half of the increase in debt is due to higher interest payments under the accommodating deficits reaction. 


\section{Box 6. Spillover Effects}

Box Figure 6.1. Effects of External Spillovers (Percent deviations from baseline by 2050)

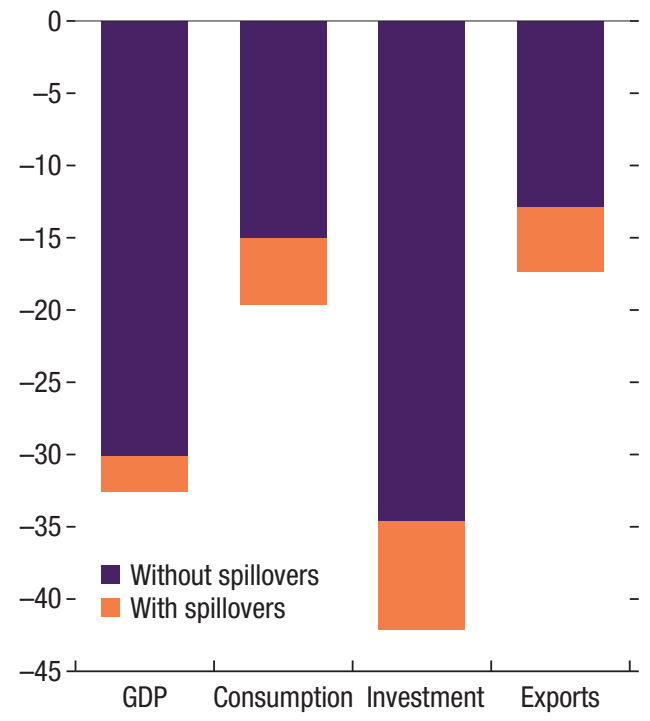

Source: IMF staff calculations.
The three channels in this study-labor supply, productivity, and fiscal-apply to each country to varying degrees. The responses for each country in these simulations therefore reflect both a purely domestic set of shocks - the labor supply, productivity, and fiscal stresses to that country alone-and a set of foreign shocks. Hence, the spillovers from the effects of demographics on neighboring countries add to the effects from the country's own demographic changes.

To illustrate, we run a simulation in which a "typical" country faces its own domestic demographic shocks only. Comparing against the responses in which all countries face demographic shocks allows us to calculate the scale of spillover effects (Box Figure 6.1).

As expected, adverse spillovers contribute to the responses seen earlier in Chapter 6. External spillovers make GDP 3 percentage points worse by 2050. This spillover effect is only one-tenth of the overall effect on the level of GDP, but it is more pronounced for other variables. For investment, the contribution is closer to 20 percent, and for consumption-arguably a better measure of the effect on welfare-the contribution is nearly a quarter. ${ }^{1}$

The difference is understood when the need for external sustainability is taken into account. When all countries face demographic shocks, the country faces weaker demand for its exports than when the country only faces its own demographic shocks. (Note that even without spillovers, exports fall, because potential output is directly affected by the domestic shocks.) The ensuing import compression falls heavily on consumption and investment. Hence, although the economy would adjust to ensure external sustainability, the spillover effects make a significant contribution to the adverse effects on households.

${ }^{1}$ The spillover effects are larger on private consumption and investment than on GDP, as the terms of trade deteriorate when trading partners are subjected to negative demographic shocks while the government spending is kept constant in our simulations. 


\section{Box 7. Another Perspective on External Balances: The IMF's External Balance Assessment Model}

For tractability, the simulations shown here using the Europe-oriented version (EEUMOD) of the IMF's Flexible System of Global Models only incorporate a narrow range of demographic effects: those being the size of the total population and labor force, and the age composition effect on productivity. Empirical evidence indicates that several mechanisms are potentially important for understanding the relationship between demographic changes and external balances, such as expected lifespan, retirement age, and pension support for the saving rates of workers. To provide a cross-check on the simulation results presented in Chapter 6, we use the current account model of the IMF's External Balance Assessment (see Annex 7). The latest version features four demographic variables, all of which are expressed in deviations from the world average: population growth, the old-age dependency ratio, the share of prime-age savers, and the life expectancy of prime-age savers.

Applying the model to projections for these variables for CESEE countries corroborates the results in Chapter 6 that external balances are likely to increase over the next 20 years in all CESEE countries except Turkey. From now through to about 2030, this effect weakens slightly, but increases thereafter, quite sharply in the case of Eastern European economies, before easing again.

The effects are mainly driven by slower population growth in CESEE countries relative to the world, but the prime savers share and old-age dependency ratio are also important. The populations of CESEE countries are projected to grow more slowly than the world average, with the sole exception of Turkey, meaning that population growth makes a consistently positive contribution to current account norms. ${ }^{1}$ The importance of the share of prime savers increases over time, whereas the old-age dependency ratio is important for understanding variation in the current account norms across countries (Box Figure 7.1).

- In the near term, the norms are driven mainly by relatively low population growth, with little contribution from the prime savers share. The effect of the old-age dependency ratio is to reduce current account norms in most EU-member CESEE states, reflecting that their populations are older than other CESEE countries. (See discussion of old-age dependency in Chapter 2).

- The relative shares of prime savers increase for more than two-thirds of CESEE countries, increasing current account norms.

- The positive pressure on current account norms of most CESEE countries is likely to peak during 2035-40 and declines rapidly thereafter as the gap in population growth

\footnotetext{
${ }^{1}$ Current account norms indicate current account balances that are implied by underlying macroeconomic fundamentals, assuming all policy variables are set at their medium-term desirable levels. Nondemographic External Balance Assessment variables are assumed to be constant in the analysis.
} 


\section{Box 7. Another Perspective on External Balances (continued)}

Figure 7.1. EBA Model Results

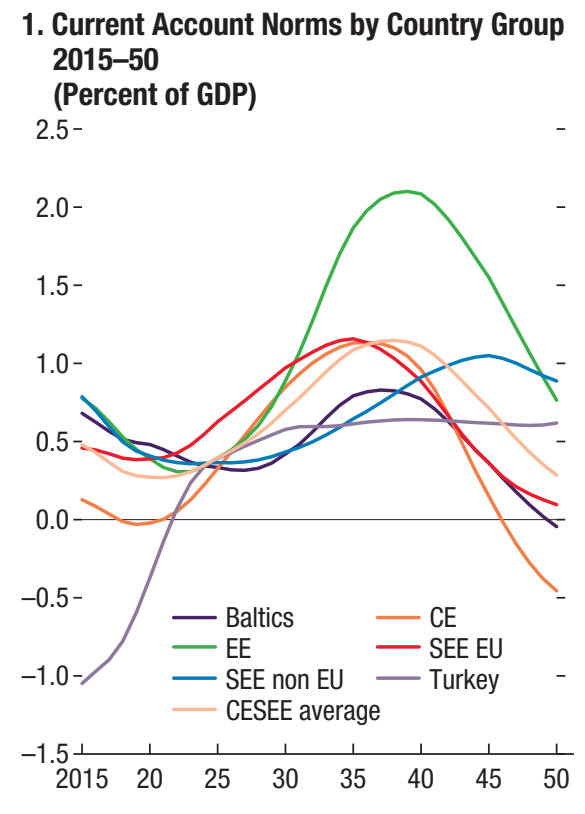
2. Contribution of Demographic Variables to Current Account Norm 2030 (Percent of GDP)

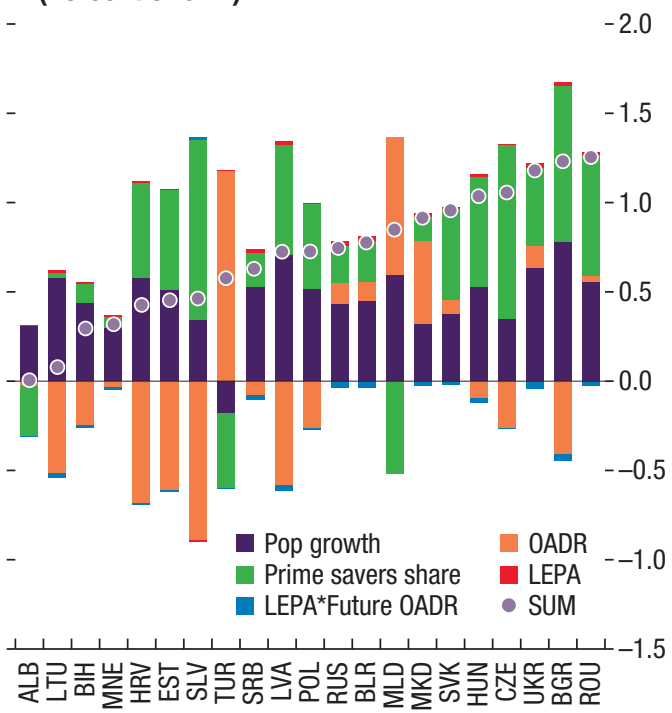

Source: IMF staff calculations.

Note: $\mathrm{CE}=$ Central Europe; CESEE = Central, Eastern, and Southeastern Europe; $\mathrm{EE}=$ Eastern Europe; $\mathrm{EU}=$ European Union; LEPA = life expectancy at prime age; $0 A D R=$ old age dependency ratio; SEE = Southeastern Europe; SUM = sum of all effects. Data labels use International Organization for Standardization (ISO) codes.

rates between CESEE countries and rest of the world becomes smaller. Old-age dependency ratios are expected to rapidly increase in higher-income CESEE countries, generating downward pressure on current accounts. Hence, the simulations also mimic the profile of increasing then declining current account balances seen from the EEUMOD simulations. This phenomenon is expected as countries work their way through demographic change-earlier in demographic transitions, national savings are high as households attempt to provision for their own old age and to support the already elderly; later, at a stage when the share of the elderly is sufficiently large, savings decline and the current account deteriorates as the elderly run down their assets in retirement. ${ }^{2}$

\footnotetext{
${ }^{2}$ See Batini, Callen, and McKibbin (2006) for an earlier exposition of this result.
} 


\section{Box 8. Implications for Interest Rates}

The potential for significant changes in saving and investment shown in the simulations raise the question of the potential for changes in interest rates.

As with external balances, demographic effects have multiple and sometimes opposing effects. Increases in expected time in retirement motivate increased savings, all else equal, as do increases in the expected costs during retirement. Lower population growth leads to lower returns on capital, the more so if productivity also falls. An increase in the share of retirees - who are assumed to consume only, and have low propensity to save-would put upward pressure on real interest rates (Carvalho, Ferrero, and Nechio 2016); decreases in expected incomes, whether from public or private pension schemes, would push rates down (Kreuger and Ludwig 2007).

Model-based and empirical work typically find that, overall, population aging can be expected to be accompanied by falling real interest rates. For example, simulations by Gagnon, Johannsen, and Lopez-Salido (2016) find that most of the decline in real rates since 1980 can be accounted for by demographic trends. Panel regressions using euro area data find similar results (Ferrero, Gross, and Neri 2017). The simulation results shown in Chapter 6 also show declining real interest rates. ${ }^{1}$ The scale of the change to the "world" rate is small (only 0.1 percentage points), but greater for Central, Eastern, and Southeastern European countries (0.6 percentage points for the region), reflecting the relatively worse demographic trends. Additional movements in real interest rates are caused by changes in risk premiums, depending on the accumulation of public debt implied by age-related spending pressures and the effects of growth on revenues.

Caution should be applied when interpreting these results: first, to project world rates, we would need to project demographic changes for those countries that account for the bulk of world savings, which is outside the scope of this paper. Second, the model abstracts from the richer demographic dynamics described earlier. Nonetheless, in the simulations using the Europe-oriented version (EEUMOD) of the IMF's Flexible System of Global Models, the fall in equilibrium interest rates is not sufficient to offset the increase in sovereign rates that arises because of risk premiums, so there is no "hidden dividend" for debt sustainability. In addition, countries would face the problems for monetary policy of more frequently hitting the zero nominal bound (Eggertsson, Lancastre, and Summers 2018).

\footnotetext{
${ }^{1}$ The real interest rate in the simulations is defined as the ex-ante yield on a one-year bond, deflated by consumer price index inflation. The world real rate is defined as a purchasing power parity GDP-weighted average of individual country rates.
} 
This page intentionally left blank 


\section{Chapter}

\section{Summary and Implications for Policies}

The total population of the CESEE region as a whole is expected to decline significantly. And total population growth in the Baltic, Central European, Southeastern European EU, and Southeastern European non-EU states is worse than for the CESEE region as a whole-only Turkey, of all CESEE countries, is expected to have positive population growth.

The adverse population dynamics of the CESEE region are driven mainly by high mortality rates and persistent net outward migration. CESEE countries generally have younger populations than those in Western Europe. Projected CESEE birth rates are on average lower than in most other regions, but mostly in line with those in Western Europe. But mortality rates are projected to remain significantly higher than those of Western Europe, and about half of CESEE countries are projected to experience both negative natural population growth rates and outward migration over the next 30 years.

Hence, populations are expected to decline and age significantly. Nearly half of CESEE countries are projected to experience net total population losses of 5 percent between now and 2030, and 15 percent by 2050. (One exception is Turkey, which is expected to have positive population growth.) CESEE countries are projected to age more quickly than the Western European average, and the populations of younger and poorer CESEE countries are generally expected to age more quickly than those in other CESEE countries.

We have highlighted three important implications of these demographic pressures:

- First, declining and aging population is associated with a smaller pool of available workers. In CESEE countries, indeed, the populations of those of working age are expected to shrink even more rapidly than total populations. Even after accounting for legislated increases in retirement ages 
Table 6. Effects of Demographic Shocks on GDP Growth Rates

(Average yearly impact over 2020-2050, percentage points)

\begin{tabular}{lcc}
\hline & $\begin{array}{c}\text { Production Function } \\
\text { (Section VI.A) }\end{array}$ & EEUMOD (Section VI.C) \\
\hline Real GDP & -1.4 & -1.2 \\
Real GDP per-capita & -1.0 & -0.6 \\
\hline
\end{tabular}

that are expected to increase average participation rates, the labor force in CESEE countries is still projected to decline by 10 percent by 2030 and by 26 percent by 2050 - more than the decrease in total population.

- Second, all CESEE countries, even Turkey, will rapidly reach old-age dependency ratios higher than considered already problematic in comparatively rich Western European countries-in half of CESEE countries, the ratio of elderly to those aged 20 to 64 years is projected to exceed 50 percent. The aging of the total population significantly will increase the demand for public spending on pensions and health care for the elderly in all CESEE countries, in most cases by over 5 percentage points of GDP and in some by 10 or more.

- Third, the aging of the workforce potentially decreases productivity growth. The share of workers aged 55 years or older in the workforce is expected to increase to over 20 percent, posing questions about whether such workers have the health and skills to perform well in a changing work environment.

These mechanisms interact, and each has implications for growth, convergence to higher living standards, and fiscal sustainability. The effects are reinforced by spillovers from neighboring countries. Taken together, the projections (over 2020-50) indicate that average yearly growth-in per capita terms - would be lower by 0.6 percentage points than it would have been without these demographic developments (or a cumulative loss of 17 percent). Convergence to higher Western European incomes will continue, in most cases, but more slowly than otherwise-even though Western European economies are also facing adverse demographic forces (Table 6).

The developments mean that pressures on the public finances will increase. In the absence of offsetting policies, the average fiscal deficit across CESEE (excluding Turkey) would increase by 9 percentage points of GDP from 2020 to 2050 . The cost of letting debt accumulate would be higher debt servicing and sovereign risk, deterring investment. But the cost of raising taxes to meet expenditure pressures would also be significant - the net effects on output growth shown in Chapter 6 are essentially the same whether debt increases to finance deficits or instead tax rates are increased, the balance depending crucially on how sovereign risk reacts to debt and the distortions created by additional taxation. 
Table 7. Impact of Labor Market Reforms

(Percentage points)

\begin{tabular}{lccc}
\hline & Baseline & $\begin{array}{c}\text { Moderate labor } \\
\text { reforms }\end{array}$ & $\begin{array}{c}\text { Ambitious labor } \\
\text { reforms }\end{array}$ \\
\hline GDP growth & -1.16 & -1.00 & -0.88 \\
GDP per capita growth & -0.60 & -0.46 & -0.43 \\
GDP & -30.9 & -27.0 & -24.2 \\
GDP per capita & -16.9 & -13.1 & -12.2 \\
\hline Note: Rows 1 and 2: average yearly impact over 2020-2050; rows 3 and 4: level deviation by 2050.
\end{tabular}

What can be done to mitigate the adverse consequences of demographic changes? In essence, more workers working more productively is the answer. There is no simple or universal means to that end, but there is an increasing body of evidence on the efficacy of policy options. We can capture all options in terms of increasing effective labor inputs, capital deepening, and raising productivity.

In this paper, we have shown simulations illustrating the gains from increasing labor force participation, given limited evidence that policies to support higher fertility could be effective, and limited appetite for substantially higher inward migration. Policies to increase labor force participation would indeed help to reduce the decline in the labor force. Measures to increase the participation of women in the labor force could increase the available labor force compared to the baseline labor force projection, especially before 2030; boosting participation of older workers would have a larger impact, whereas the most significant impact over the longer term would come from raising statutory retirement ages. Reforms could usefully reduce the declines in labor supply in most countries, in a typical case by half in the moderate reform scenario. However, in only a few cases would the reforms fully offset the decline in labor supply, and in some countries the measures would not significantly reduce the decline. In most countries, even ambitious reforms would ultimately be overwhelmed by population changes. Moreover, when other factors - fiscal crowding out of investment through higher sovereign risk (or taxes), and negative effects of population aging on productivityare considered, the relative impact of participation increases on output is smaller still: the average yearly GDP growth rate improves by 0.3 percentage points (to -0.88), which is relatively small given the reduction in growth of 1.15 percent points projected in the model simulations (Table 7 ).

Differences in growth rates cumulate to potentially large differences in levels over time-for example, GDP is 6 percentage points higher ( -24 percent) with ambitious labor reforms than would be under the no-reform baseline. And the labor reforms make a significant difference for fiscal sustainability. Nonetheless, for most CESEE economies, increasing participation rates will not fully offset falling working-age populations. This motivates looking at the 
full range of complementary policies to boost labor intensity, capital stock, and productivity.

\section{Policies to Increase Effective Labor Inputs}

Increasing labor at work means some combination of more people and/ or greater labor "intensity" — numbers of people or hours-from the existing population.

- Boosting working-age population: As noted in Chapter 3, significantly increased fertility seems neither possible nor sufficient. Bringing in foreign workers (for example, by worker import arrangements and permanent immigration) is one way to address shrinking labor supply. Many countries are having ongoing national debates on migration, including on its socially agreeable pace.

- Boosting labor intensity: There is considerable room to increase labor participation and employment rates, especially of women and older workers. Raising participation rates would fully offset the decline in the working-age population in Albania and Bosnia and Herzegovina, and more than offset it in Belarus, Republic of North Macedonia, and Moldova. The contributions could be significant in the cases of Poland, Romania, and Slovakia (see Chapter 3).

What policies could increase labor intensity? In general, evidence from cross-country studies indicates that increased spending on lower labor tax wedges, lower unemployment replacement rates, and active labor market policies tend to boost participation and employment. Of the last, policies to subsidize jobs directly have poor returns; active labor market policies would be better directed at training schemes (Card, Kluve, and Weber 2010). Product market liberalization is also associated with increased employment (see Égert and Gal 2016; IMF 2016d and references therein.)

The evidence also indicates that some policies are better for targeting different problems of participation, and these are important for thinking of how demographic challenges vary across CESEE economies:

o Raising female labor employment: In many CESEE countries, raising female labor participation is one of the most promising options in the short term. More spending on "in kind" family benefits (such as childcare) are empirically found to increase female employment rates (Égert and Gal 2016).

o Raising employment of older workers: Many CESEE countries will need to boost employment of older workers and face the threat of displacement of less educated workers - in this situation, the finding that higher unemployment benefit rates affect most negatively the employment of older workers and the less skilled (Égert and Gal 2016) is particularly 
relevant. As with female participation, policies to increase workplace flexibility to accommodate those who might want only to work part time should also be promoted. These policies can usefully complement raising the legal retirement age.

- In theory, one option to increase effective labor inputs is to increase hours worked. However, hours worked in CESEE countries are already substantially higher than in Western European countries and can be expected to decrease as national incomes increase.

The empirical evidence on the effects of labor market liberalization on employment and participation are mixed (IMF 2015b and references therein). The evidence on wage bargaining systems is also mixed, perhaps owing to the complexity of how wages are determined in each country. Different systems reflect societal preferences (Blanchard, Jaumotte, and Loungani 2014); both "Anglo-Saxon" and "Nordic" models can deliver high employment. What appears to be most important for employment is that macroeconomic considerations are properly internalized, whether through completely independent or tightly centralized bargaining (Organisation for Economic Co-operation and Development 2018).

- Policies to retain and attract skilled workers: The CESEE region has endured a large wave of outward migration since the early 1990s. Many emigrants were well-educated and young, significantly reducing the labor force and productivity, adversely affecting growth in sending countries, and slowing per capita income convergence. In addition, outward migration appears in many cases to have reduced competitiveness and increased the size of government, by pushing up social spending in relation to GDP, and made the budget structure less growth-friendly.

Atoyan and others (2016) find that the key determinants of the direction and scale of migration have been differences in per capita income levels, quality of institutions, and employment prospects. Their analysis suggests that the quality of institutions matters more for skilled migrants, whereas unskilled migrants appear to be attracted by more generous social benefits in the receiving countries.

What does that imply for policies? In countries experiencing or likely to experience outward migration, active labor market policies could help mitigate the negative impact of emigration. Such countries should also focus on creating an environment that encourages potential emigrants to stay; this implies strengthening institutions and improving the overall economic environment. Further liberalization of immigration regimes, especially for skilled workers, could be considered as well.

- Boosting health and life expectancy: As noted in Chapter 2, people in CESEE countries face relatively high risks of mortality, mainly due to both noncommunicable diseases and injuries. The United Nations estimates that the region would achieve a 5.9-year gain in life expectancy at birth solely 
by reducing mortality from heart diseases to that of populations with the highest life expectancies (see United Nations 2012). Boosting health would raise both participation rates and extend viable working lifespans.

\section{Policies to Support Capital Deepening}

As seen in Chapter 6, the response of private investment plays a key role in the slowdown of growth and convergence. Hence, conditions affecting returns on investment are crucial, such as infrastructure, human capital, and institutions. Policies to subsidize private capital investment are more likely to lead to inefficient capital allocation, absent clear distortions. However, financial sector reforms can encourage efficient allocation (IMF 2015b and references therein). For the most part, CESEE countries have open capital accounts and domestic banking systems open to foreign competition. In that context, governance reforms are a useful complement-policies to ensure consistent application of rule of law and property rights are found to boost investment growth (Acemoglu and Johnson 2005).

Automation can in principle offset the fall in the numbers of available workers and boost productivity. Experiences in other countries are mixed-in some, automation has supported higher employment and raise incomes; in others, it appears to have displaced workers. To avoid the latter, it is important for policymakers to consider how labor market policies and public assistance can ensure that workers have the right skills. This is especially important in cases - as for all CESEE countries-where the share of older workers in the working-age population is increasing, potentially lowering productivity all else equal.

As seen in Chapters 4 and 6, demographic forces could put considerable pressure on countries' fiscal positions. The danger is that public investment could be squeezed out-given considerable needs for investment in public infrastructure, this should be resisted, good public infrastructure also being a condition for private investment.

\section{Policies to Boost Productivity}

Ultimately, significant improvements in total factor productivity will be needed to mitigate the effects of demographic change. This can be thought of in two aspects: first, improving the efficiency of the allocation of capital and labor across firms (or establishments); second, the level and utilization of human capital; and third, institutions supportive of productivity growth. 
- Allocation of labor and capital: a large part of the differences in total factor productivity — given the swift technology diffusion in the modern agecan be explained by differences in the efficiency with which capital and labor are allocated to higher-productivity firms (see, for example, Restuccia and Rogerson 2017; Hsieh and Klenow 2016 and references therein).

o Product market reforms are associated with higher capital stock (Égert and Gal 2016) and help boost total factor productivity growth, especially if they boost competition (IMF 2015b and references therein).

o Other reforms that facilitate more efficient resource allocation would also help increase productivity (Hsieh and Klenow 2016). Examples include strengthening state-owned enterprise governance or privatizing state-owned enterprises, reductions in red tape, and reducing the size of informal sector.

- Human capital: The evidence is overwhelming that growth differences across countries over long periods of time are primarily driven by human capital (and not physical capital) accumulation (C. Jones 2005). Why is human capital so important? Whereas increasing physical capital faces diminishing returns, there are increasing returns to human capital. In the context of demographic change, two policies to boost human capital are important:

- Preschool, primary, secondary, and tertiary/vocational education: There is a strong relationship between educational attainment and growth rates. ${ }^{1}$ Education becomes all the more important when dependency ratios increase. The literature on what policies can boost educational attainment is substantial; note, in the context of the fiscal pressures outlined earlier, that there appears to be little connection between public spending and educational attainment (Hanushek and Woessmann 2017). But some factors found to be significant—such as regular assessments (Woessmann 2016) — would not require substantial increases in public spending.

o Lifelong learning will likely increase in importance with policies to encourage greater participation of older workers. Evidence on the effects of lifelong learning is thin, but the Organisation for Economic Co-operation and Development's Survey of Adult Skills shows that Nordic countries - with high levels of participation and human capitalspend proportionately more on lifelong learning than other countries.

\footnotetext{
${ }^{1}$ Early literature focused on the relationship between years of schooling and growth (Barro and Lee 2010). The results are stronger when educational attainment is refined to measure skills levels (Lutz, Cuaresma, and Sanderson 2008), and stronger and more consistent still when a measure of cognitive ability is used in place of grade attainment (Hanushek and Woessmann 2010, 2012).
} 
- There is also another important dimension to human capital: fostering inclusive growth. First, the exclusion of underrepresented groups from labor force by not equipping them with qualifications can seriously dampen growth (Hsieh and others 2018). Second, technological change displaces unskilled workers and exacerbates inequality (Acemoglu 2002).

Hence, as for capital expenditure, it will be important for governments to preserve spending on education and training - even though the numbers of the young will decrease, the need to increase educational attainment motivates increased spending. Attention will need to be paid to retraining older workers - as shown in the Organisation for Economic Co-operation and Development's Survey of Adult Skills scores, the region lags Western Europe in the numbers of adults engaged in retraining and lifelong learning programs.

Once educated, retaining the educated workforce has been a common challenge for most CESEE countries. New EU member states have experienced a large exit of its population, often with emigrants better educated than the home-country average. Differences in income levels and quality of institutions have been among key drivers of migration, with institutions playing a larger role in the migration of the skilled labor (Atoyan and others 2016).

- Governance: Improving the quality of institutions, including government efficiency, helps slow outward migration and improve productivity growth. Related, high levels of "social infrastructure" (that is, the extent to which inward investment and transfer of technology are rewarded) are associated with both higher average skill levels and total factor productivity (Hall and Jones 1995). Indeed, for CESEE countries, the quality of institutions has been found to be a key constraining factor to the efficient use of technologies and resources (IMF 2016b). The effect will likely be larger for CESEE countries that typically have relatively high levels of educational attainment compared with other countries of similar incomes (European Bank for Reconstruction and Development 2019).

\section{Policies to Ensure Sustainability of the Public Finances}

A second major concern is fiscal sustainability. Aging populations will substantially increase demands on health care resources. On current fiscal policies, costs related to pensions and health care in CESEE are expected to increase by nearly 4 percentage points of GDP, on average, between 2015 and 2050. Almost half of the increase is explained by rapidly rising health care spending. Public pension systems currently appear sustainable, but only with very low pension payments - spending would increase substantially if pensions were more in line with preretirement earnings. Bringing replacement rates to the recommended minimum level of 40 percent would increase estimated fiscal costs of pensions by 4 percentage points of 
GDP, on average. Total pension and health care costs in the CESEE region would therefore increase by nearly 7 percentage points of GDP, on average, between 2015 and 2050 .

Reforms would help offset projected age-related fiscal costs. The moderate reform scenario helps offset about half of the projected increase in aging-related government spending and debt for the period 2020 to 2050 . The ambitious reforms would fully offset projected increases in pension costs in most countries; when all factors are accounted for, including the reduction in debt pressures, the ambitious labor reform scenario could more than offset the baseline results. But these increases in participation rates could be very challenging for many countries. As a complement, raising retirement ages with improvements in life expectancy would help directly by reducing the number of pensioners, and indirectly by helping complement efforts to boost the labor force participation of older workers.

However, fiscal space also needs to be preserved for measures to increase labor participation and raise skills. Besides the fiscal costs of reform measures themselves, higher participation of older workers would require higher spending on public health (European Bank for Reconstruction and Development 2019). This motivates a broader examination of tax systems and more efficient public expenditure.

\section{Policy Priorities}

As noted at the start of this paper, there is considerable heterogeneity across CESEE countries - all face challenges from demographics, but in different ways.

- Labor supply: As noted, all countries except Turkey face the prospect of sharply decreasing workforces, based on projections for working-age population and participation rates. The issue is particularly pressing for Bulgaria, Latvia, Poland, and Ukraine (see Figure 8 and Table 8).

- In terms of the factors determining participation rates, the priorities differ notably across countries. Participation of younger women is noticeably low in Moldova and Turkey; participation of older women is low in Bosnia and Herzegovina, Croatia, Republic of North Macedonia, Romania, Turkey, and Ukraine, whereas that of older men is particularly low in Bosnia and Herzegovina, Romania, Slovenia, Turkey, and Ukraine.

- Reform of retirement ages is likely necessary across most CESEE countries, but would be especially beneficial in Belarus, Moldova, Russia, Turkey, and Ukraine, both from the point of view of labor supply and fiscal sustainability. 
- Workforce aging: Here the picture is quite mixed, with some countries' workforces not aging very much, and others' aging rapidly (see Table 1, in addition to Table 8). In the latter group we note Moldova and Slovakia.

- Old-age dependency is expected to increase substantially in general but will not substantially affect Moldova and Turkey. By contrast, it is a more pressing issue in the Central European countries, notably Poland and Slovenia.

- Notwithstanding differences in other respects, all CESEE countries will experience increased fiscal pressures from age-related spending, especially Albania, Bosnia and Herzegovina, Croatia, Lithuania, Moldova, Poland, Russia, Slovenia, and Ukraine (see Figure 13, panel 2, in addition to Table 8).

Hence, policy priorities should differ for each country. Latvia and Lithuania, for example, face both sharply decreasing labor supply and already have relatively high participation rates, indicating that policies should be directed at migration policies and conditions to boost productivity. By contrast, in some countries — such as Bosnia and Herzegovina, Moldova, Romania, and Ukraine-labor supply is also expected to decrease sharply, but there are opportunities to substantially improve output and fiscal sustainability with policies directed at raising participation rates. 


\section{Table 8. Policy Priorities}

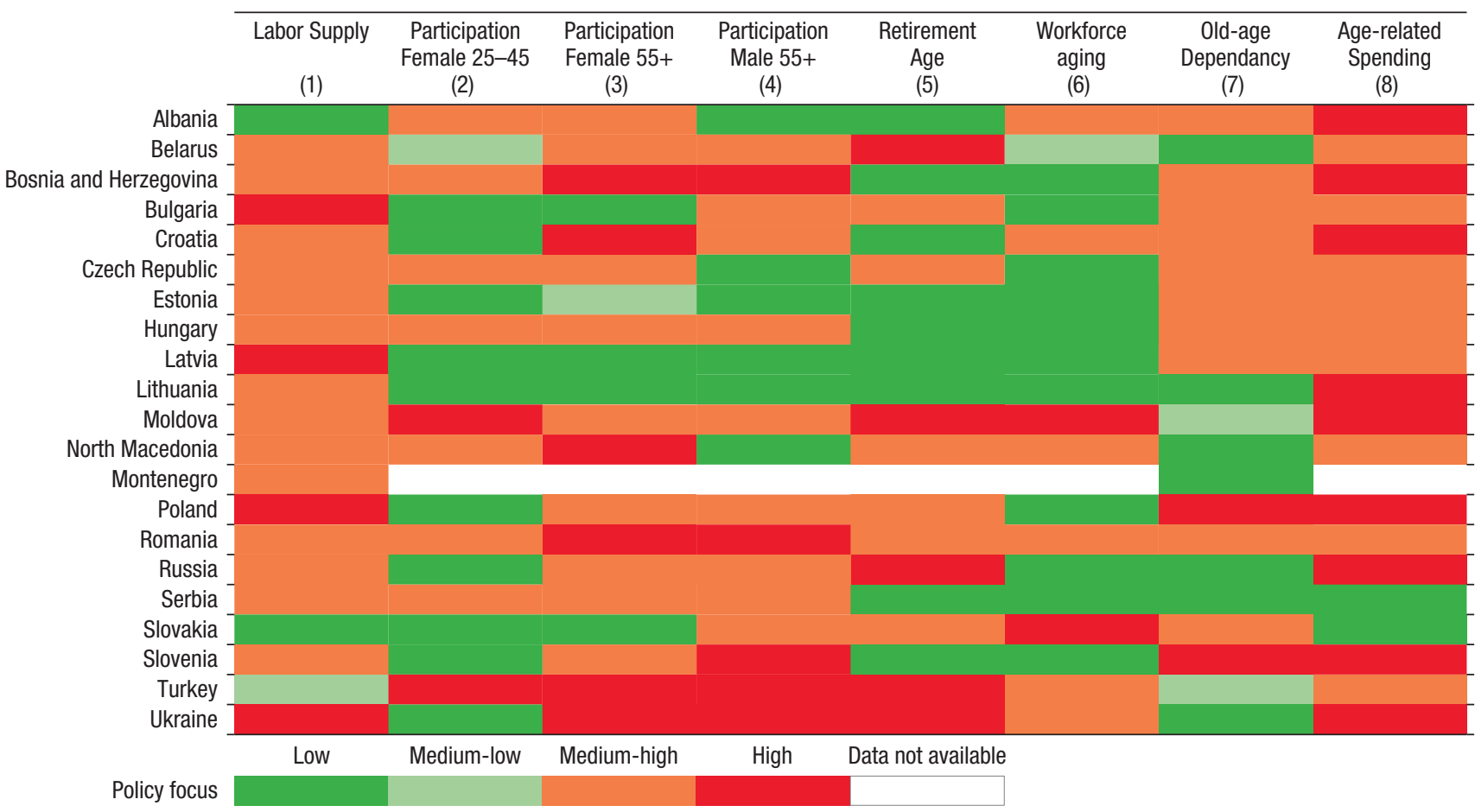

Source: United Nations; International Labour Organization; and IMF staff calculations.

Note: (1) Change in labor supply (in percent): Green above 0, Light green between -20 and 0, Orange between -30 and -20 ; Red below -30 ;

(2) Female LFP ages 25-45 (in percent): Green above 90, Light green between 77.5 and 90, Orange between 60.5 and 77.5, Red below 60.5;

(3) Female LFP ages 55-64 (in percent): Green above 63, Light green between 63 and 52.1, Orange between 35.2 and 52.1, Red below 35.2;

(4) Male LFP 55-64 (in percent): Green above 77, Light green between 64.7 and 77, Orange between 54.2 and 64.7, Red below 54.2;

(5) Retirement age: Green above 67, Light green between 67 and 65, Orange between 65 and 60, Red below 60;

(6) Change in share of workforce above 55 years (in percentage points): Green below 3, Light green between 3 and 6, Orange between 6 and 10, Red above 10;

(7) Ratio of population above 65 years to population aged 20-64 (in percent): Green below 40, Light green between 40 and 50, Orange between 50 and 60, Red above 60;

(8) Increase in age-related spending (in percent of GDP): Green below 0, Light green between 0 and 4, Orange between 4 and 8, Red above 8. 
This page intentionally left blank 


\section{Annex 1. The UN Population Projections}

\section{Data Sources}

For this study, we use projections published by the UN Population Division, specifically the 2017 vintage of the World Population Prospects. The population historical estimates and projections cover the period from 1950 to 2015 and from 2015 to 2100, respectively, at five-year intervals. (Some series are interpolated to produce estimates and projections at annual frequency, but the interpolated data are not used in this study.) The World Population Prospects contains data and projections for, inter alia, population by country (total, by age cohort, male and female), young- and old-age dependency ratios, fertility, mortality, life expectancy, and net migration. Projections are made for several scenarios: a "medium variant," the most frequently used set of projections in this study; a "high variant" scenario that assumes higher fertility; a "low variant" scenario with lower fertility; and constant fertility and instant-replacement scenarios. The World Population Prospects also includes 80 and 95 percent prediction intervals around the medium trajectory. ${ }^{1}$

The twin motivations for using the UN projections are coverage and consistent methodology. Projections are also available from Eurostat, but do not cover non-EU CESEE economies; projections from the International Labour Organization cover nearly the same range of countries as the United Nations but do not offer the same range of measures. Projections are also available from national sources—sometimes many, from different agencies—but are difficult to compare and problematic to aggregate, as they have been prepared with different methodologies and assumptions.

Comparisons show that there are relatively small differences in population growth rates across the UN and International Labour Organization projections. Eurostat projections show stronger population growth in the cases of

${ }^{1}$ For more discussion of the scenarios and methodology used to construct them, see United Nations (2017a). 
Croatia, the Czech Republic, Estonia, Hungary, Poland, Slovakia, and Slovenia, with weaker population growth projected for Lithuania. In some countries, projections by national agencies are more optimistic about population prospects than the UN projections.

\section{Are the Projections Too Pessimistic About Fertility?}

The population growth rates in the UN projections are below those of some of the projections from national authorities, raising the question of whether the UN projections are too pessimistic. In particular, some fertility rates have recovered during the past few years from the lows seen during the 1990s and first part of the millennium, raising the question of whether this will continue.

The UN medium scenarios used for our analysis already project a continuation in the recovery in fertility rates. There is also a recovery in fertility rates built into the projections for other countries, including those of Western Europe, but the rate of increase is greater for CESEE countries. ${ }^{2}$

The UN "high variant" scenarios assume yet higher fertility still for all regions. The average rates for CESEE and Western Europe rapidly ascend above replacement rates (just over 2 percent). Such rates are much higher than those seen in CESEE countries since the 1950s. Countries with lower fertility rates are projected to have the highest increases in fertility (Annex Figure 1.1).

\section{How Accurate Are the Projections?}

As seen in Chapter 2, the projections are striking for CESEE countries-but how reliable are such projections?

To evaluate forecast errors, we compare the forecast of total population in 2010 projected in the 2000 UN World Population Prospects revision and actual levels recorded in the 2010 revision. To examine the role of migration, we compare projections of total population that include changing migration with so-called zero migration projections, which are driven by births and deaths only.

We find that previous forecast errors were not noticeably larger for CESEE economies compared with those for Western Europe, and there is little evidence that the projections were biased. Specifically, the results show that

\footnotetext{
${ }^{2}$ The reasons for the recent recovery in fertility are complex and thought to mainly include economic recovery, increased female labor participation, and better childcare support-see Hoorens and others (2011).
} 


\section{Annex Figure 1.1. Fertility}

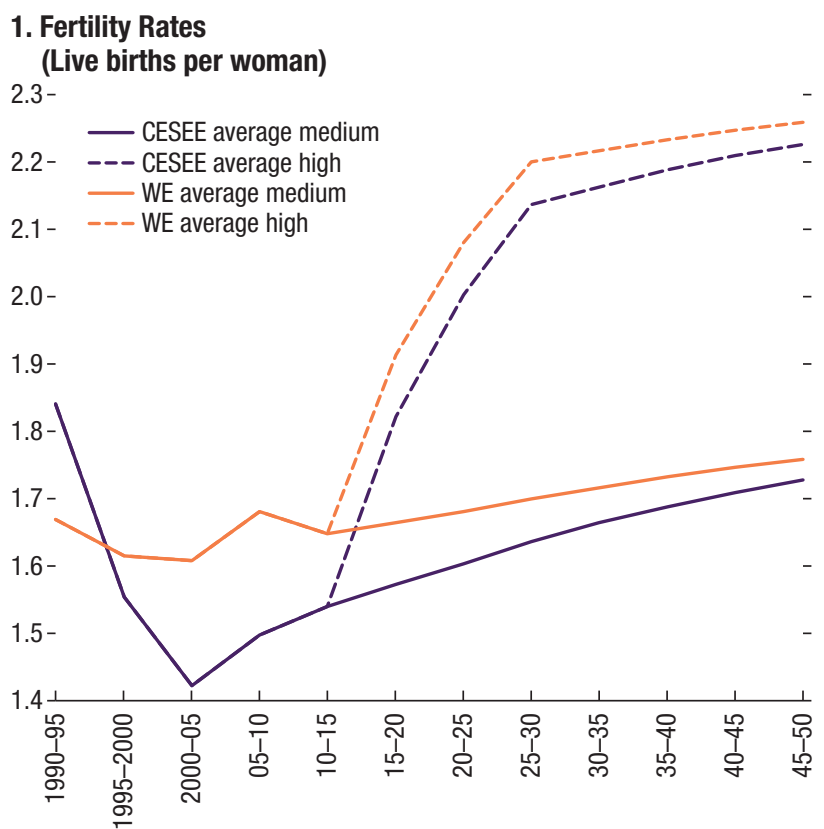

\section{Changes in Fertility Rates}
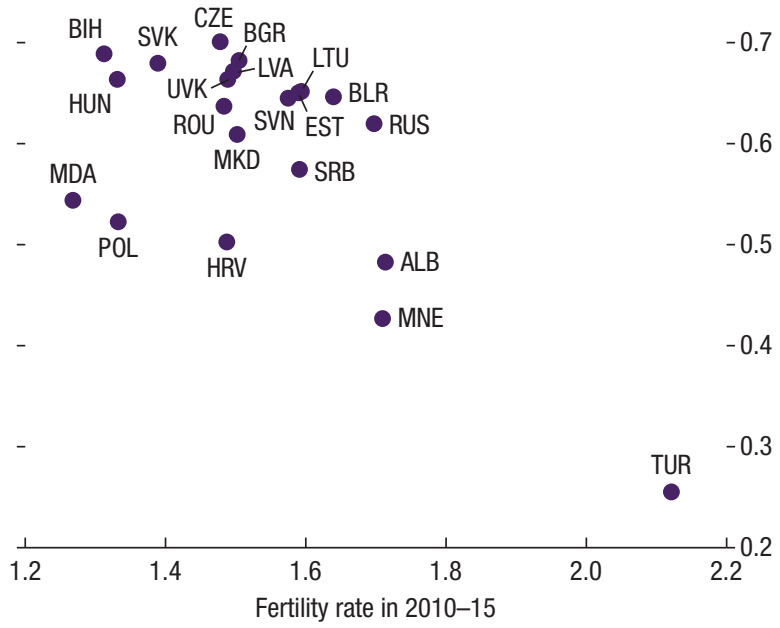

Sources: United Nations; and IMF staff calculations.

Note: CESEE = Central, Eastern, and Southeastern Europe; WE = Western Europe. Data labels use International Organization for Standardization (ISO) codes.

forecast errors have been smaller on average for CESEE countries than other European countries. This picture improves further when outliers are excluded: the median error of the CESEE projections is notably smaller than average error, in fact close to zero. Rather than being too negative, the 2000 Revision projections typically overestimated what CESEE populations would be and underestimated populations in other European countries (Annex Table 1.1)

Comparing forecast errors across CESEE countries, we can see that the UN tended to overestimate total populations in Southeastern Europe and underestimate those in Central Europe, although there are exceptions (Annex Figure 1.2).

Annex Table 1.1. Forecast Errors

(Total population, 10 years ahead, percent of actual)

\begin{tabular}{llcc}
\hline & & All Europe & CESEE only \\
\hline Average error & with migration & 2.9 & -1.2 \\
& zero migration & 3.5 & -1.8 \\
Median error & with migration & 3.4 & -0.3 \\
& zero migration & 4.1 & -0.9 \\
Mean absolute error & with migration & 5.6 & 4.3 \\
& zero migration & 6.4 & 4.1 \\
\hline
\end{tabular}

Note: CESEE $=$ Central, Eastern, and Southeastern Europe. 
Annex Figure 1.2. Forecast Errors

(UN World Population Prospects 2000 revision projection of total

population in 2010 against actual, percent of actual)

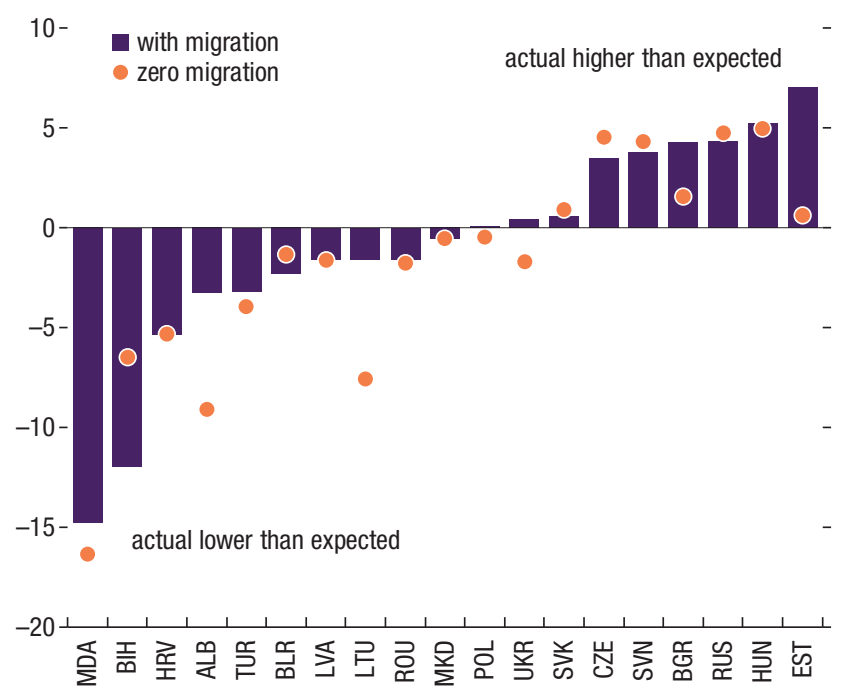

Sources: United Nations; and IMF staff calculations.

Note: Data labels use International Organization for Standardization (ISO) codes.
As seen in Chapter 2, migration assumptions are important for population projections and are particularly important for estimates of the labor force used in later chapters. Migration is difficult to predict. That said, the analysis here indicates that incorporating migration projections has mostly improved forecast accuracy (with the notable exceptions of Bosnia and Herzegovina, Bulgaria, and Estonia, each of which have experienced large outward migrations).

In conclusion, the projections were mostly unbiased and not systematically too pessimistic. The forecasting performance for CESEE countries was not worse than for advanced countries. As difficult as they are, migration projections aided overall forecast performance.

\section{Are the Projections Too Uncertain?}

The United Nations publishes ex ante uncertainty estimates with its projections. The United Nations also produces probabilistic projections for population, based on estimates of uncertainty about fertility and mortality; it does not estimate uncertainty about migration. The estimates of uncertainty are quantified as 80 and 95 percent confidence intervals around the medium scenario.

The qualitative impressions shown in Chapter 2-for example, of declining total and working-age populations - still hold even at wide confidence intervals. There is more uncertainty about fertility than mortality rates; this in turn implies quite low levels of uncertainty about working-age population (which is more important than total population for our analysis) over the next 15 years. The United Nations does not produce estimates of uncertainty around migration paths, but other analysis suggests that incorporating uncertainty about migration would accentuate the declines in expected population (Azose, Sevcikova, and Raferty 2016). Overall, for the total population of the CESEE region as a whole, the United Nations estimates only a $2 \frac{1}{2}$ percent chance that growth rates will not be negative in 20 years' time (Annex Figure 1.3). This overall assessment is mitigated by population growth in Turkey; 


\section{Annex Figure 1.3. UN Estimates of Confidence Intervals Around Medium Scenario Total Population Growth Paths}

\section{CESEE}

(Percent)

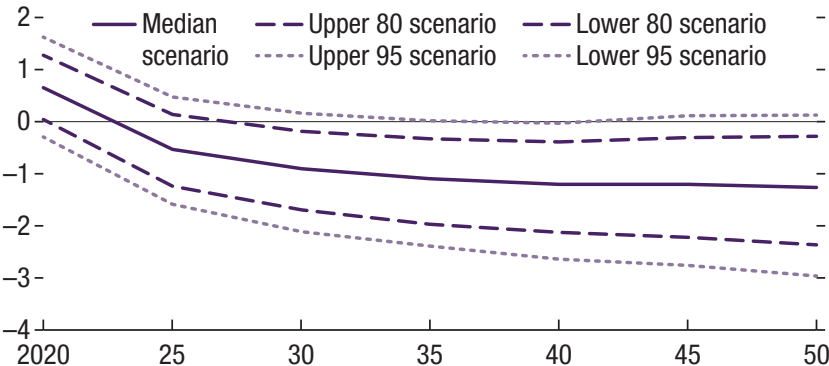

3. CE

\section{(Percent)}

1 - _ Median _- - Upper 80 scenario - - Lower 80 scenario 0 ......... scenario ..... Upper 95 scenario …. Lower 95 scenario

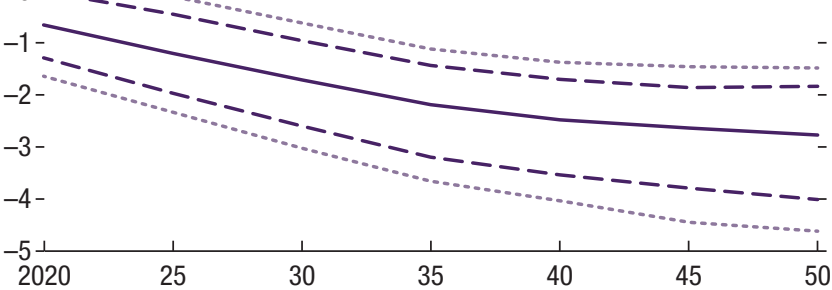

5. EE

(Percent)

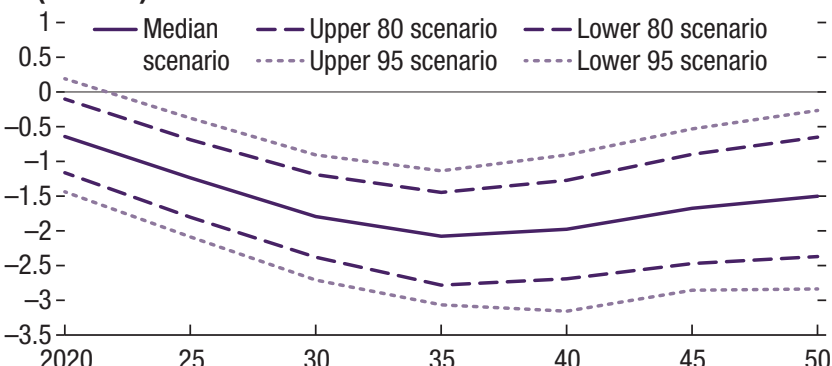

\section{SEE non-EU}

(Percent)

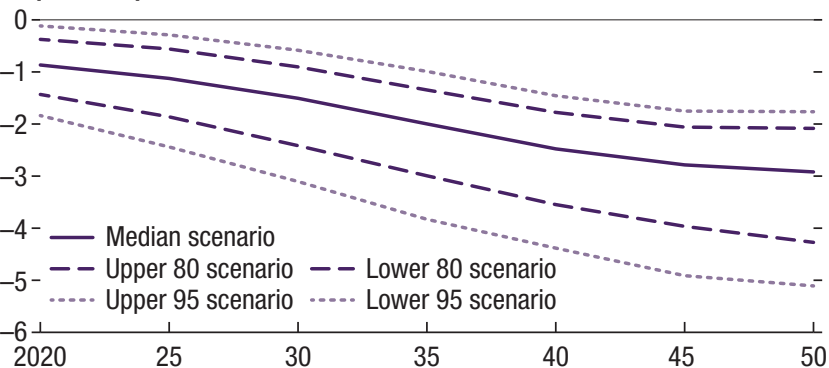

\section{Western Europe}

(Percent)

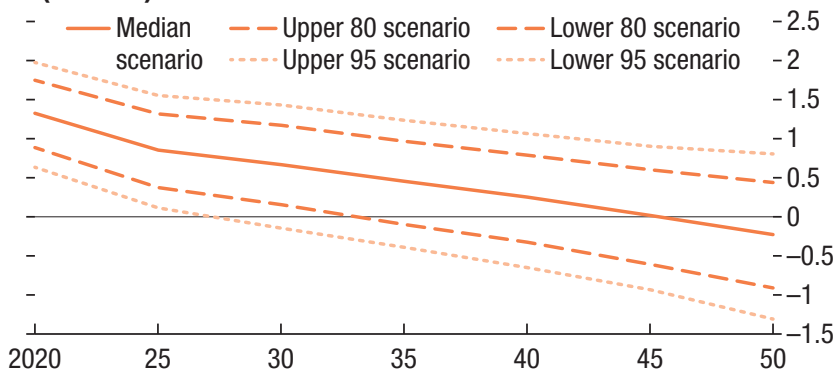

4. Baltic

(Percent)

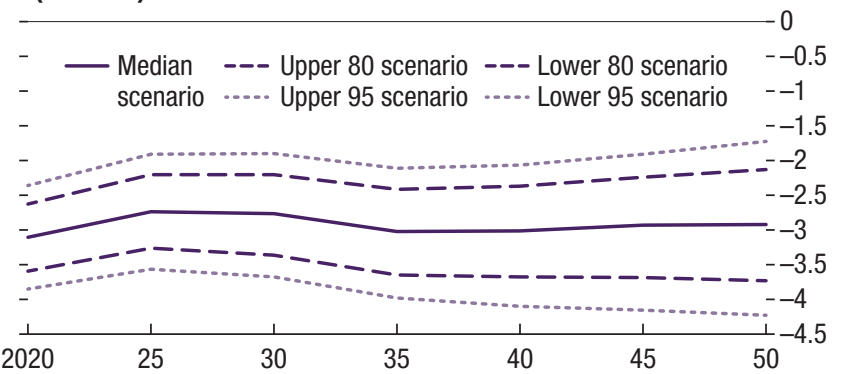

6. SEE EU

(Percent)

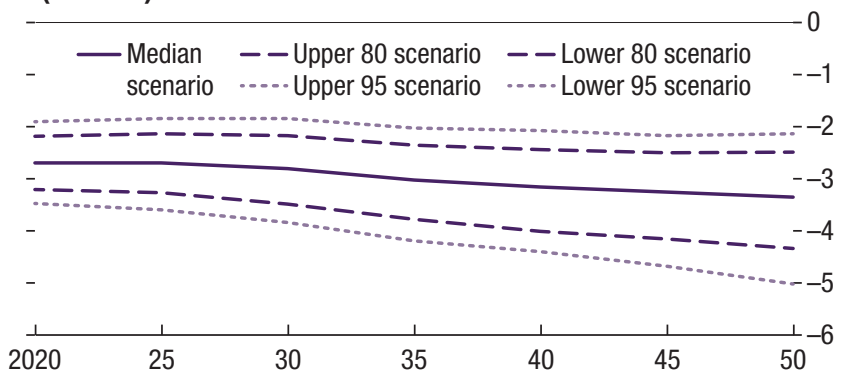

8. Turkey

(Percent)

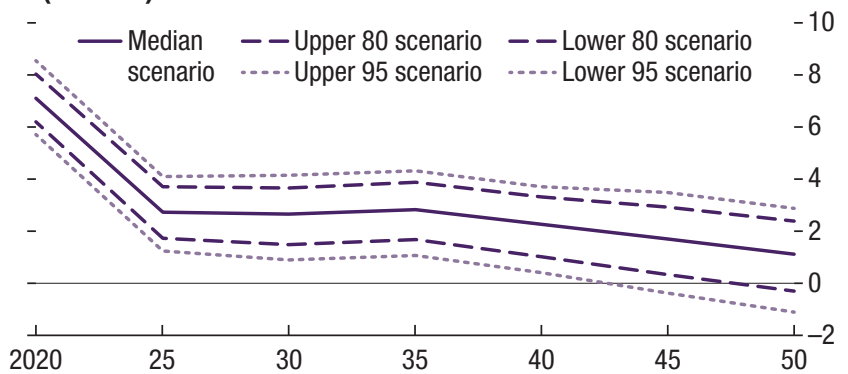

Source: United Nations.

Note: $\mathrm{CE}=$ Central Europe; CESEE = Central, Eastern, and Southeastern Europe; EE = Eastern Europe; EU = European Union; SEE = Southeastern Europe. 


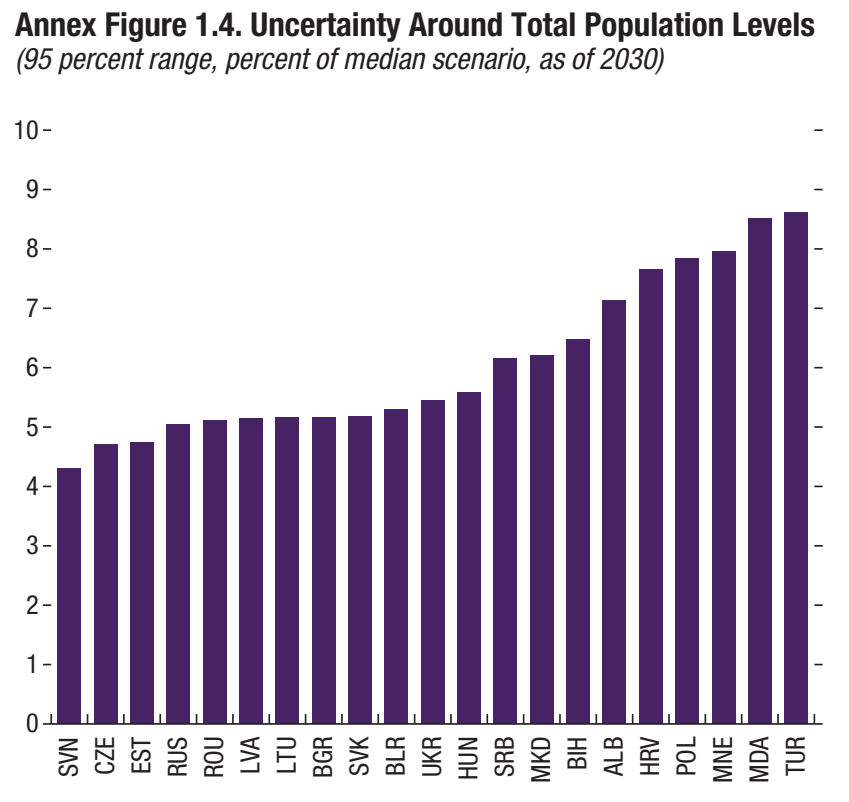

Sources: United Nations; and IMF staff calculations. Note: Data labels use International Organization for Standardization (ISO) codes. for all the other CESEE subregions, negative population growth is evaluated to be a near certainty within 10 years at most.

By country, the uncertainty around the medium path is greater for Balkan economies and Turkey, consistent with fertility uncertainty being greater in general and the younger populations of those economies. Conversely, the uncertainty is less for older economies that have conventionally "Western" demographic profiles.

Much of the analysis in later chapters focuses on working-age rather than total population. The confidence intervals for CESEE aggregate and regional aggregate working-age population growth are shown in

Annex Figure 1.4. In comparison to Annex Figure 1.3, two points stand out. First, even with Turkey in the CESEE aggregate, population growth is always negative, even at 95 percent confidence limits. Second, there is hardly any uncertainty estimated for working-age population for the next 15 years - this is a consequence of much greater uncertainty about fertility than mortality; as those that will be of working age during the next 15 years have already been born, the confidence intervals are comparatively very tight.

But how good are the UN estimates of uncertainty? Analysis of UN projections indicates that the UN estimates of the uncertainty around fertility and mortality is very good (Azose, Sevcikova, and Raferty 2016). However, not including uncertainty around migration paths is potentially problematic. Prediction intervals for population paths for North America and Europe are found to be substantially underestimated when migration uncertainty is not included. Note, however, that the central tendency of migration uncertainty is not the same as for fertility and mortality uncertainty-with the implication that adding uncertainty about migration would tilt error bands downwards (Azose, Sevcikova, and Raferty 2016). On this basis, it would not be correct to infer that the lack of migration uncertainty biases the projections toward being too pessimistic about population prospects in Europe (Annex Figure 1.5). 


\section{Annex Figure 1.5. UN Estimates of Confidence Intervals Around Medium Scenario Working-Age Population Growth Paths}

\section{CESEE} (Percent)

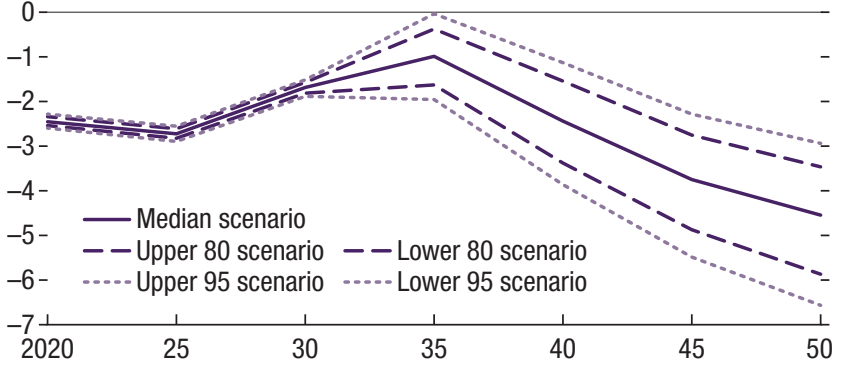

3. CE

(Percent)

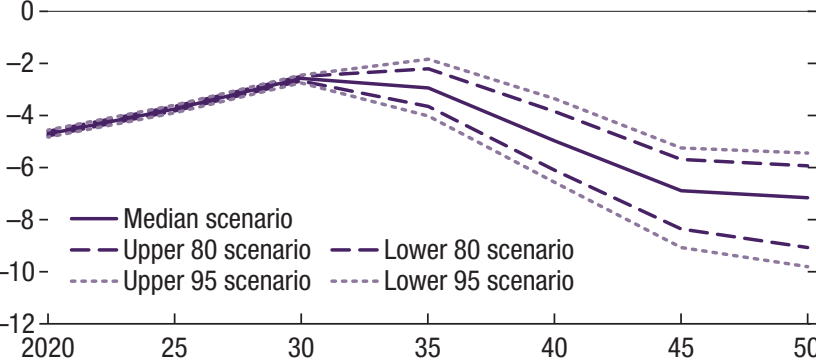

5. EE

\section{(Percent)}

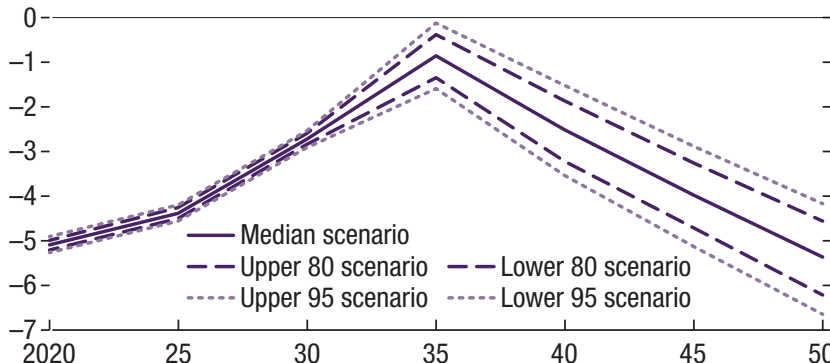

\section{SEE non-EU}

\section{(Percent)}

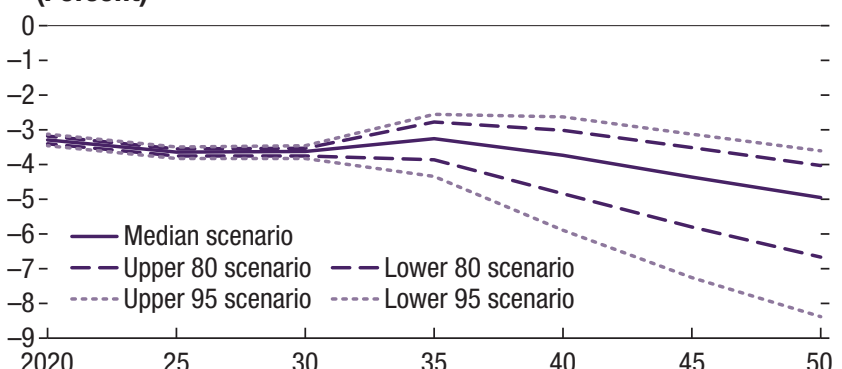

\section{Western Europe}

(Percent)

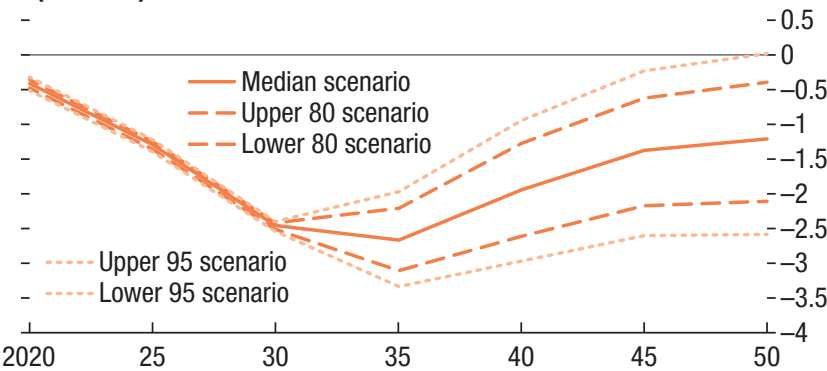

\section{Baltic}

(Percent)

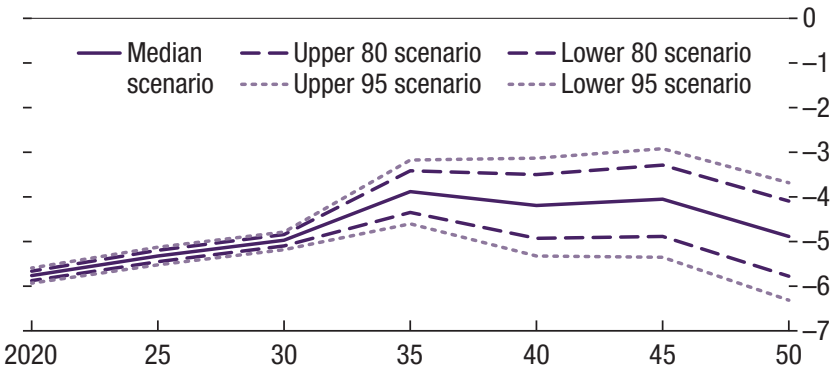

\section{SEE EU}

(Percent)

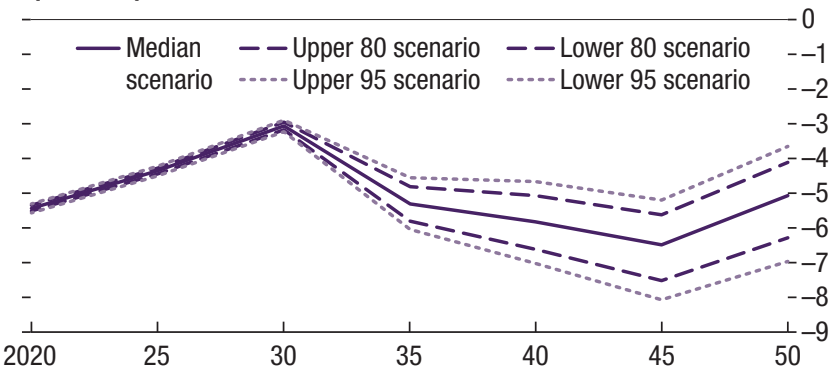

8. Turkey (Percent)

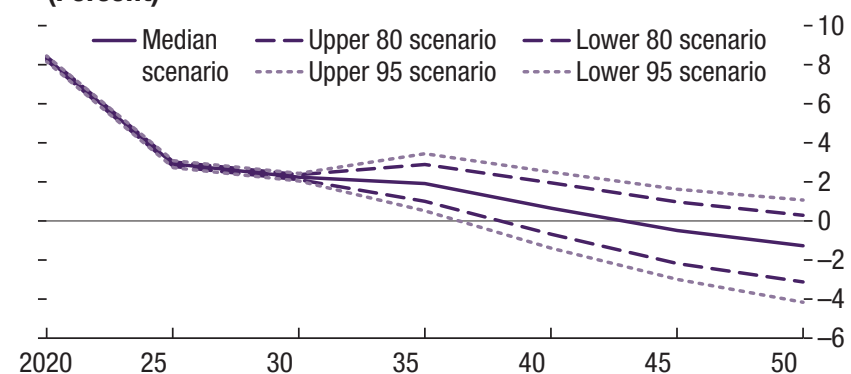

Source: United Nations.

Note: $\mathrm{CE}=$ Central Europe; CESEE = Central, Eastern, and Southeastern Europe; EE = Eastern Europe; EU = European Union; SEE = Southeastern Europe. 
This page intentionally left blank 


\section{Annex 2. Participation Rates and Labor Force Projections}

\section{Baseline Labor Force Projections}

The total labor force for each country is estimated by projecting the population of five-year age cohorts and participation rates for each cohort, per the labor force decomposition

$$
\text { Laborforce }=\sum_{j} \text { Population }_{j}^{*} \text { Participationrate }_{j}
$$

where $j$ is a five-year cohort of men or women from 16 to 80 years old. We use the UN population projections (2017 vintage, medium fertility scenario) for population projections. For future participation rates, current labor force participation rates for each cohort (from International Labour Organization data) are used. In cases where there are planned increases in statutory retirement ages, the participation rates of the older cohorts (those aged 55 to 70 years) are increased to match the rates in countries that have similar statutory retirement ages. (Annex Table 2.1 shows participation rates for men and women by country over the projection period.)

\section{Policy Scenarios}

The policy scenarios are calibrated by changing participation rates for older workers and women. Population projections in all scenarios remain the same as in the baseline labor force scenarios. The scenarios are

- Increasing participation of young women (25-45 years old). The female labor force participation (FLFP) is assumed to increase to the highest EU levels of the corresponding age-gender cohort. The rate of increase is 
Annex Table 2.1. Labor Force Participation Rates of Older Workers Under Baseline Scenario

\begin{tabular}{|c|c|c|c|c|c|c|c|c|}
\hline & 2015 & 2020 & 2025 & 2030 & 2035 & 2040 & 2045 & 2050 \\
\hline & \multicolumn{8}{|c|}{ Men 55-64 } \\
\hline Albania & 76.0 & 75.1 & 74.2 & 74.6 & 74.9 & 75.4 & 75.3 & 75.1 \\
\hline Belarus & 63.0 & 60.5 & 59.0 & 61.0 & 61.3 & 62.1 & 61.1 & 57.8 \\
\hline Bosnia and Herzegovina & 44.1 & 43.8 & 42.4 & 43.7 & 43.4 & 43.5 & 43.5 & 43.1 \\
\hline Bulgaria & 62.7 & 62.7 & 62.8 & 63.9 & 63.3 & 62.6 & 63.2 & 62.0 \\
\hline Croatia & 54.5 & 54.3 & 53.8 & 54.9 & 54.6 & 54.4 & 54.1 & 59.5 \\
\hline Czech Republic & 68.2 & 69.2 & 69.7 & 71.3 & 69.8 & 67.3 & 68.5 & 68.0 \\
\hline Estonia & 67.7 & 67.4 & 67.0 & 67.9 & 67.2 & 67.4 & 67.6 & 65.8 \\
\hline FYR Macedonia & 67.1 & 66.9 & 67.1 & 66.7 & 67.2 & 67.2 & 66.6 & 66.2 \\
\hline Hungary & 57.6 & 58.4 & 62.3 & 62.6 & 61.5 & 59.0 & 60.7 & 61.3 \\
\hline Latvia & 68.0 & 67.3 & 66.6 & 67.4 & 66.8 & 67.5 & 67.4 & 65.8 \\
\hline Lithuania & 69.8 & 69.1 & 68.0 & 68.4 & 68.1 & 68.7 & 69.2 & 68.9 \\
\hline Moldova & 54.4 & 54.9 & 53.0 & 55.2 & 55.5 & 55.7 & 55.5 & 52.9 \\
\hline Poland & 57.7 & 55.9 & 56.8 & 58.2 & 58.2 & 57.7 & 56.2 & 56.2 \\
\hline Romania & 54.9 & 53.4 & 57.6 & 59.4 & 59.5 & 57.9 & 60.5 & 57.6 \\
\hline Russia & 60.5 & 59.8 & 57.2 & 61.3 & 60.4 & 61.0 & 60.4 & 56.7 \\
\hline Serbia & 55.1 & 55.6 & 56.0 & 56.5 & 56.3 & 55.7 & 56.2 & 55.5 \\
\hline Slovak Republic & 58.3 & 59.1 & 60.3 & 64.0 & 65.1 & 67.2 & 70.9 & 74.6 \\
\hline Slovenia & 45.5 & 45.5 & 45.5 & 45.4 & 46.4 & 44.9 & 44.2 & 43.2 \\
\hline Turkey & 50.4 & 50.4 & 50.2 & 50.2 & 50.1 & 49.9 & 49.7 & 49.7 \\
\hline \multirow[t]{2}{*}{ Ukraine } & 46.8 & 46.5 & 45.0 & 47.4 & 47.2 & 47.5 & 46.2 & 43.3 \\
\hline & \multicolumn{8}{|c|}{ Women 55-64 } \\
\hline Albania & 43.1 & 42.4 & 41.8 & 46.7 & 47.0 & 47.4 & 45.4 & 47.7 \\
\hline Belarus & 37.2 & 36.1 & 35.4 & 36.4 & 36.4 & 36.8 & 36.4 & 34.9 \\
\hline Bosnia and Herzegovina & 23.1 & 23.4 & 22.4 & 23.1 & 22.9 & 23.0 & 23.1 & 22.9 \\
\hline Bulgaria & 53.7 & 53.8 & 54.2 & 55.3 & 54.5 & 53.1 & 54.6 & 52.1 \\
\hline Croatia & 34.0 & 33.8 & 33.3 & 40.1 & 44.7 & 47.5 & 47.1 & 52.5 \\
\hline Czech Republic & 48.3 & 50.9 & 52.8 & 56.1 & 55.5 & 52.4 & 54.2 & 53.5 \\
\hline Estonia & 69.3 & 69.0 & 68.7 & 69.6 & 69.0 & 69.5 & 69.5 & 67.6 \\
\hline FYR Macedonia & 34.0 & 34.0 & 33.9 & 33.7 & 34.1 & 34.1 & 33.7 & 33.3 \\
\hline Hungary & 39.7 & 42.4 & 48.6 & 48.9 & 48.1 & 45.9 & 47.2 & 48.0 \\
\hline Latvia & 63.5 & 62.7 & 61.9 & 62.9 & 62.2 & 63.0 & 63.2 & 61.3 \\
\hline Lithuania & 63.3 & 62.3 & 60.7 & 61.5 & 60.7 & 61.6 & 62.6 & 62.3 \\
\hline Moldova & 35.8 & 36.3 & 34.4 & 36.4 & 36.7 & 36.8 & 37.1 & 34.4 \\
\hline Poland & 37.5 & 35.3 & 36.6 & 38.4 & 38.4 & 37.7 & 35.9 & 35.9 \\
\hline Romania & 34.6 & 33.2 & 36.8 & 47.4 & 47.8 & 46.0 & 48.5 & 45.9 \\
\hline Russia & 40.8 & 40.3 & 38.6 & 41.4 & 41.0 & 41.1 & 40.8 & 38.2 \\
\hline Serbia & 29.2 & 35.5 & 41.8 & 48.1 & 47.8 & 47.2 & 47.7 & 47.0 \\
\hline Slovak Republic & 51.8 & 52.8 & 54.2 & 59.0 & 60.5 & 62.1 & 65.5 & 68.7 \\
\hline Slovenia & 32.2 & 37.5 & 42.5 & 44.6 & 45.7 & 44.6 & 44.2 & 43.5 \\
\hline Turkey & 18.4 & 18.3 & 18.3 & 18.3 & 18.2 & 18.2 & 18.1 & 18.1 \\
\hline Ukraine & 28.4 & 28.3 & 27.5 & 28.8 & 28.9 & 28.7 & 28.3 & 26.6 \\
\hline
\end{tabular}

assumed to be constant across years and countries and calibrated based on historical data. A scenario of a moderate FLFP increase assumes an average annual FLFP increase of 0.5 percentage points, corresponding to the average annual increase in the EU15 countries over the period from 1995 to 2016. A scenario of an ambitious FLFP increase assumes an average annual increase of 1.3 percentage points, which is the highest average FLFP increase achieved in an EU country (Spain) over the period from 1995 to 2016.

- Increasing the participation of older workers (aged 55 years or older) without changing the retirement age. The participation rates of older men and 
women are assumed to rise to the maximum achieved in EU countries, gradually in the moderate scenario and rapidly in the ambitious scenario with similar statutory retirement ages. Participation rates start increasing from the first projection period, and the target participation rate changes with the projected increases in the retirement age.

- Raising the statutory retirement age. A moderate scenario links the increase in the statutory retirement age to changes in life expectancy until reaching a ceiling of 67 for both men and women. Both scenarios assume participation rates at the average of EU countries with similar statutory retirement ages. An ambitious scenario assumes that the retirement age increases to 67 for both men and women by 2030 and links further increases in the retirement age to increases in country- and gender-specific life expectancy in subsequent years (2030 to 2050).

Two reform packages — moderate and ambitious — combine the scenarios described here. That is, the moderate reform scenario assumes a moderate rate of FLFP increase, retirement age increases in line with life expectancy, but not higher than 67 , and participation rates of older workers improving to the maximum achieved in EU countries with corresponding statutory retirement ages (Annex Table 2.2 and Annex Table 2.3). The ambitious reform scenario assumes a rapid FLFP increase, retirement age increases to 67 by 2030 (and subsequently linked to life expectancy), and participation rates of older workers at the maximum achieved in EU countries with corresponding statutory retirement ages (Annex Table 2.4). 
Annex Table 2.2. Labor Force Participation Rates of Workers Aged 55-64 Under the Moderate Policy Scenario

\begin{tabular}{|c|c|c|c|c|c|c|c|c|}
\hline & 2015 & 2020 & 2025 & 2030 & 2035 & 2040 & 2045 & 2050 \\
\hline & \multicolumn{8}{|c|}{ Men 55-64 } \\
\hline Albania & 76.0 & 74.9 & 78.7 & 82.2 & 82.5 & 82.9 & 82.8 & 82.7 \\
\hline Belarus & 63.0 & 63.7 & 65.6 & 70.4 & 73.7 & 77.2 & 79.8 & 81.9 \\
\hline Bosnia and Herzegovina & 44.1 & 49.8 & 54.4 & 61.7 & 67.4 & 73.5 & 78.2 & 80.9 \\
\hline Bulgaria & 62.7 & 72.6 & 82.7 & 83.0 & 82.7 & 82.3 & 82.6 & 81.8 \\
\hline Croatia & 54.5 & 63.7 & 72.8 & 82.8 & 82.6 & 82.5 & 82.3 & 82.0 \\
\hline Czech Republic & 68.2 & 71.9 & 74.9 & 78.6 & 80.2 & 81.8 & 82.3 & 82.1 \\
\hline Estonia & 67.7 & 70.5 & 73.1 & 77.0 & 79.5 & 82.7 & 82.8 & 81.5 \\
\hline FYR Macedonia & 67.1 & 72.1 & 77.0 & 79.6 & 82.8 & 82.8 & 82.5 & 82.3 \\
\hline Hungary & 57.6 & 63.4 & 71.7 & 77.6 & 82.9 & 81.8 & 82.5 & 82.8 \\
\hline Latvia & 68.0 & 72.4 & 77.1 & 82.9 & 82.5 & 82.9 & 82.9 & 81.9 \\
\hline Lithuania & 69.8 & 73.7 & 77.5 & 82.5 & 82.3 & 82.8 & 83.1 & 82.9 \\
\hline Moldova & 54.4 & 60.9 & 65.0 & 73.2 & 76.0 & 79.8 & 83.3 & 81.8 \\
\hline Poland & 57.7 & 68.9 & 82.4 & 83.1 & 83.1 & 82.9 & 82.1 & 82.1 \\
\hline Romania & 54.9 & 67.6 & 84.0 & 82.6 & 82.7 & 81.9 & 83.1 & 81.7 \\
\hline Russia & 60.5 & 64.6 & 66.4 & 72.5 & 74.1 & 76.9 & 79.8 & 81.6 \\
\hline Serbia & 55.1 & 61.6 & 68.0 & 74.5 & 79.1 & 81.5 & 82.8 & 82.3 \\
\hline Slovak Republic & 58.3 & 62.6 & 67.3 & 73.9 & 78.4 & 82.4 & 82.3 & 82.2 \\
\hline Slovenia & 45.5 & 57.8 & 70.2 & 82.5 & 82.8 & 82.3 & 82.1 & 81.7 \\
\hline Turkey & 50.4 & 56.4 & 62.2 & 68.2 & 72.3 & 78.1 & 82.4 & 82.5 \\
\hline \multirow[t]{2}{*}{ Ukraine } & 46.8 & 52.5 & 57.0 & 65.4 & 68.5 & 71.4 & 75.2 & 76.5 \\
\hline & \multicolumn{8}{|c|}{ Women 55-64 } \\
\hline Albania & 43.1 & 48.1 & 53.3 & 59.6 & 63.1 & 66.3 & 64.4 & 70.2 \\
\hline Belarus & 37.2 & 40.6 & 44.4 & 49.9 & 54.4 & 59.3 & 63.4 & 66.4 \\
\hline Bosnia and Herzegovina & 23.1 & 29.4 & 34.4 & 41.1 & 46.9 & 53.0 & 58.7 & 64.5 \\
\hline Bulgaria & 53.7 & 57.0 & 60.7 & 64.7 & 67.3 & 69.7 & 73.7 & 75.9 \\
\hline Croatia & 34.0 & 38.4 & 42.4 & 47.9 & 52.2 & 56.7 & 60.9 & 64.8 \\
\hline Czech Republic & 48.3 & 54.2 & 57.5 & 61.8 & 62.3 & 61.9 & 63.6 & 65.1 \\
\hline Estonia & 69.3 & 70.1 & 70.9 & 72.8 & 73.3 & 74.9 & 75.9 & 75.7 \\
\hline FYR Macedonia & 34.0 & 40.0 & 45.9 & 51.7 & 58.1 & 63.8 & 65.9 & 69.9 \\
\hline Hungary & 39.7 & 43.9 & 52.3 & 57.5 & 61.6 & 64.2 & 65.6 & 66.4 \\
\hline Latvia & 63.5 & 65.5 & 67.6 & 71.3 & 73.6 & 76.9 & 77.0 & 76.0 \\
\hline Lithuania & 63.3 & 64.4 & 65.2 & 68.0 & 69.6 & 72.4 & 75.1 & 77.0 \\
\hline Moldova & 35.8 & 42.3 & 46.4 & 54.4 & 60.7 & 65.0 & 67.6 & 64.0 \\
\hline Poland & 37.5 & 39.5 & 44.9 & 50.7 & 54.8 & 58.2 & 60.8 & 64.9 \\
\hline Romania & 34.6 & 39.3 & 48.6 & 52.7 & 58.9 & 63.8 & 71.3 & 75.9 \\
\hline Russia & 40.8 & 44.8 & 47.6 & 54.9 & 59.0 & 63.6 & 65.7 & 63.3 \\
\hline Serbia & 29.2 & 35.7 & 42.1 & 48.6 & 54.3 & 59.8 & 64.6 & 65.4 \\
\hline Slovak Republic & 51.8 & 53.0 & 54.7 & 59.5 & 61.3 & 61.5 & 63.4 & 65.0 \\
\hline Slovenia & 32.2 & 37.1 & 41.7 & 46.1 & 52.1 & 55.9 & 60.3 & 64.5 \\
\hline Turkey & 18.4 & 24.3 & 30.3 & 36.3 & 42.2 & 48.2 & 53.3 & 56.3 \\
\hline Ukraine & 28.4 & 34.3 & 39.5 & 46.8 & 52.9 & 58.7 & 63.3 & 63.8 \\
\hline
\end{tabular}


Annex Table 2.3. Labor Force Participation Rates of Workers Aged 55-64 Under the Ambitious Policy Scenario

\begin{tabular}{|c|c|c|c|c|c|c|c|c|}
\hline & 2015 & 2020 & 2025 & 2030 & 2035 & 2040 & 2045 & 2050 \\
\hline & \multicolumn{8}{|c|}{ Men 55-64 } \\
\hline Albania & 76.0 & 74.9 & 78.7 & 82.2 & 82.5 & 85.7 & 88.5 & 90.0 \\
\hline Belarus & 63.0 & 64.7 & 66.3 & 72.7 & 76.8 & 80.9 & 84.4 & 88.0 \\
\hline Bosnia and Herzegovina & 44.1 & 49.8 & 54.4 & 61.7 & 67.4 & 73.5 & 78.2 & 80.9 \\
\hline Bulgaria & 62.7 & 69.3 & 76.1 & 83.0 & 83.9 & 84.8 & 86.2 & 87.1 \\
\hline Croatia & 54.5 & 63.7 & 72.8 & 82.8 & 83.6 & 84.4 & 85.3 & 86.1 \\
\hline Czech Republic & 68.2 & 73.7 & 78.4 & 83.4 & 84.5 & 85.7 & 87.8 & 89.7 \\
\hline Estonia & 67.7 & 72.5 & 77.2 & 83.1 & 83.9 & 85.4 & 86.7 & 87.7 \\
\hline FYR Macedonia & 67.1 & 72.1 & 76.1 & 79.6 & 82.8 & 85.7 & 88.4 & 90.0 \\
\hline Hungary & 57.6 & 65.5 & 75.5 & 83.4 & 84.2 & 84.8 & 86.6 & 88.1 \\
\hline Latvia & 68.0 & 72.4 & 77.1 & 82.9 & 83.9 & 85.6 & 86.9 & 88.0 \\
\hline Lithuania & 69.8 & 73.7 & 77.5 & 82.5 & 83.8 & 85.6 & 87.1 & 88.5 \\
\hline Moldova & 54.4 & 60.9 & 65.0 & 73.2 & 79.3 & 82.1 & 84.6 & 86.5 \\
\hline Poland & 57.7 & 64.6 & 73.9 & 83.1 & 84.2 & 85.0 & 85.6 & 86.8 \\
\hline Romania & 54.9 & 62.8 & 75.2 & 82.6 & 83.7 & 84.1 & 85.9 & 86.2 \\
\hline Russia & 60.5 & 67.5 & 73.6 & 83.4 & 84.3 & 85.8 & 86.9 & 87.9 \\
\hline Serbia & 55.1 & 61.6 & 68.0 & 74.5 & 79.1 & 81.5 & 84.8 & 87.5 \\
\hline Slovak Republic & 58.3 & 65.9 & 74.0 & 83.2 & 84.5 & 85.5 & 87.0 & 88.5 \\
\hline Slovenia & 45.5 & 57.8 & 70.2 & 82.5 & 83.7 & 84.2 & 85.0 & 85.8 \\
\hline Turkey & 50.4 & 56.4 & 62.2 & 68.2 & 74.1 & 79.9 & 84.3 & 85.4 \\
\hline \multirow[t]{2}{*}{ Ukraine } & 46.8 & 52.5 & 57.0 & 65.4 & 70.5 & 73.4 & 75.2 & 76.5 \\
\hline & \multicolumn{8}{|c|}{ Women 55-64 } \\
\hline Albania & 43.1 & 48.1 & 53.3 & 59.6 & 65.8 & 72.0 & 75.1 & 79.2 \\
\hline Belarus & 37.2 & 42.1 & 47.4 & 54.4 & 60.4 & 66.8 & 72.4 & 74.6 \\
\hline Bosnia and Herzegovina & 23.1 & 29.4 & 34.4 & 41.1 & 46.9 & 53.0 & 59.1 & 64.9 \\
\hline Bulgaria & 53.7 & 61.4 & 69.3 & 77.2 & 78.6 & 79.9 & 81.9 & 83.4 \\
\hline Croatia & 34.0 & 48.1 & 62.0 & 77.0 & 77.3 & 77.7 & 77.9 & 78.1 \\
\hline Czech Republic & 48.3 & 58.7 & 68.1 & 77.7 & 78.8 & 79.9 & 82.0 & 83.8 \\
\hline Estonia & 69.3 & 71.6 & 73.8 & 77.1 & 78.6 & 80.8 & 82.7 & 84.5 \\
\hline FYR Macedonia & 34.0 & 40.0 & 45.9 & 51.7 & 58.1 & 64.1 & 69.7 & 73.3 \\
\hline Hungary & 39.7 & 51.2 & 65.7 & 77.5 & 78.2 & 78.5 & 80.3 & 81.7 \\
\hline Latvia & 63.5 & 67.4 & 71.5 & 76.9 & 78.4 & 80.5 & 82.3 & 83.9 \\
\hline Lithuania & 63.3 & 67.2 & 71.1 & 76.7 & 78.3 & 80.5 & 82.6 & 84.4 \\
\hline Moldova & 35.8 & 42.3 & 46.4 & 54.4 & 60.7 & 66.8 & 73.1 & 74.2 \\
\hline Poland & 37.5 & 48.9 & 63.2 & 77.4 & 78.2 & 78.7 & 79.0 & 79.9 \\
\hline Romania & 34.6 & 47.4 & 64.4 & 76.7 & 77.4 & 77.0 & 78.7 & 78.1 \\
\hline Russia & 40.8 & 52.4 & 63.4 & 77.4 & 77.9 & 78.8 & 79.4 & 79.2 \\
\hline Serbia & 29.2 & 35.7 & 42.1 & 48.6 & 54.3 & 59.8 & 66.2 & 71.5 \\
\hline Slovak Republic & 51.8 & 59.5 & 67.8 & 77.4 & 79.3 & 81.0 & 83.1 & 85.3 \\
\hline Slovenia & 32.2 & 47.1 & 61.9 & 76.6 & 77.8 & 78.1 & 78.7 & 79.3 \\
\hline Turkey & 18.4 & 24.3 & 30.3 & 36.3 & 42.2 & 48.2 & 54.1 & 60.1 \\
\hline Ukraine & 28.4 & 34.3 & 39.5 & 46.8 & 52.9 & 58.7 & 64.3 & 68.6 \\
\hline
\end{tabular}




\section{Annex Table 2.4. Statutory Retirement Ages}

\begin{tabular}{lcc}
\hline Country & Retirement age men & Retirement age women \\
\hline Albania & 65.0 & 63.0 \\
Belarus & 60.0 & 55.0 \\
Bosnia and Herzegovina & 65.0 & 65.0 \\
Bulgaria & 63.9 & 61.1 \\
Croatia & 65.0 & 61.5 \\
Czech Republic & 63.7 & 62.0 \\
Estonia & 63.0 & 63.0 \\
\hline North Macedonia & 64.0 & 62.0 \\
Hungary & 64.1 & 64.1 \\
Latvia & 63.8 & 63.8 \\
\hline Lithuania & 63.3 & 61.7 \\
Moldova & 62.0 & 57.0 \\
Poland & 65.0 & 60.0 \\
Romania & 64.8 & 60.4 \\
Russia & 60.0 & 55.0 \\
\hline Serbia & 65.0 & 63.0 \\
Slovakia & 62.7 & 61.5 \\
\hline Slovenia & 65.0 & 64.0 \\
Turkey & 60.0 & 58.0 \\
Ukraine & 60.0 & 57.0 \\
\hline Average WE & 65.6 & 65.2 \\
\hline Note: WE Western Eur. & & \\
\hline
\end{tabular}

Note: WE = Western Europe. 


\section{Annex 3. Projecting Pension and Health Care Costs}

\section{Baseline Pension and Health Care Projections}

Pension expenditure (PE) to GDP is calculated as the product of four key components: (1) the replacement rate, calculated as the average pension over average output per worker; (2) the coverage ratio, expressed as the share of pensioners in the total population above the retirement age (above 65); (3) the old-age dependency ratio, measured as the ratio of population above 65 to the working-age population (15-64); and (4) the inverse of labor participation, defined as the share of workers in the total working-age population. ${ }^{1}$

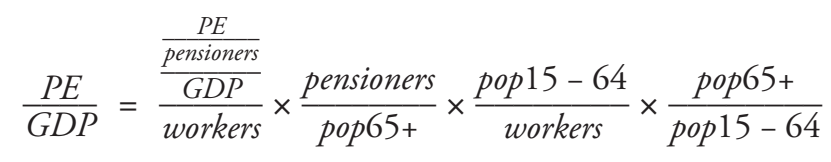

This implies that pension spending grows in line with the old-age dependency ratio. Intuitively, changes in the old-age dependency ratio affect spending through exogenous changes in either the older population or the working-age population. For example, assuming constant benefit and coverage ratios, an increase in the population ages 65 and older due to an unexpected increase in longevity would translate into higher pension spending for the same level of GDP, thereby increasing pension expenditure to GDP.

Health care expenditure (HE) to GDP is expressed as the product of three elements: (1) the generosity of the health care package for the young (average health spending per population 0-64 to GDP per capita); (2) the inverse of the labor force participation rate for the population 0-64; and (3) a function that depends on the ratio of the per capita health spending for the older population to the per capita health spending for the young $(\alpha)$ and the old-age dependency ratio

\footnotetext{
${ }^{1}$ Amaglobeli and Shi 2016.
} 


$$
\frac{H E}{G D P}=\frac{\frac{H E_{0-64}}{p o p 0-64}}{\frac{\mathrm{GDP}}{\text { workers }}} \times \frac{\text { pop } 0-64}{\text { workers }} \times\left(1+\alpha \times \frac{\text { pop65+ }}{\text { pop } 0-64}\right) ; \text { where } \alpha=\frac{\frac{H E_{65+}}{\text { Popul65+ }}}{\frac{H E_{0-64}}{\text { Popul0 - 64 }}}
$$

Similar to pensions, an exogenous increase in the number of elderly increases health care spending (more people receive a relatively high per capita health benefit).

\section{Policy Scenarios for Pensions}

The reform packages proposed in Chapter 3 are assessed through equation (1) in order to determine their impact on pension spending, as follows:

- The replacement rate (first component in equation 1 ) is set to take a value of at least 40, which is the minimum recommended replacement rate. As a result, pension spending increases in countries and years in which the replacement rate was originally below the set value.

- The participation of young women and old workers in the labor market inversely affects pension spending through the old-age dependency ratio (third component in equation 1). That is, policies that boost labor force participation (at different growth rates as set in the moderate and ambitious scenarios) will reduce pension spending.

- Modifying the statutory retirement age indirectly affects pension spending through the coverage ratio (second component in equation 1). That is, policies aimed at increasing the statutory retirement age (at different speeds as set in the moderate and ambitious scenarios) will reduce the share of pensioners in the total population above 65 , thus reducing pension spending. 


\section{Annex 4. Estimating the Effects of Aging on Productivity}

A production function approach forms the basis for our empirical investigation. The standard Cobb-Douglas production function with constant returns to scale, can be expressed as:

$$
y_{i t}=\left(\frac{K}{Y}\right)_{i t}^{\frac{\alpha}{1-\alpha}} A_{i t} h_{i t}
$$

where $y_{i t}$ is output per worker, $K$ is capital per worker, $Y$ is output, $A_{i t}$ is TFP, $h_{i t}$ is human capital per worker, and $\alpha$ is the share of capital in output. We assume that the age structure of the workforce may have an impact on productivity growth:

$$
\Delta \log y_{i t}=\mathrm{f}\left(\sum_{s} \beta_{s} w_{s i t}\right)
$$

where $w_{s i t}$ is the share of each age cohort $s$ in the workforce and $\beta_{s}$ is the contribution of this age cohort to productivity growth.

The workforce age structure could affect labor productivity through several channels. Labor productivity can be determined by a combination of several drivers (equation 1)—capital intensity, human capital, and TFP—that could act as transmission channels from workforce aging to labor productivity. In the subsequent analysis, we examine the relative importance of each.

The empirical analysis of the impact of workforce aging on labor productivity growth and its main drivers follows Feyrer (2007); Aiyar, Ebeke, and Shao (2016); and Adler and others (2017), with a regression specification taking the form 


$$
\Delta \log Y L_{i t}=\alpha_{i}+\gamma_{t}+\sum_{s} \beta_{s} w_{s i t}+\delta y a d r_{i t}+\varphi o a d r_{i t}+\varepsilon_{i t}
$$

where $Y L_{i t}$ denotes output per worker, $\alpha_{i}$ is a country fixed effect, $\gamma_{t}$ are time dummies for several periods (1990-95, 1998-99, and 2008-09), oadr $r_{i t}$ is the old-age dependency ratio, and $y a d r_{i t}$ is the young-age dependency ratio.

We further decompose labor productivity to understand the relative importance of the channels through which workforce aging operates, thus estimating four equations, one for each of labor productivity: (physical) capital, human capital, and TFP. Regressing each component of the production function on the workforce age composition measures will therefore gauge whether workforce aging affects worker productivity through factor accumulation or TFP.

The regressions are potentially plagued by endogeneity issues. For example, experienced individuals may supply more labor in response to labor-augmenting technological innovations and people may migrate to higher-productivity countries. At the same time, higher income arising from faster aggregate productivity growth may induce older workers to leave the labor force (Adler and others 2017). To address the possible endogeneity bias, we instrument the worker age shares with the 10-year lagged shares of the respective population cohorts and instrument the youth and old-age dependency ratios with the 10-year lag of the population share under the age of 4 and the population share of those aged 55 to 59 years, respectively.

The estimation uses a panel data set with 167 countries over 1990-2014. Population data are taken from the UN World Population Prospects (2017) database and are available from 1950 onwards. The workforce data are from ILOSTAT. The young and old-age dependency ratios are calculated as the share of the population aged 0 to 14 and $65+$ to the active population aged 15 to 64, respectively. The output per worker, capital stock, human capital, and TFP data, which end in 2014, are taken from the Penn World Table 9.0.

The regressions (Table 4 in the main text) were subjected to several robustness checks and alternative specifications. In a specification that included all age cohorts except for the 45- to 54-year reference group, all coefficients except those for the older workers were insignificant. (The value for the significant coefficient was about -0.8.) Limiting the impact of outliers by excluding small countries with populations of less than 1 million, excluding oil and commodity exporting countries, and limiting the sample to European countries yielded a coefficient with an unchanged sign and broadly similar magnitude while maintaining statistical significance at the 1 percent level. Furthermore, we explored whether the impact on TFP growth could be region specific by interacting the old-age worker share with sub-CESEE 
regional dummies. The results were either broadly consistent with the findings from the specifications in Table 4 or insignificant. A quadratic term of the old-age worker share was added to gauge whether the marginal impact of a change in the share depends on its initial level, but the results were implausible, possibly because instrumentation becomes difficult in this case. To control for structural characteristics, we added the uninstrumented share of manufacturing in total value added, which yields a slightly lower coefficient on the older worker share. To gauge whether the impact of an aging workforce differs across occupations, we interacted the old-age worker share with the share of people employed in different occupations along the lines of Box 4. The results were counterintuitive or insignificant, which is most likely again related to problems of finding suitable instruments for additional regressors and in particular interacted ones. Similarly, we explored whether the impact on TFP growth varies with education by using data on educational attainment shares within the older worker cohort, which again did not yield further insights. 
This page intentionally left blank 


\section{Annex 5. Evaluating Growth Prospects Through a Production Function Approach}

A simple Cobb-Douglas production function can be used to provide a benchmark assessment of the impact of labor supply and TFP on growth and convergence.

A simplifying assumption used here to focus on labor supply and TFP is to assume balanced growth, in which the capital-to-output ratio remains constant. This yields the expression

$$
g Y=g K=g A / \alpha+g L
$$

where $g Y$ is output growth, $g K$ is capital growth, $g A$ is TFP growth, $g L$ is labor growth, and $\alpha$ is the labor income share. The aging impact is estimated as the difference in growth rates between the "aging" and the "no-change" scenarios:

$$
g Y^{\text {aging }}-g Y^{\text {no-change }}=\left(g A^{\text {aging }}-g A^{\text {no-change }}\right) / \alpha+\left(g L^{\text {aging }}-g L^{\text {no-change }}\right),
$$

where the "no-change" scenario assumes the size of the labor force is constant and the rate of TFP growth is the same as in the initial year (here, 2023, to be consistent with current staff forecasts for CESEE). This implies that $g L^{\text {no-change }}=0$ and $g A^{\text {no-change }}=g A_{2023}$. The aging scenario incorporates the projected demographic changes: (1) the growth rate of labor supply ( $\left.g L^{\text {aging }}\right)$, and (2) the growth rate of TFP (derived by multiplying the change in the share of older workers by the coefficient estimated in Chapter 5):

$$
g A^{\text {aging }}-g A^{\text {no-change }}=-0.608 *\left(\text { Share } 55+\text { aging }- \text { Share } 55+{ }^{2023}\right)
$$


Hence, this simplified framework only requires a few inputs in estimating the aging impact, as shown in Annex Table 5.1.

Annex Table 5.1. Inputs for Productivity Projections

\begin{tabular}{ll}
\hline Key Inputs & \multicolumn{1}{c}{ Data Sources } \\
\hline Labor force projections & IMF staff estimates (Section III) \\
Projected share of older workers (55+) and the initial value in 2023 & UN demographic database \\
Regression coefficient of the share of older workers on total factor productivity growth & IMF staff estimates (Section V) \\
Labor income share & Penn World Tables version 9.1 \\
\hline
\end{tabular}




\section{Annex 6. The EEUMOD Macroeconomic Model and Simulations}

The Flexible System of Global Models (FSGM) is a group of multicountry models developed by the IMF for policy analysis. Each FSGM module is an annual frequency, multiregion, general equilibrium model of the global economy combining both micro-founded and reduced-form formulations (to ensure computational feasibility) of various economic sectors. Each country or regional block is structurally identical, but with potentially different key steady-state ratios and behavioral parameters. These are calibrated individually for the respective countries or blocks. ${ }^{1}$

The Europe-oriented version (EEUMOD) of the IMF's Flexible System of Global Models models nine individual Central, Eastern, and Southeastern European countries and six Central, Eastern, and Southeastern European country blocks. Countries modeled individually are Bulgaria, Croatia, the Czech Republic, Hungary, Poland, Romania, Russia, Serbia, and Ukraine. The country blocks are the remainder of Eastern Europe (Belarus and Moldova); Central European Euro Area (Estonia, Latvia, Lithuania, Slovakia, Slovenia); Southeastern Europe (Albania, Bosnia and Herzegovina, Republic of North Macedonia, Montenegro); two euro area blocks (Austria, Belgium, Germany, Finland, France, Ireland, Netherlands, Portugal, Luxembourg, Malta; Greece, Italy, Spain, and Cyprus); and an Other European Union block (Denmark, Sweden, the United Kingdom). The rest of the world is split into the United States, China, Japan, Turkey, and aggregated blocks for Emerging Asia, Latin America, Other Advanced Countries, Oil Exporters, and Remaining Countries.

Increased health care costs are modeled as an increase in public consumption spending as a share of GDP, whereas higher public pension spending takes the form of increased general transfers to households. For simplicity, public investment spending as a share of GDP is assumed to stay unchanged.

${ }^{1}$ For a full description of the model, see Andrle and others (2015). 
Deficits are financed by public debt until 2050, after which time public debt is stabilized using (lump-sum) general transfers as the fiscal instrument. The sovereign interest rate is assumed to include a risk premium that increases with the level of public indebtedness. Per the evidence in Laubach (2009), the sovereign risk premium increases by three basis points for each percentage point of GDP increase in the level of public debt. 


\section{Annex 7. The IMF's External Balance Assessment Model of Current Account Balances}

The IMF External Balance Assessment (EBA) methodology was developed in 2013 for assessing current accounts and exchange rates. ${ }^{1}$ The coefficients in the EBA current account model are estimated from a panel regression covering a sample of 49 countries. The empirical specification is informed by structural models of demographic transition, which commonly focus on two drivers of demographic trends: first, the age composition (the "static" effect), driven mostly by declining fertility rates; and second, the old-age survival risk (the "dynamic" effect), the key driver of household savings in quantitative models.

Three variables in the empirical model aim to capture "static" effects of demographics on the current account: total population growth; the old-age dependency ratio, expressed as the size of population age 65 and up as a share of the working-age population aged 30 to 64; and the current share of prime savers (that is, those aged 45 to 64 years) as a share of the working-age population (here, those aged 30 to 64), to capture the "hump-shaped" savings profile implied by life-cycle models.

- Population growth. Relatively low population growth is associated with higher current account balances. This is consistent with decreases in the youth dependency ratio and therefore the share of nonsavers. Also, lower population growth would imply less investment (for a given capital-to-labor ratio), which would also increase current account balances.

- The old-age dependency ratio. A relatively high old-age dependency ratio is associated with lower current account balances, as it reflects a higher share of consumers relative to savers.

- The share of prime-age savers. An increase in the share of prime-age savers is found, as expected, to boost current account balances.

${ }^{1}$ See Phillips and others 2013; IMF 2015a, 2018. 
These are complemented by two variables that aim to capture "dynamic" (or longevity) effects of demographics on the current account - the remaining life expectancy of the current prime-age saver cohort and the interaction of longevity with future old-age dependency — to capture the extent to which current savers expect to rely on future workers for their old-age support.

- The life expectancy of prime-age savers. This variable should capture both mortality risk during working age and life expectancy at retirement. An increase in life expectancy in countries with relatively low initial life expectancy tends to be associated with lower current account balances-in such countries, it increases the incentives to invest. As countries become wealthier, their financial markets deeper, and their populations older, an increase in life expectancy increasingly has a positive effect on saving, driven by the need to finance old-age consumption and boosted by higher precautionary savings in response to the uncertainties of the costs of long-term elderly care. Across the sample, an increase in life expectancy is associated with a very small negative effect on current account balances.

- Life expectancy at prime age interacted with future old-age dependency ratio. This variable aims to capture the likely returns from formal and informal old-age transfer systems - that is, workers can be expected to save more not only when they expect to live longer, but also when they expect to rely less on future generations for support. An increase is associated with an increase in current account balances.

The estimates show expected signs and significant coefficients (with the exception of the old-age dependency ratio) for the variables that capture static and dynamic effects (Annex Table 7.1).

\section{Annex Table 7.1. EBA Current Account Model: Demographic \\ Variables}

\begin{tabular}{lc}
\hline Demographics & EBA regression coefficient \\
\hline Population Growth & -0.692 \\
Old-age Dependency Ratio (OADR) & -0.069 \\
Prime Savers Share & 0.138 \\
Life Expectancy at Prime Age & -0.005 \\
Life Expectancy at Prime Age ${ }^{\star}$ Future OADR & 0.013 \\
\hline
\end{tabular}

Note: All demographic variables are constructed relative to world average. 
The empirical model is applied to projections of demographic variables to estimate the impact of the demographic trends on current account balances. First, the five demographic variables are projected for each CESEE country from 2015 to 2050, using the same UN population database (but with slightly different definitions of some variables compared with previous sections, particularly for the working-age population). Next, the deviations of these variables from the corresponding world averages are calculated. Then the estimated coefficients from the current account model are applied to the projected demographic variables. The result is a set of projections of the effects of demographics on the so-called current account "norm" - the value of the current account implied by the empirical model if all policies were at desirable levels, and all other regressor variables were at their actually observed levels_-abstracting from other effects on current account balances. This exercise assumes that nondemographic EBA variables are constant and does not consider the impact of demographic changes on other macro or policy determinants. Instead of showing the overall level of current account norms, the simulation results indicate the contribution of demographic variables to current norms, which may better illustrate the trend of the external balances of Central, Eastern, and Southeastern European countries. 
This page intentionally left blank 


\section{References}

Acemoglu, Daron. 2002. "Technical change, inequality, and the labor market." Journal of economic literature 40 (1): 7-72.

Acemoglu, Daron, and Simon Johnson. 2005. "Unbundling Institutions." Journal of Political Economy 113 (5): 949-95.

Acemoglu, Daron, Ufuk Akcigit, Murat Alp and Celik. 2014. "Young, restless and creative: Openness to disruption and creative innovations.” NBER Working Paper 19894, National Bureau of Economic Research, Cambridge, MA.

Acemoglu, Daron, and Pascual Restrepo. 2017. "Secular Stagnation? The Effect of Aging on Economic Growth in the Age of Automation.” NBER Working Paper 23077, National Bureau of Economic Research, Cambridge, MA.

. 2018a. "Demographics and Automation." NBER Working Paper 24421, National Bureau of Economic Research, Cambridge, MA.

. 2018b. "Robots and Jobs: Evidence From US Labor Markets.” NBER Working Paper 23285, National Bureau of Economic Research, Cambridge, MA.

—. Forthcoming. "Artificial Intelligence, Automation and Work." Economics of Artificial Intelligence.

Adler, Gustavo, Romain Duval, Davide Furceri, Sinem Kilic Celik, Ksenia Koloskova, and Marcos Poplawski-Ribeiro. 2017. "Gone with the Headwinds: Global Productivity.” IMF Staff Discussion Note 17/04, International Monetary Fund, Washington, DC.

Aiyar, Shekhar, and Ashoka Mody. 2013. "The Demographic Dividend:

Evidence from the Indian States." India Policy Forum, National Council of Applied Economic Research 9 (1): 105-48. 
Aiyar, Shekhar, Christian Ebeke, and Xiabao Shao. 2016. "The Impact of Workforce Aging on European Productivity.” IMF Working Paper 16/238, International Monetary Fund, Washington, DC.

Aksoy, Yunus, Henrique Basso, Tobias Grasl, and Ron Smith. 2015. "Demographic Structure and Macroeconomic Trends.” Birkbeck Working Papers in Economics and Finance 1501, Birkbeck University, London.

Amaglobeli, David, and Wei Shi. 2016. "How to Assess Fiscal Implications of Demographic Shifts: A Granular Approach.” How To Note, International Monetary Fund, Washington, DC.

Andrle, Michal, Patrick Blagrave, Pedro Espaillat, Keiko Honjo, Benjamin Hunt, Mika Kortelainen, René Lalonde, Douglas Laxton, Eleonora Mavroeidi, Dirk Muir, Susanna Mursula, and Stephen Snudden. 2015. "The Flexible System of Global Models-FSGM.” IMF Working Paper 15/64, International Monetary Fund, Washington, DC.

Arslanalp, Serkan, Jaewoo Lee, and Umang Rawat. 2017. "Demographics and Interest Rates in Asia." IMF Working Paper 18/172, International Monetary Fund, Washington, DC.

Atoyan, Ruben, Lone Christiansen, Allan Dizioli, Christian Ebeke, Nadeem Ilahi, Anna Ilyina, Gil Mehrez, Haonan Qu, Faezeh Raei, Alaina Rhee, and Daria Zakharova. 2016. "Emigration and Its Economic Impact on Eastern Europe.” IMF Staff Discussion Note 16/07, International Monetary Fund, Washington, DC.

Azose, Jonathan A., Hana Sevcikova, and Adrian E. Raferty. 2016. "Probabilistic Population Projections with Migration Uncertainty." Proceedings of the National Academy of Sciences 113 (3): 6460-65.

Barro, Robert, and Jong-Wha Lee. 2010. "A New Data Set of Educational Attainment in the World, 1950-2010." Journal of Development Economics 104: 184-98.

Batini, Nicoletta, Tim Callen, and Warwick McKibbin. 2006. "The Global Impact of Demographic Change.” IMF Working Paper 06/9, International Monetary Fund, Washington, DC.

Blanchard, Olivier, Florence Jaumotte, and Prakash Loungani. 2014. "Labor Market Policies and IMF Advice in Advanced Economies During the Great Recession.” IZA Journal of Labor Policy 3 (1): 1-23.

Bloom, David, David Canning, and Pia Malaney. 2000. "Population Dynamics and Economic Growth in Asia." Population and Development Review 26 (Supplement): 257-90. 
Börsch-Supan, Axel, and Matthias Weiss. 2016. "Productivity and age: Evidence from work teams at the assembly line." The Journal of the Economics of Ageing 7: 30-42.

Bown, Chad P., and Caroline Freund. 2019. "Active Labor Market Policies: Lessons from Other Countries for the United States.” Working Paper 19-2, Peterson Institute for International Economics, Washington, DC.

Bradshaw, Jonathan, and Kenichi Hirose. 2016. Child Benefits in Central and Eastern Europe: A Comparative Review. Budapest: International Labour Organization.

Bussolo, Maurizio, Johannes Koettl, and Emily Sinnott. 2015. Golden Aging: Prospects for Healthy, Active, and Prosperous Aging in Europe and Central Asia. Washington, DC: World Bank.

Card, David, Jochen Kluve, and Andrea Weber. 2010. "Active Labor Market Policy Evaluations: A Meta-Analysis.” The Economic Journal 120 (November): F452-F477.

Carvalho, Carlos, Andrea Ferrero, and Fernando Nechio. 2016. "Demographics and Real Interest Rates: Inspecting the Mechanism." European Economic Review 88: 208-26.

Chiacchio, Francesco, Georgios Petropoulos, and David Pichler. 2018. "The Impact of Industrial Robots on EU Employment and Wages: A Local Labour Market Approach.” Working Paper Issue 2, Bruegel, Josse-ten-Noode, Belgium.

Clements, Benedict, David Coady, and Sanjeev Gupta. 2012. The Economics of Public Health Care Reform in Advanced and Emerging Economies. Washington, DC: International Monetary Fund.

Clements, Benedict, Frank Eich, and Sanjeev Gupta (eds.). 2014. Equitable and Sustainable Pensions: Challenges and Experience. Washington: International Monetary Fund.

Clements, Benedict, Kamil Dybczak, Vitor Gaspar, Sanjeev Gupta, and Mauricio Soto. 2015. "The Fiscal Consequence of Shrinking Populations.” IMF Staff Discussion Note 15/21, International Monetary Fund, Washington, DC.

Cutler, David M., James M. Poterba, Louise Sheiner, and Lawrence H. Summers. 1990. "An Aging Society: Opportunity or Challenge?” Brookings Papers on Economic Activity 21 (1).

Dao, Mai Chi, and Callum Jones. 2018. "Demographics, Old-Age Transfers and the Current Account.” IMF Working Paper 18/264, International Monetary Fund, Washington, DC. 
Disney, Richard. 1996. Can We Afford to Grow Older? A Perspective on the Economics of Aging. Cambridge, MA: MIT Press.

Dixon, Sylvia. 2003. "Implications of population ageing for the labour market." Labour Market Trends 111(2): 67-76.

Égert, Balázs, and Peter Gal. 2016. "The Quantification of Structural Reforms in OECD Countries: A New Framework." OECD Economics Department Working Papers 1354, Organisation for Economic Co-operation and Development, Paris.

Eggertsson, Gauti B., Manuel Lancastre, and Lawrence H. Summers. 2018. "Aging, Output per Capita and Secular Stagnation." NBER Working Paper 24902, National Bureau of Economic Research, Cambridge, MA.

European Bank for Reconstruction and Development. 2019. Transition Report 2018-2019. London.

European Commission. 2015. The Aging Report: Economic and budgetary projections for the 28 EU Member States (2013-2060). Brussels: European Commission.

- 2018. The 2018 Ageing Report: Economic and Budgetary Projections for the 28 EU Member States (2016-2070). Brussels: European Commission.

Ferrero, Giuseppe, Marco Gross, and Stefano Neri. 2017. “On Secular Stagnation and Low Interest Rates: Demography Matters." ECB Working Paper 2088, European Central Bank, Frankfurt.

Feyrer, James. 2007. "Demographics and Productivity." Review of Economics and Statistics 89 (1): 100-09.

_. 2008. "Aggregate Evidence on the Link Between Age Structure and Productivity." Population and Development Review 34: 78-99.

Gagnon, Etienne, Benjamin K. Johannsen, and David Lopez-Salido. 2016. "Understanding the New Normal: The Role of Demographics." Finance and Economics Discussion Series 2016-080, Board of Governors of the Federal Reserve System, Washington, DC.

Galenson, David W., and Bruce Weinberg. 2000. "Age and the Quality of Work: Modern American Painters." Journal of Political Economy 108: 761-77.

Galenson, David W., and Bruce Weinberg. 2005. "Creative Careers: The Life Cycles of Nobel Laureates in Economics." NBER Working Paper 11799, National Bureau of Economic Research, Cambridge, MA.

Göbel, Christian, and Thomas Zwick. 2012. "Age and Productivity: Sector Differences.” De Economist 160 (1): 35-57. 
Habakkuk, John. 1962. American and British Technology in the Nineteenth Century. Cambridge: Cambridge University Press.

Hanushek, Eric A., and Ludger Woessmann. 2010. "Education and Economic Growth." In International Encyclopedia of Education, edited by Penelope Peterson, Eva Baker, and Barry McGaw, volume 2, 245-52. Oxford: Elsevier.

. 2012. "Do Better Schools Lead to More Growth? Cognitive Skills, Economic Outcomes, and Causation.” Journal of Economic Growth 17: 267-321.

- 2017. "School Resources and Student Achievement: A Review of Cross-Country Economic Research." In Cognitive Abilities and Educational Outcomes: A Festschrift in Honour of Jan-Eric Gustafsson, edited by Monica Rosén, Kajsa Yang Hansen, and Ulrika Wolff, Chapter 8. New York: Springer.

Hall, Robert E., and Charles I. Jones. 1995. "Why Do Some Countries Produce So Much More Output per Worker than Others?" Quarterly Journal of Economics 114: 83-116.

Hoorens, Stijn, Jack Clift, Laura Staetsky, Barbara Janta, Stephanie Diepeveen, Molly Morgan Jones, and Jonathan Grant. 2011. Low Fertility in Europe: Is There Still Reason to Worry? Arlington, VA: RAND Corporation.

Hopenhayn, Hugo, Julian Neira, and Rish Singhania. 2018. "From Population Growth to Firm Demographics: Implications for Concentration, Entrepreneurship and the Labor Share." NBER Working Papers 25382, National Bureau of Economic Research, Cambridge, MA.

Hsieh, Chang-Tai, Erik Hurst, Charles I. Jones, and Peter J. Klenow. 2018. "The Allocation of Talent and U.S. Economic Growth." Manuscript.

Hsieh, Chang-Tai, and Peter J. Klenow. 2016. "Productivity and Misallocation.” NBER Reporter 2016 Number I: Research Summary, National Bureau of Economic Research, Cambridge, MA.

International Monetary Fund (IMF). 2014. Fiscal Monitor: Back to Work: How Fiscal Policy Can Help. Washington, October.

- 2015a. Technical Background Note: 2015 Refinements to the External Balance Assessment (EBA) Methodology. Washington: International Monetary Fund.

- 2015b. "Structural Reforms and Macroeconomic Performance: Initial Considerations for the Fund.” International Monetary Fund, Washington, DC.

_. 2016a. "Methodological Note on EBA-Lite." IMF Policy Paper, International Monetary Fund, Washington, DC. 
- 2016b. Regional Economic Issues: Central, Eastern and Southeastern Europe-Effective Government for Stronger Growth. Washington, November.

_. 2016c. "Republic of Latvia: Selected Issues Paper." IMF Country Report 16/172, International Monetary Fund, Washington, DC.

_. 2016d. "Time for a Supply-Side Boost? Macroeconomic Effects of Labor and Product Market Reforms in Advanced Economies." In World Economic Outlook. Washington, April.

—. 2017. "Asia: At Risk of Growing Old before Becoming Rich?” In Regional Economic Outlook: Asia and Pacific. Washington, April.

- 2018. External Sector Report-Refinements to the External Balance Assessment Methodology_Technical Supplement. Washington: International Monetary Fund.

Jaimovich, Nir, and Henry Siu. 2009. "The Young, the Old, and the Restless: Demographics and Business Cycle Volatility." American Economic Review 99 (3): 804-26.

Jones, Benjamin F. 2005. “Age and Great Invention.” NBER Working Paper 11359, National Bureau of Economic Research, Cambridge, MA.

Jones, Charles I. 2005. "Growth and Ideas." In Handbook of Economic Growth, edited by P. Aghion and S. Durlauf, volume 1B, 1063-11. New York: Elsevier.

Kalwij, Adriaan. 2010. "The Impact of Family Policy Expenditure on Fertility in Western Europe.” Demography 47 (2): 503-19.

Kanavos, Panos, Anna-Maria Fontrier, Jennifer Gill, Olina Efthymiadou, and Nicola Boekstein. 2017. The Impact of External Reference Pricing Within and Across Countries. London: London School of Economics.

Kreuger, Dirk, and Alexander Ludwig. 2007. "On the Consequences of Demographic Change for Rates of Returns to Capital, and the Distribution of Wealth and Welfare." Journal of Monetary Economics 54: 49-87.

Laubach, Thomas. 2009. "New Evidence on the Interest Rate Effects of Budget Deficits and Debt." Journal of the European Economic Association 7: 858-85.

Liang, James, Hui Wang, and Edward P. Lazear. 2018. "Demographics and Entrepreneurship.” Journal of Political Economy 216: S140-96.

Lindh, Thomas, and Bo Malmberg. 1999. "Age Structure Effects and Growth in the OECD 1950-1990." Journal of Population Economics 12: 431-49.

Lutz, Wolfgang, Jesus Crespo Cuaresma, and Warren Sanderson. 2008. "The Demography of Educational Attainment and Economic Growth.” Science 319: 1047-48. 
Maestas, Nicole, Kathleen J. Mullen, and David Powell. 2016. “The Effect of Population Aging on Economic Growth, the Labor Force and Productivity." NBER Working Paper 22452, National Bureau of Economic Research, Cambridge, MA.

National Research Council of the National Academies. 2012. Aging and the Macroeconomy: Long-Term Implications of an Older Population. Washington, DC: The National Academies Press.

Organisation for Economic Cooperation and Development. 1998. "Work-force ageing." OECD Employment Outlook 1998. Paris: OECD Publishing, pp. 123-51.

_. 2017. "Economic Policy Reforms 2017: Going for Growth.” Paris: OECD Publishing.

- 2018. Employment Outlook 2018. Paris: OECD Publishing.

Organisation for Economic Cooperation and Development/European Observatory on Health Systems and Policies. 2017. Austria: Country Health Profile 2017, State of Health in the EU. Paris: OECD Publishing.

Phillips, Steven, Luis Catão, Luca Ricci, Rudolfs Bems, Mitali Das, Julian Di Giovanni, D. Filiz Unsal, Marola Castillo, Jungjin Lee, Jair Rodriguez, and Mauricio Vargas. 2013. "The External Balance Assessment (EBA) Methodology.” IMF Working Paper 13/272, International Monetary Fund, Washington, DC.

Restuccia, Diego, and Richard Rogerson. 2017. "The Causes and Costs of Misallocation." Journal of Economic Perspectives 31 (3): 151-74.

Romer, Paul M. 1990. "Capital, Labor, and Productivity." Brookings Papers on Economic Activity: Microeconomics 337-67.

Schneider, Todd, Gee Hee Hong, and Anh Van Le. 2018. "Land of the Rising Robots." Finance and Development 28.

Schwierz, Christoph. 2016 "Cost-Containment Policies in Hospital Expenditure in the European Union." European Commission Discussion Paper 037, Brussels.

Simon, Julian L. 1981. The Ultimate Resource. Princeton: Princeton University Press.

United Nations. 2012. Changing Levels and Trends in Mortality. New York: United Nations.

. 2013. World Fertility Report: Fertility at the Extremes. New York: United Nations.

_. 2015. World Mortality Report 2015. New York: United Nations. 
- 2017a. World Population Prospects: Methodology of the United Nations Population Estimates and Projections, 2017 Revision. New York: United Nations.

—. 2017b. World Population Prospects: Volume II: Demographic Profiles, 2017 Revision. New York: United Nations.

Veen, Stephan. 2008. Demographischer Wandel, alternde Belegschaften und Betriebsproduktivität. Munich: Rainer Hampp Verlag.

Wattenberg, Ben J. 1987. The Birth Dearth. New York: Pharos Books.

Werding, Martin. 2008. "Ageing and Productivity Growth: Are there Macro-level Cohort Effects of Human Capital?" CESifo Working Paper Series 2207, CESifo Group Munich.

Woessmann, Ludger. 2016. "The Importance of School Systems: Evidence from International Differences in Student Achievement." Journal of Economic Perspectives 30 (3): 3-31. 